\title{
DISCLAIMER
}

This report was prepared as an account of work sponsored by an agency of the United States Government. Neither the United States Government nor any agency thereof, nor any of their employees, makes any warranty, express or implied, or assumes any legal liability or responsibility for the accuracy, completeness, or usefulness of any information, apparatus, product, or process disclosed, or represents that its use would not infringe privately owned rights. Reference herein to any specific commercial product, process, or service by trade name, trademark, manufacturer, or otherwise does not necessarily constitute or imply its endorsement, recommendation, or favoring by the United States Government or any agency thereof. The views and opinions of authors expressed herein do not necessarily state or reflect those of the United States Government or any agency thereof.

\section{Coal Log Pipeline Research at the University of Missouri}

\author{
4th Quarterly Report for 1994
}

\author{
$10 / 1 / 94-12 / 31 / 94$ \\ Henry Liu \\ Professor and Director \\ Capsule Pipeline Research Center
}

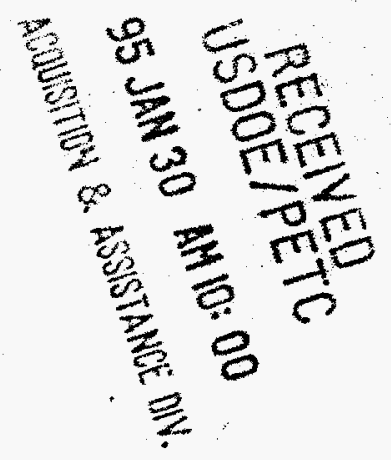

CLEARED BY PATENT COUNSEL. 


\section{DISCLAIMER}

Portions of this document may be illegible in electronic image products. Images are produced from the best available original document. 


\section{CONTENTS}

Page

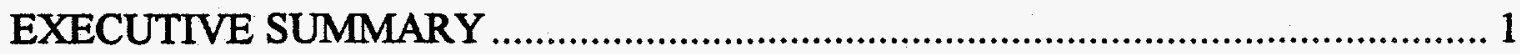

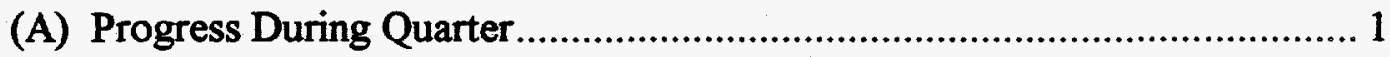

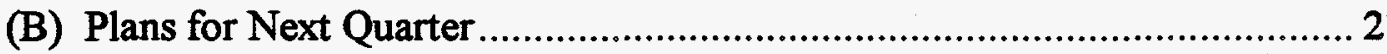

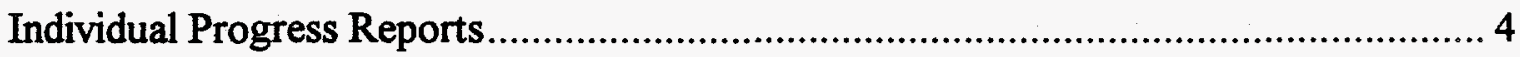

Coal Log Fabrication Using Hydrophobic Binders........................................ 4

Effectiveness of Adding Fiber to Enhance Coal Log Quality............................ 12

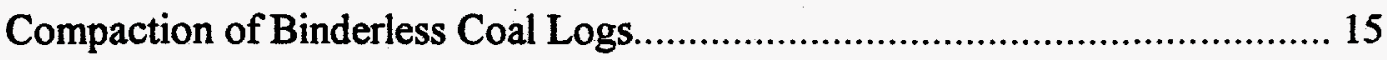

Effect of Pressure Cycling on Coal Log Quality........................................... 17

Effect of Mold Type on Coal Log Quality .................................................. 25

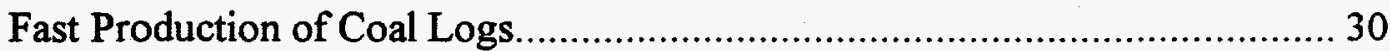

Lubricant Effects on Coal Log Compaction..................................................46

Effects of Militec-1 Conditioning on Coal Log Qualities................................ 75

Conceptual Design and Cost Estimate of a Coal Log Compaction Plant .......... 90

Vacuum Systems to Enhance Coal Log Production and Quality ................... 101

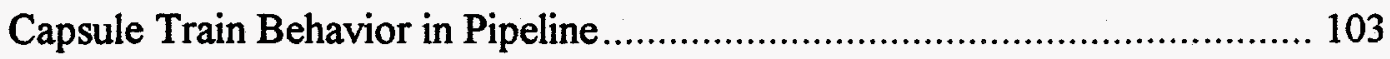

Automatic Control of Coal Log Pipeline System ....................................... 104 


\section{EXECUTIVE SUMMARY}

(A) Progress During Quarter:

During this quarter, major progress has been made in the following areas of coal log pipeline (CLP) research:

1. It was found that curing has a significant effect on the wear-resistance of coal logs compacted at room temperature with Orimulsion. The wear-resistance doubled approximately after a four-day curing.

2. The aspect ratio of coal logs was also found to have a strong impact on coal log wear. Generally, longer logs produce less wear. Logs with an aspect ratio less than 1.5 should be avoided for they wear much more than longer logs.

3. The top size of coal particles was found to have insignificant effect on coal log wear. Those of -30 mesh produce the same quality logs as those of -6 mesh.

4. It was found that by mixing $0.4 \%$ of fiber (wood pulp) with coal and $3 \%$ Orimulsion, good (wear-resistant) coal logs can be produced at room temperature. The logs with $0.4 \%$ fiber had 8 times less weight loss due to wear than those without fiber.

5. Coal logs were tested in a water chamber with pressure varying between $200 \mathrm{psi}$ and $2,000 \mathrm{psi}$, in order to simulate the condition of coal logs passing through a long commercial coal log pipeline. Each cycle of the pressure lasted 6 hours. The test showed that exposure to high pressure cycles for 66 hours had negligible effect on coal $\log$ wear.

6. The quality of coal logs compacted in a single-piece mold was compared to that of the two-piece mold under otherwise similar conditions. It was found that the single-piece mold with an expanding outlet produced better (more wear-resistant) coal logs than the two-piece mold.

7. The effect of fast compaction of coal logs by using fast strokes has been studied. It was found that with proper proportioning of water and proper mixing, logs compacted in 30 seconds are as good (wear-resistant) as those produced in a much slower process- -5 minutes. The 30 -second compaction time was limited by the capability of 
the available machine, not by log quality. Therefore, it is expected that good logs can be compacted in much less than 30 seconds.

8. Studies were conducted to test the effect of lubricants and surface conditioning of steel molds on the quality of the coal logs produced. It was found that both calcium stearate (a powdered lubricant) and surface conditioning with Militec-1 produce better (more wear-resistant) logs.

9. Another revision of the design of a commercial coal-log compaction machine has been completed. The machine is based on the proven process of 30-second compaction time. The machine needed to produce 2.8 million tons of coal logs a year is estimated to cost $\$ 6.1$ million. Should the 30 -second compaction time be reduced in the future through additional research, the machine cost will also reduce significantly.

10. The facility to test the effects of vacuum and steam heating on coal log compaction has been completed. Preliminary tests indicate that vacuum produces better (more wear- . resistant) logs.

11. Completed the Conway test report and finished the first draft prospectus of Capsule Pipeline Company.

12. Completed demonstration site survey; five companies submitted projects for consideration.

13. Submitted a proposal to DOE/PETC for a $\$ 300,000$ study entitled "Planning and Design of a Pilot-Plant Coal Log Pipeline."

(B) Plan for Next Quarter:

Major activities planned for the next quarter include:

1. Complete 1st draft of the Manual of Practice.

2. Complete second draft of prospectus of Capsule Pipeline Company.

3. Complete and submit EPRI-TC proposal.

4. Complete and submit $\mathrm{NICE}^{3}$ proposal.

5. Complete revision of 1993 CLP economic report.

6. Conduct research in the following areas.

a) Complete design of CLP injection and pumping stations. 
b) Test coal log compaction at reduced hold time--10 seconds.

c) Get more data on vacuuming effect and steam heating effect.

d) More data on fiber effect on coal log wear-resistance.

e) More data on chrome-plating and Militec-1 conditioning of mold.

f) Construct a large (5.3-inch-diameter) single-piece mold with expanding outlet and test the quality of the logs made by the mold.

g) Conduct other tests with 5.3-inch-diameter mold.

h) Complete study of coal-log train separation system.

i) Conduct capsule train jamming study.

j) Design an alternate coal log fabrication machine based on the concept of rotary press (tablet machine). 


\title{
4th Quarterly Report Coal Log Pipeline Project
}

\author{
Oct. 1 - Dec. 31,1994
}

Project Title: Coal Log Fabrication Using Hydrophobic Binders

PI:

Dr. John W. Wilson

Post-Doctoral Fellow:

Dr. Yungchin Ding

Graduate Research Assistant: Bing Zhao and Brent Ward

\section{OVERVIEW:}

Several factors involved in coal log fabrication, storage and handling, such as curing time, aspect ratio and particle size distribution, were evaluated during the fourth quarter of 1994.

When Orimulsion is used for coal $\log$ fabrication, a certain period of time is required to build up the strength of coal log. From the test results obtained, the longer the curing period the greater the wear resistance of the coal log.

From previous studies, the coal log length to diameter ratio (aspect) was found to be an important factor affecting coal log performance during the pipeline degradation test. From the 2" pipeline degradation test results, coal logs with aspect ratios ranging from 1.6 to 2.2 traveled in a more stable manner, and had lower weight loss than coal logs with aspect ratios less than 1.6.

The influence of particle size on the performance of a coal log was evaluated to determine the optimum particle size for coal log fabrication, based on practical and economical considerations.

\section{PROGRESS TO DATE:}

A. Influence of curing time on the performance of coal logs

From previous studies, the use of Orimulsion as a binding agent for coal $\log$ fabrication requires a certain period of time to build up the strength of the coal logs. From an economical point of view, the shorter the curing period the less storage space is needed at the coal $\log$ fabrication plant. In order to investigate 
the influence of the curing periot on the performance of coal logs, several coal logs were made using the same fabrication and storage conditions.

Small (1.75" in diam.) coal logs were fabricated at 10,000 psi pressure using $2 \%$ bitumen (3.3\% of Orimulsion) by weight of coal. After the coal logs were made, they were stored at ambient room conditions for various curing periods, $0,0.5,1,2,4,8,16$, and 24 hours. After curing, the coal logs were tested for their water and wear resistance by means of water absorption and tumbling tests.

The influence of the curing period on the performance of coal logs (in less than 24 hours) is shown in Figure 1. The water absorption test was carried out by submerging a coal $\log$ in the water pressure chamber at a pressure of $500 \mathrm{psi}$ for one hour. The amount of water absorbed by the coal log was used to evaluate the water resistance of the log. After the water absorption test, the coal logs were placed upright on a table, and the moisture content of the coal logs were measured and recorded, along with the elapsed curing time periods. The tumbling test was conducted by running the coal logs in an 8 in. diameter tumbler at $60 \mathrm{rpm}$ for 10 minutes. The percentage weight loss of the coal logs after the tumbling tests was used as an index for evaluating the wear resistance of the coal logs.

As shown in Figure 1, the moisture contents of the tested coal logs decreased as the curing period increased. It was also noted that the wear resistance (weight loss) of the coal logs decreased as the curing period increased. The most rapid decrease appears to be in the first four hours.

From the previous studies on curing time, the wear resistance of the coal logs were evaluated for a period up to 8 days of curing period. As shown in Figure 2, the change in weight loss of coal logs were insignificant after more than 1 day of curing time. However, the optimum coal log curing period will depend upon the actual pipeline requirement and economic considerations. 


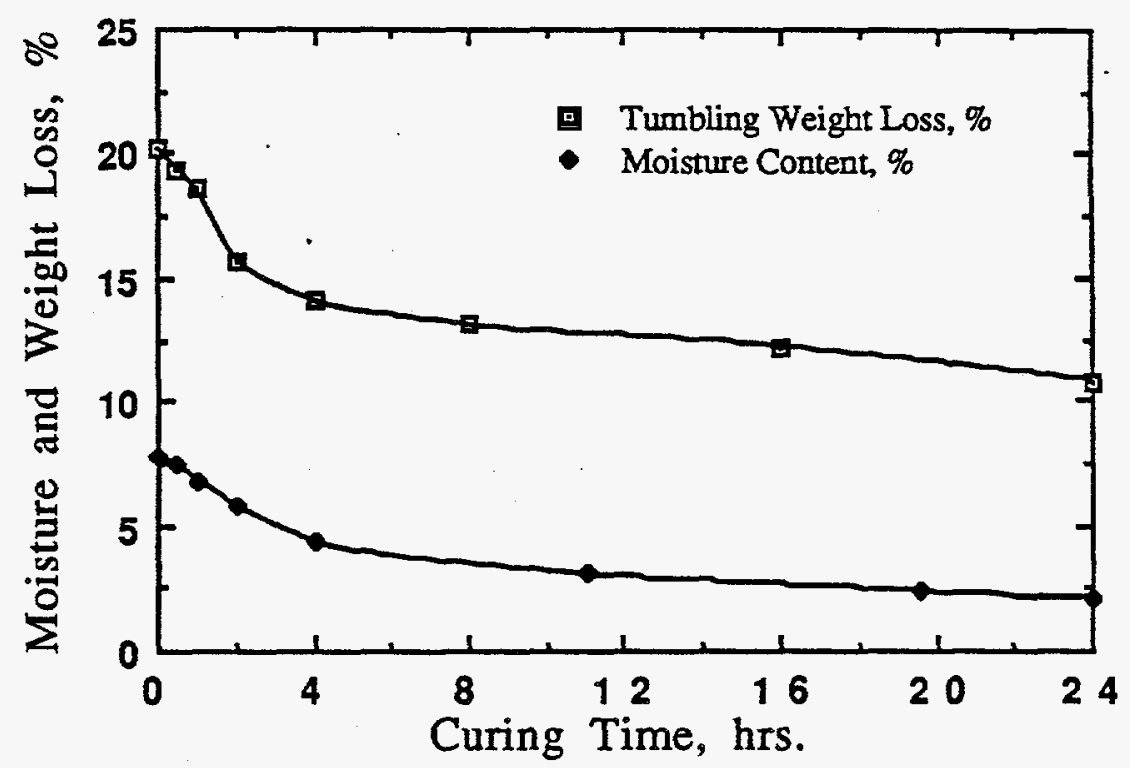

Figure 1. Effect of Curing Time on the Performance of Coal Logs

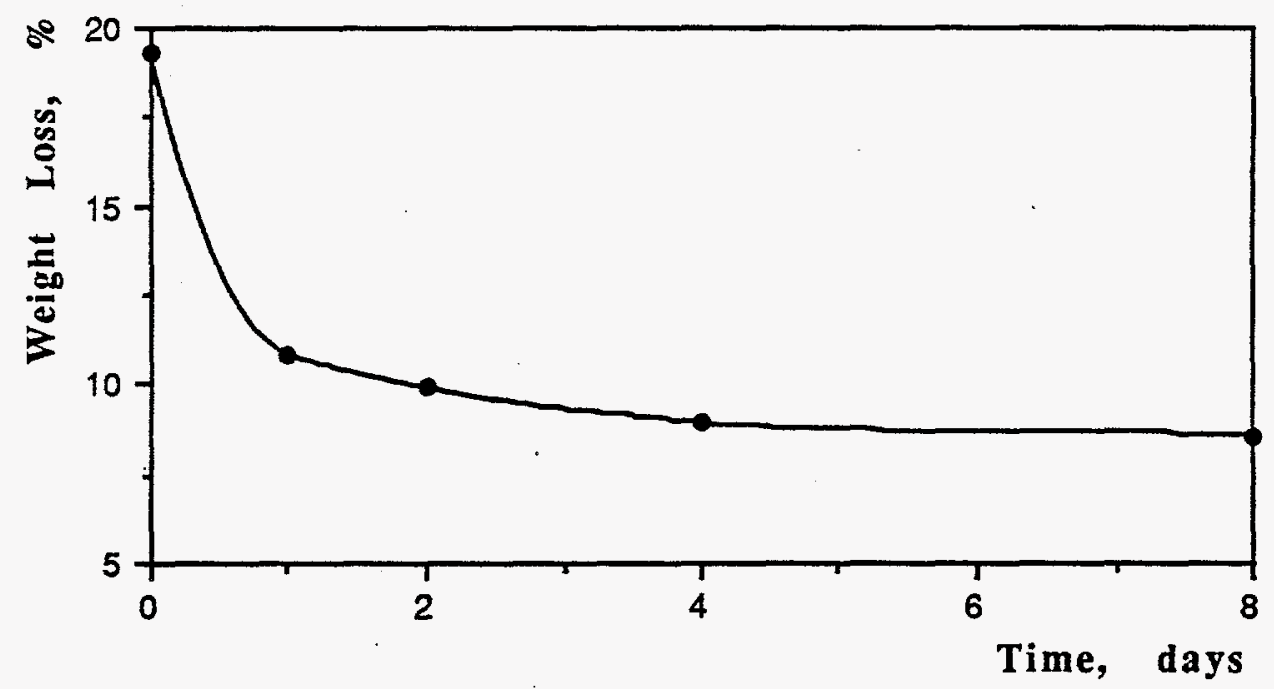

Figure 2. Effect of Curing Time on the Wear Resistance of Coal Logs 
B. Influence of aspect ratio on the performance of coal logs

By monitoring the travel of the small (1.75" in diam.) coal logs in the 2" pipeline, it was found that the longer coal logs (greater aspect ratio) traveled more stable in the water pipeline than the shorter coal logs at the same velocity. To further study the relationship between aspect ratio and coal log performance, four sets of coal logs with aspect ratios of 1.4 to 2.6 were made under the same conditions. These coal logs were then tested to evaluate the effect of the aspect ratio on the performance of coal logs in the $2 "$ pipeline loop.

a. Coal Log Fabrication

All coal logs were fabricated using the same parameters and procedures: 10,000 psi compaction pressure, room temperature, $2 \%$ bitumen (3.3\% Orimulsion by weight of dry coal), 5 min peak loading time, and two days of curing time.

Table 1. Properties and Parameters of Coal Logs

\begin{tabular}{|c|c|c|c|c|c|c|c|c|c|c|c|c|}
\hline \multirow[t]{2}{*}{ Group } & \multicolumn{2}{|c|}{ No.Coal } & \multirow{2}{*}{$\begin{array}{c}\text { Binder } \\
\mathrm{g}\end{array}$} & \multirow{2}{*}{$\begin{array}{r}\log \\
\mathrm{g}\end{array}$} & \multirow{2}{*}{$\begin{array}{c}\text { Lgth. } \\
\text { in. }\end{array}$} & \multirow{2}{*}{$\begin{array}{r}\text { Dia. } \\
\text { in. }\end{array}$} & \multicolumn{2}{|c|}{ Aspect $\mathrm{Ra}$. } & \multicolumn{2}{|c|}{ Specific Gra } & \multicolumn{2}{|c|}{ Moisture, $\%^{*}$} \\
\hline & & $\mathrm{g}$ & & & & & & avg. & & avg. & & avg. \\
\hline \multirow{3}{*}{ I } & 1 & 120 & 4.0 & 131.6 & 2.572 & 1.775 & 1.449 & \multirow{3}{*}{1.44} & 1.262 & \multirow{3}{*}{1.27} & 8.358 & \multirow{3}{*}{8.64} \\
\hline & 2 & 120 & 4.0 & 132.5 & 2.575 & 1.775 & 1.451 & & 1.269 & & 8.981 & \\
\hline & 3 & 120 & 4.0 & 131.9 & 2.545 & 1.775 & 1.434 & & 1.277 & & 8.567 & \\
\hline \multirow{3}{*}{ II } & 1 & 150 & 50 & 1648 & 2100 & (1775 & 708 & \multirow{3}{*}{1.81} & 1273 & & & \multirow{3}{*}{8.98} \\
\hline & 2 & 150 & 5.0 & $\begin{array}{l}104.8 \\
166.8\end{array}$ & $\begin{array}{l}3.192 \\
3.228\end{array}$ & 1.775 & $\begin{array}{l}1.198 \\
1.819\end{array}$ & & $\begin{array}{l}1.212 \\
1.274\end{array}$ & \multirow[t]{2}{*}{1.27} & $\begin{array}{l}8.525 \\
9.622\end{array}$ & \\
\hline & 3 & 150 & 5.0 & 165.3 & 3.214 & 1.775 & 1.811 & & 1.268 & & 8.802 & \\
\hline & & & & & & & & & & & & \\
\hline \multirow{3}{*}{ III } & 1 & 185 & 6.2 & 202.9 & 3.918 & 1.775 & 2.207 & \multirow{3}{*}{2.21} & 1.277 & \multirow{3}{*}{1.28} & 8.366 & \multirow{3}{*}{8.56} \\
\hline & 2 & 185 & 6.2 & 203.9 & 3.932 & 1.775 & 2.215 & & 1.279 & & 8.791 & \\
\hline & 3 & 185 & 6.2 & 203.3 & 3.925 & 1.775 & 2.211 & & 1.277 & & 8.522 & \\
\hline \multirow{3}{*}{$\Gamma$} & 1 & 225 & 7.5 & 2400 & 4640 & 1775 & 2.614 & \multirow{3}{*}{2.65} & 1276 & \multirow{3}{*}{1.28} & 5781 & \multirow{3}{*}{7.33} \\
\hline & 2 & 225 & 7.5 & 246.2 & 4.740 & 1.775 & 2.670 & & 1.284 & & 8.154 & \\
\hline & 3 & 225 & 7.5 & 245.9 & 4.737 & 1.775 & 2.668 & & 1.280 & & 8.042 & \\
\hline A & & & & $f$ & & 10 & & & 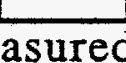 & $f_{t}$ & the & ats \\
\hline
\end{tabular}


Table 1 lists the properties of coal logs that were made using a split mold. In order to obtain consistent results, three logs with the same aspect ratio were fabricated for each set of tests.

\section{b. Water Absorption and 2" Pipeline Degradation Tests}

The water absorption tests were conducted at 500 psi pressure for one hour. The pipeline degradation tests were carried out by running coal logs in a 75 feet 2 " steel pipeline loop for 350 cycles, except for Group IV, which broke up only after running in excessive of 100 cycles.

Table 2 lists the water absorption and 2" pipeline degradation test results for the coal logs tested. The degradation (wear) tests were conducted at the lift-off velocity of each log measured from the average $\log$ velocity circulating through the loop rather than the fluid velocity.

Table 2. Final Parameters of Coal Logs

\begin{tabular}{|c|c|c|c|c|c|c|c|c|c|c|c|c|}
\hline & \multirow{3}{*}{$\mathrm{Nq}$} & \multicolumn{9}{|c|}{ Post-water absorption test } & \multirow{2}{*}{$\begin{array}{l}\text { Velo } \\
\text { city }\end{array}$} & \multirow{2}{*}{$\begin{array}{r}\text { Post- } \\
\text { Wt. loss } \\
\end{array}$} \\
\hline & & \multirow{2}{*}{$\begin{array}{c}\log \\
\mathrm{g}\end{array}$} & \multirow{2}{*}{$\begin{array}{l}\text { Lgth. } \\
\text { in. }\end{array}$} & \multirow{2}{*}{$\begin{array}{l}\text { Dia. } \\
\text { in. }\end{array}$} & \multicolumn{2}{|c|}{ Aspect Ra. } & \multicolumn{2}{|c|}{ Spe. Grav. } & \multicolumn{2}{|c|}{ Moisture $\%$} & & \\
\hline & & & & & & avg. & & avg & & avg. & $\mathrm{ft} / \mathrm{s}$. & \\
\hline & 1 & 136.6 & 2.577 & 1.778 & 1.449 & & 1.304 & & 11.71 & & & 6.08 \\
\hline I & 2 & 137.0 & 2.580 & 1.778 & 1.451 & 1.44 & 1.306 & 1.31 & 11.97 & 11.73 & 4.77 & 8.03 \\
\hline & 3 & 136.3 & 2. 550 & 1.778 & 1.434 & & 1.314 & & 11.52 & & & 9.14 \\
\hline & 1 & 170.8 & 3.197 & 1.778 & 1.798 & & 1.314 & & 11.74 & & & 791 \\
\hline II & 2 & 172.6 & 3.233 & 1.778 & 1.819 & 1.81 & 1.313 & 1.31 & 12.66 & 12.15 & 5.40 & 6.07 \\
\hline & 3 & 171.4 & 3.219 & 1.778 & 1.810 & & 1.309 & & 12.05 & & & 5.38 \\
\hline & 1 & 210.1 & 3.923 & 1.778 & 2.206 & & 1.317 & & 11.51 & & & 2.3 \\
\hline III & 2 & 211.2 & 3.937 & 1.778 & 2.214 & 2.21 & 1.319 & 1.32 & 11.97 & 11.73 & 6.00 & 2.75 \\
\hline & 3 & 210.6 & 3.930 & 1.778 & 2.210 & & 1.317 & & 11.72 & & & 2.61 \\
\hline & 1 & 249.0 & 4.645 & 1.778 & 2.612 & & 1.318 & & 9.19 & & & Broken \\
\hline IV & 2 & 254.8 & 4.745 & 1,778 & 2.669 & 2.65 & 1.320 & 1.32 & 11.2 & 10.45 & 6.58 & \\
\hline & 3 & 253.8 & 4.742 & 1.778 & 2.667 & & 1.316 & & 10.90 & & & Broken \\
\hline
\end{tabular}

As shown in Table 2, the moisture contents of coal logs that have various aspect ratios were very close to each other (post water absorption). This suggests that the influence of aspect ratio on the water resistance of coal logs is negligible. In the pipeline degradation tests, it was found that the greater the aspect ratio 
the better the performance of the coal log, except for group IV, which were excessively long $(a=2.65)$.

As observed in the $2^{\prime \prime}$ pipeline degradation test, all coal logs with an aspect ratio of 2.65 were broken into two pieces at the midpoint of the logs. This is believed to be due to the sudden impact of the coal $\log$ at the sharp curve of the pipeline, when the coal logs traveled at a speed of $6.6 \mathrm{ft} / \mathrm{sec}$.

C Influence of particle size distribution on the performance of coal logs

From an economic standpoint, the fabrication of coal logs using larger particle size can reduce the grinding and pulverizing costs. In order to ensure the performance of coal logs with different particle size distribution, three coal samples of different particle size distribution, -6 mesh $\times 0,-10$ mesh $\times 0$ and -30 mesh $\times 0$, were used to fabricate coal logs. These coal samples were prepared at T.J. Gunlach Machine Company using a hammer mill. The water absorption and wear resistance tests were used to evaluate the influence of coal particle sizes on the performance of the coal logs. All coal logs fabricated for this study were made with $2 \%$ bitumen (3.3\% Orimulsion) by weight of coal at 10,000 psi pressure and at room temperature.

The particle size distributions of the coal sample used for this study are listed in Table 3. The water and wear (tumbling-test) resistance indexes of coal logs made with these three types of coal samples are shown in Table 4.

Table 3. Particle Size and Distribution of Coal Samples

\begin{tabular}{cccc} 
Mesh & Group I, \% & Group II, \% & Group III, \% \\
\hline $6-10$ & 9.52 & & \\
$10-20$ & 11.16 & 7.97 & \\
$20-30$ & 10.83 & 7.76 & \\
$30-50$ & 21.38 & 20.37 & 12.21 \\
$50-100$ & 16.87 & 25.57 & 17.31 \\
$100-200$ & 12.84 & 22.73 & 22.87 \\
-200 & 17.94 & 15.60 & 47.61 \\
\hline Bulk Density & 0.95 & 0.86 & 0.75
\end{tabular}


Table 4. Effect of Particle Size and Distribution on the Performance of Coal Logs

\begin{tabular}{|c|c|c|c|c|c|c|c|}
\hline \multirow[b]{2}{*}{ Group } & \multirow[b]{2}{*}{ No } & \multicolumn{4}{|c|}{ Moisture Content, $\%$} & \multicolumn{2}{|c|}{ Weight Loss, $\%$} \\
\hline & & $\begin{array}{l}\text { Pre- } \\
\text { each }\end{array}$ & $\begin{array}{l}\text { Abs. } \\
\text { avg. }\end{array}$ & $\begin{array}{l}\text { Post- } \\
\text { each }\end{array}$ & $\begin{array}{l}\text { V. Abs. } \\
\text { avg. }\end{array}$ & & \\
\hline$\stackrel{I}{-6 M} \times 0$ & $\begin{array}{l}1 \\
2 \\
3\end{array}$ & $\begin{array}{l}5.28 \\
5.56 \\
5.44\end{array}$ & 5.43 & $\begin{array}{r}9.84 \\
9.88 \\
10.06\end{array}$ & 9.93 & $\begin{array}{r}10.06 \\
8.89 \\
9.49\end{array}$ & 9.48 \\
\hline$\underset{-10 \mathrm{M} X 0}{\text { II }}$ & $\begin{array}{l}1 \\
2 \\
3\end{array}$ & $\begin{array}{l}6.11 \\
6.36 \\
6.27\end{array}$ & 6.25 & $\begin{array}{l}10.35 \\
10.52 \\
10.54\end{array}$ & 10.47 & $\begin{array}{l}9.15 \\
8.64 \\
8.15\end{array}$ & 8.65 \\
\hline $\begin{array}{c}\text { III } \\
-30 \mathrm{M} \mathrm{X} 0 \\
\end{array}$ & $\begin{array}{l}1 \\
2 \\
3 \\
\end{array}$ & $\begin{array}{l}8.26 \\
7.35 \\
7.87 \\
\end{array}$ & 7.83 & $\begin{array}{l}12.30 \\
11.64 \\
12.02 \\
\end{array}$ & 11.99 & $\begin{array}{l}8.57 \\
9.14 \\
9.11\end{array}$ & 8.94 \\
\hline
\end{tabular}

As shown in Table 4, the influence of particle sizr on the water and wear resistance of coal logs were found to be insignificant. However, the findings need to be further investigated in large coal tests.

The influence of particle size on the performance of large (5.3" in diam.) coal logs are currently being tested. The tumbling test is used to evaluate the wear resistance of large coal logs. The test results will be made available as soon as they are available.

D. Large coal log fabrication and performance evaluation

Due to the fact that large commercial pipelines are inaccessible for coal log tests, a large tumbler has been designed and built to evaluate the wear resistance of large coal logs. A sketch of the large tumbler is shown in Figure 3. This large tumbler is ready for testing the wear resistance of large coal logs. 

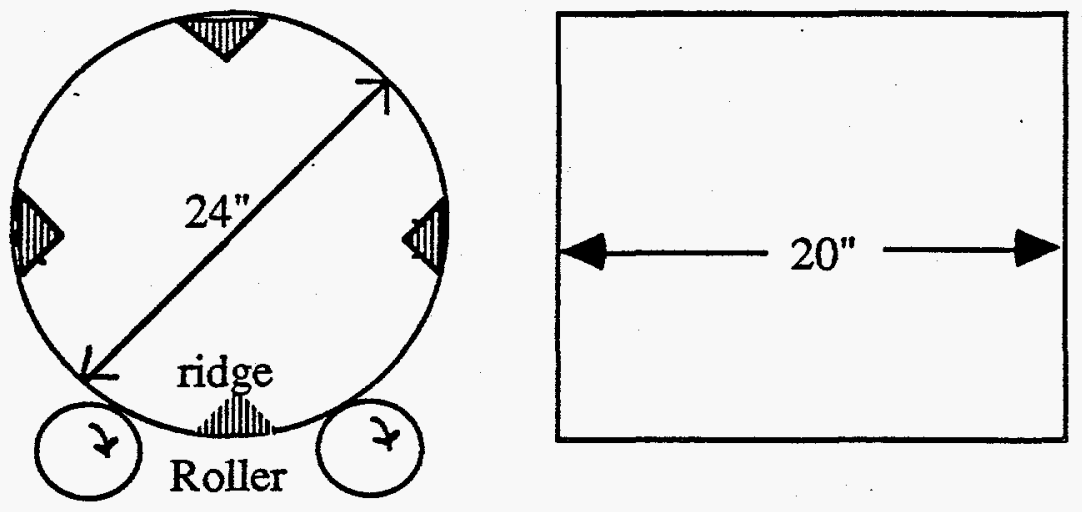

Figure 3. Sketch of large coal log tumbler

Currently, large (5.3" in diam.) coal logs are being fabricated with coal of various particle sizes and binder concentrations. The test results are not available for this reporting period, but will be reported when the tests are completed. 


\section{Capsule Pipeline Research Center}

\section{Quarterly Report}

for

\section{Individual Projects}

(Period Covered: 10/1/94-12/31/94)

Project Title: Effectiveness of Adding Fiber to Enhance Coal Log Quality

P.I.: Dr. Brett Gunnink, Associate Professor of Civil Engineering

Research Assistants: Shiping Yang

Purpose of Study: To determine whether using a small amount of low-cost, combustible fiber, such as wood pulp, can improve the wear resistance of coal logs.

\section{Work Accomplished During the Period:}

We have made several fiber reinforced coal logs. After some trial and error, the process described in Table 1 was used to make the coal logs that are discussed in this quarterly report.

Table 1 - Preparation process description for making fiber reinforced coal logs.

1. Fiber mat is soaked in water for 24 hours.

2. Fiber and water are placed in a blender; the operation of the blender is used to separate and disperse individual fibers; and finally, excess water is drained from the fibers.

3. Coal, water ( $25 \%$ of the dry weight of the coal), and saturated fiber are mixed for 5 minutes; and then allowed to soak for at least 1 hour.

4. Diluted Orimulsion (3\% of the dry weight of the coal of Orimulsion and $5 \%$ of the dry weight of the coal of water) is added and mixed for 5 minutes.

5. The mixture is place in the compaction mold and the log is made.

Wood pulp fibers produced by the Buckeye Cellulose Corporation of Memphis, Tennessee were used. Characteristics of the fibers are given in Table 2. 
Table 2 - Characteristics of the wood pulp fibers used in this study.

\begin{tabular}{|l|c|}
\hline Producer & Buckeye Cellulose \\
\hline Wood Type & South Southwood \\
\hline Name & Foley Fluffs \\
\hline Commercial Name & SSK \\
\hline Wood Species & Slash Pine \\
\hline Average Fiber Length & $3.0 \mathrm{~mm}$ \\
\hline Aspect Ratio & 62.8 \\
\hline Spring Wood / Summer Wood Ratio & $55 / 45$ \\
\hline Fibers per Gram & 0.8 million \\
\hline Dry Average Fiber Width & Spring Wood $-61 \mu \mathrm{m}$ \\
& Summer Wood $-37 \mu \mathrm{m}$ \\
\hline
\end{tabular}

Table 3 contains the common characteristics of the fiber reinforced coal logs and the compaction process that was used to make them. Three logs were made without fibers, three with $0.2 \%$ fiber, and three with $0.4 \%$ fiber. The fiber content is weight percent of the dry weight of the coal in the log.

Table 3 - Common characteristics of the fiber reinforced coal logs and the compaction process that was used to make them.

\begin{tabular}{|c|c|}
\hline Type of Coal & Mapco \\
\hline Maximum Particle Size & No. 30 Sieve \\
\hline Type of Binder & Orimulsion \\
\hline Amount of Binder & $\begin{array}{c}3 \% \text { (of dry weight of coal) } \\
\text { Orimulsion is } \approx 70 \% \text { Bitumen, } 30 \% \text { water }\end{array}$ \\
\hline Compaction Pressure & $20,000 \mathrm{psi}$ \\
\hline Compaction Temperature & Room \\
\hline Compaction Mold & Chrome Plated Split Mold \\
\hline Compaction Times & $\begin{array}{ll}\text { Loading Time - } & 1 \text { minute } \\
\text { Peak Load Holding Time }-5 \text { minutes } \\
\text { Unloading Time - } & 1 \text { minute } \\
\end{array}$ \\
\hline
\end{tabular}

After the logs were made they were place in the water absorption apparatus. Logs were exposed to $500 \mathrm{psi}$ water for 1 hour. They were then stored in atmospheric pressure water (for less than 4 days) until circulation testing was conducted. For the circulation test, the mean fluid velocity in the pipeline was equal to the theoretical lift off velocity for the coal log. Comparative weight loss results for the circulation tests are show in Figure 1. From Figure 1 it is clear that the addition of fiber improves coal log circulation performance. The improvement in circulation performance was minimal for $0.2 \%$ fiber addition, but very significant for $0.4 \%$ fiber addition. The average weight loss after 93 cycles was $18.7 \%$ for logs without fibers; the average weight loss after 95 cycles for logs with $0.2 \%$ fiber was $10.3 \%$; and the average weight loss after 88 cycles for logs with $0.4 \%$ 
fiber was $3.2 \%$. After 219 cycles, the average weight loss for logs with $0.4 \%$ fiber was $9.5 \%$.

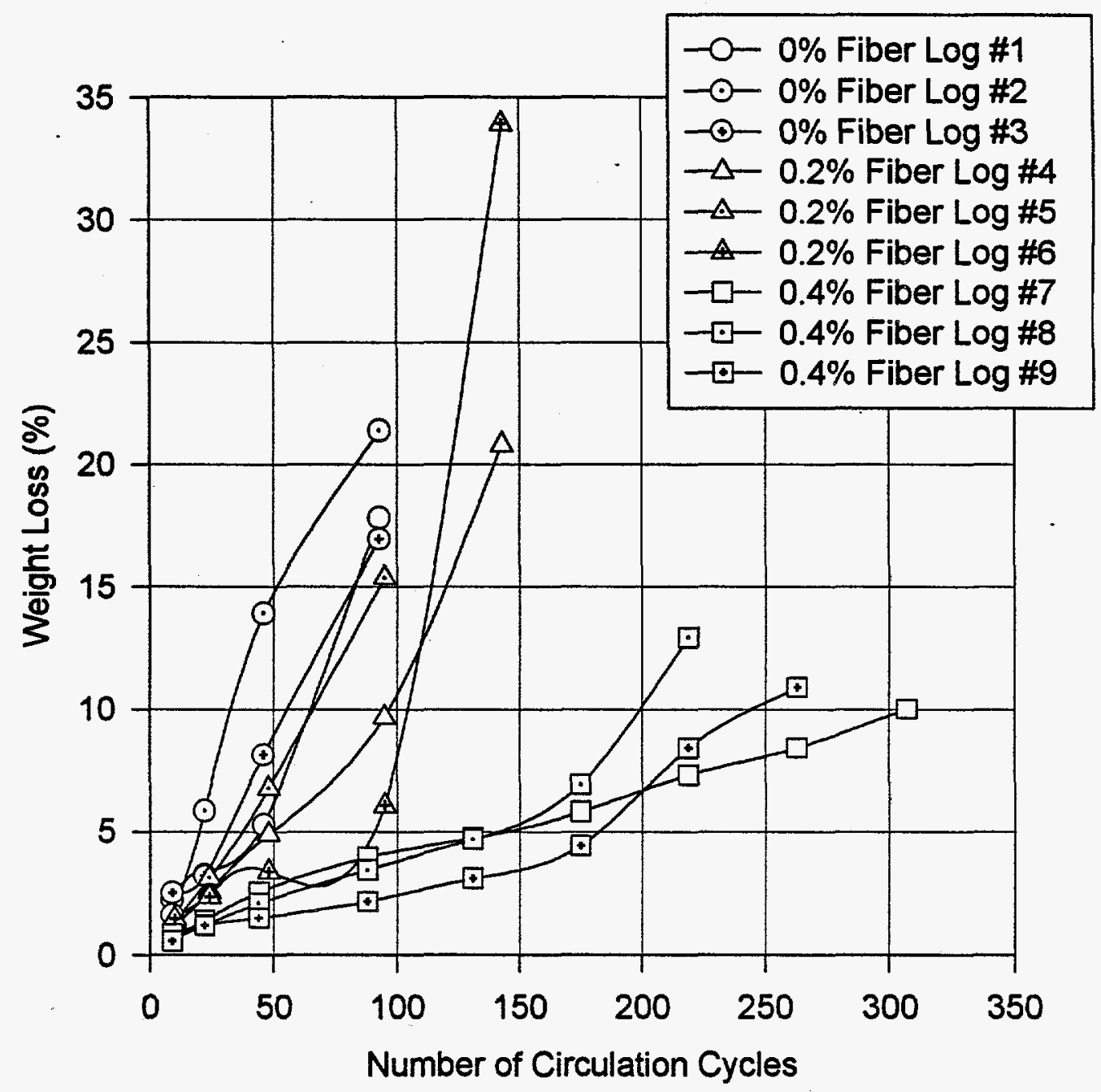

Figure 1 - Circulation performance data for fiber reinforced coal logs (3\% Orimulsion binder, room compaction temperature, 20,000 psi compaction pressure)

\section{Work Proposed for Next Quarter:}

We will continue studying the effects of fiber addition on coal log circulation performance. Specifically we will investigate other fiber concentrations, other compaction temperatures, and other binder concentrations. 


\section{Capsule Pipeline Research Center}

Quarterly Report

for

\section{Individual Projects}

(Period Covered: 10/1/94-12/31/94)

Project Title: Compaction of Binderless Coal Logs

P.I.: Dr. Brett Gunnink, Associate Professor of Civil Engineering

\section{Research Assistants: Feng Chen}

Purpose of Study: To explore and optimize a compaction technique for making binderless coal logs.

\section{Work Accomplished During the Period:}

Mr. Feng Chen completed experimental work on Hot Water Formed (HWF) coal logs and has begun writing his thesis. Patents attorneys for Senniger, Powers, Leavitt, and Roedel have completed their patent review of the HWF process and have been authorized to proceed with the filing of a patent application. An evaluation request for this invention has been submitted to the Office of Technology Evaluation and Assessment at the NIST. If the evaluation is favorable, funding from NIST may be available for the further development of this technology.

\section{Work Proposed for Next Quarter:}

Mr. Feng Chen expected to complete his MS thesis and a patent application on the HWF process will be filed. 
Publications Resulting from Work on this Project:

Gunnink, B.W., J. Kanunar, and F. Cheng, "Binderless Compaction of Hot Water Formed Coal Logs for Pipeline Transport" submitted to Fuel Processing Technology, August, 1994

Kanunar, J., (1994) "Compaction of High Strength Binderless Coal Logs for Pipeline Transportation" thesis presented to the University of Missouri-Columbia, at Columbia, Missouri, in partial fulfillment of the requirements for the degree of Master of Science.

Gunnink, B.W. and Liang, Z. (1994), "Compaction of Binderless Coal for Coal Log Pipelines", Fuel Processing Technology, Elsevier, Amsterdam, 37: 237-254.

Gunnink, B.W., Kanunar, J., and Liang, Z. (1993) "Compaction of Hot Water Dried Coal Agglomerates", Preliminary Invention Disclosure, April 15, 1993.

Liang, Z., (1993) "Compaction of Binderless Coal for Coal Log Pipelines", thesis presented to the University of Missouri-Columbia, at Columbia, Missouri, in partial fulfillment of the requirements for the degree of Master of Science.

Gunnink, B.W. and Liang, Z., (1992) "Compaction of Binderless Coal Logs for Coal Pipelines", Proceedings 17th International Conference on Coal Utilization and Slurry Technologies, Coal and Slurry Technology Association, 677-686. 


\title{
Effect of Pressure Cycling on Coal Log Quality
}

\author{
William J. Burkett and Rebecca J. Smith \\ Capsule Pipeline Research Center \\ January 17, 1995
}

\section{Introduction}

Coal log transport in the CLP from a manufacturing plant to a power plant may involve distances of hundreds of miles. Booster pumps spaced at regular intervals are needed for long distance coal log transport. The high pressure generated at a pump station gradually declines over a distances of tens of miles to the next pump station. Pressure gradients are in the range of 2000 to 200 psi. Assuming a 250 mile transport would require 10 booster pump stations, the logs would be subjected to 10 pressure cycles. The purpose of this study is to investigate the effect of pressure cycling on coal $\log$ quality.

\section{Experiments}

All coal logs were compacted from Mettiki (MAPCO) coal. The coal was ground by a hammer mill and screened through 30 mesh. The water, coal, and Orimulsion were mixed and allowed to equilibrate for approximately 24 hours. Three separate batches (six logs per batch) of material were mixed for the 18 logs. The compaction mixture feed contained $21 \%$ moisture. The amount of Orimulsion used was $3 \%$ by dry coal weight. Orimulsion is an emulsion containing $70 \%$ asphalt and $30 \%$ water. 
The coal logs were compacted in the stainless steel single-piece mold at a pressure of 20,000 psi and a temperature of $97^{\circ} \mathrm{C}$. Both pistons had flat ends. The loading and unloading rates were $3300 \mathrm{psi} / \mathrm{min}$. The peak pressure was maintained for five minutes. The mold was cooled to $32^{\circ} \mathrm{C}$ before ejection of the coal log. The ejection speed was 2.5 in/min.

\section{Results and Discussion}

To contrast the effect of pressure cycling to constant water pressure, three logs were placed in a 500 psi water absorption test cell, three logs in an open container of water, and three logs in a 2000 to 200 psi pressure cycling test chamber. The pressure cycling test is shown in Figure 1. The pressure drops from 2000 to 200 psi over a six hour time span, corresponding to 25 miles traveled at $6 \mathrm{ft} / \mathrm{s}$ in a pipeline. The pressure then increases back to $2000 \mathrm{psi}$ in a $100 \mathrm{ft}$ distant to imitate passage through a jet pump. The cycles were repeated 10 times for a total of 60 hours. Logs remained in the test cell under water at atmospheric pressure for five additional hours until the wear test was performed. A test duration of 66 hours was used for the 500 psi and atmospheric pressure water absorption tests. An additional three logs were subjected to the standard one hour $500 \mathrm{psi}$ water absorption test as controls.

The circulation wear tests were performed in the 2 " steel pipeline. The three coal logs for each test group were circulated at the same time but separately from any other test group. The water velocity was calculated by Liu's lift-off velocity equation and monitored by the flow meter. This lift-off velocity was approximately $6.3 \mathrm{ft} / \mathrm{sec}$.

The wear test results are presented in Figure 2. Each line is the average of three coal logs. Two of the three coal logs subjected to atmospheric pressure water "capped" during circulation. A one to two millimeter thick cap ( 5 to $6 \mathrm{~g}$ ) came off the front end of 
the logs during circulation. This caused the weight loss jump seen between 100 and 150 cycles and again at 300 to 350 cycles. The densities and weight gain of the two capped logs after the water absorption test were low, averaging $1.300 \mathrm{~g} / \mathrm{cm}^{3}$ and $3.3 \mathrm{~g}$, compared to $1.310 \mathrm{~g} / \mathrm{cm}^{3}$ and $4.2 \mathrm{~g}$ for the third uncapped $\log$. Entrapped air or other causes may have caused the low densities and the capping. If the capping is ignored the 350 cycle average weight loss drops from $5.92 \%$ to $3.76 \%$.

Pressure cycling did not have an adverse effect on coal log quality. The logs subjected to 10 six hour pressure cycles lost an average of 3.4 weight percent during the 350 cycles wear test compared to 4.5 weight percent for the logs subjected to one hour or 66 hours of 500 psi water pressure. All logs gained between 4.9 and $5.1 \mathrm{~g}$ water during the water absorption tests.

The duration of $\log$ testing in the 500 psi test also did not effect coal log quality. The logs subjected to 66 hours of water immersion performed as well as the logs subjected to only one hour.

For all logs tested, nearly half of the total weight loss occurs in the first 50 cycles. This is a result of the "rounding" of the flat trailing end as the log circulates. Use of a beveled piston would reduce this initial weight loss.

A second set of pressure cycles experiments were also conducted. Three logs were placed in the 500 psi water absorption test for one hour as controls. Three logs were placed in separate pressure cycles test cells for the 2000 to 200 psi cycling test. Twelve hour cycles were used for these tests. The first log was removed after two cycles ( 24 hours), the second after four cycles ( 48 hours), and the last log after six cycles ( 72 hours). Each log was removed without interrupting the continuing cycles. The weight gains of the logs after the pressure cycling tests increased with increasing number of pressure cycles; $4.3 \mathrm{~g}$ for the two cycle $\log , 5.0 \mathrm{~g}$ for the four cycle $\log , 5.1 \mathrm{~g}$ for the six cycle $\log$. The logs subjected to one hour $500 \mathrm{psi}$ gained an average of $4.5 \mathrm{~g}$. 
After the water absorption tests the logs were subjected to circulation wear tests. The logs were circulated at a capsule velocity of approximately $6.2 \mathrm{ft} / \mathrm{sec}$ as calculated by Liu's lift-off velocity equation. The velocity was monitored by a stopwatch.

The wear test results are shown in Figure 3. The weight loss of the control logs ( 1 hour at 500 psi) ranged from $6 \%$ to $8.25 \%$ after 350 cycles, and averaged $7 \%$ for the three logs. The logs subjected to multiple pressure cycles show a decrease in log quality with increasing number of pressure cycles.

Several variables negate a direct comparison between results shown in Figure 2 and 3. The logs in Figure 2 subjected to 500 psi for one hour averaged $4.5 \%$ weight loss after 350 cycles compared to $7 \%$ for logs subjected to the same test as shown in Figure 3 .

Prior to compaction of the logs shown in Figure 1, the mold was treated with a surface conditioner for experiments detailed in a separate study. The effect of this conditioner is not currently known.

The circulation tests in Figure 2 were ran at the correct fluid lift-off velocity monitored by a flow meter. Those results in Figure 3 were obtained from coal logs ran at the faster capsule lift-off velocity measured by a stopwatch. The results shown in Figure 3 may reflect excessive wear caused by the faster velocity.

Experiments also indicate that one end of the coal log is stronger. Failure to ensure that the same end (top or bottom after compaction) is always in the direction of flow during the circulation wear test can result in erratic data. All logs represented in Figure 2 were carefully marked, but less attention was given to the logs represented in Figure 3.

The pressure cycle duration may also effect coal log quality. Twelve-hour cycles may have a more deleterious effect on the coal log quality than the six-hour cycles. 


\section{Conclusions}

1. Coal logs subjected to water pressure cycling from 2000 to $200 \mathrm{psi}$ perform in the circulation wear test as well as coal logs subjected to constant water pressure of $500 \mathrm{psi}$ for the same test duration.

2. Coal logs subjected to 66 hours of 500 psi water pressure perform in the circulation wear test as well as coal logs subjected to one hour of 500 psi water pressure.

3. Coal logs circulated at a lift-off velocity as measured by the log itself with a stopwatch degrade faster in the wear test than coal logs circulated at the true fluid lift-off velocity monitored by the flow meter.

Future Work

Refinement of the coal log fabrication method is planned. Repeating these experiments with varying number and duration of pressure cycles will be done.

\section{Acknowledgement :}

The authors thank Yu Lin for his cooperation in performing the experimental work. 


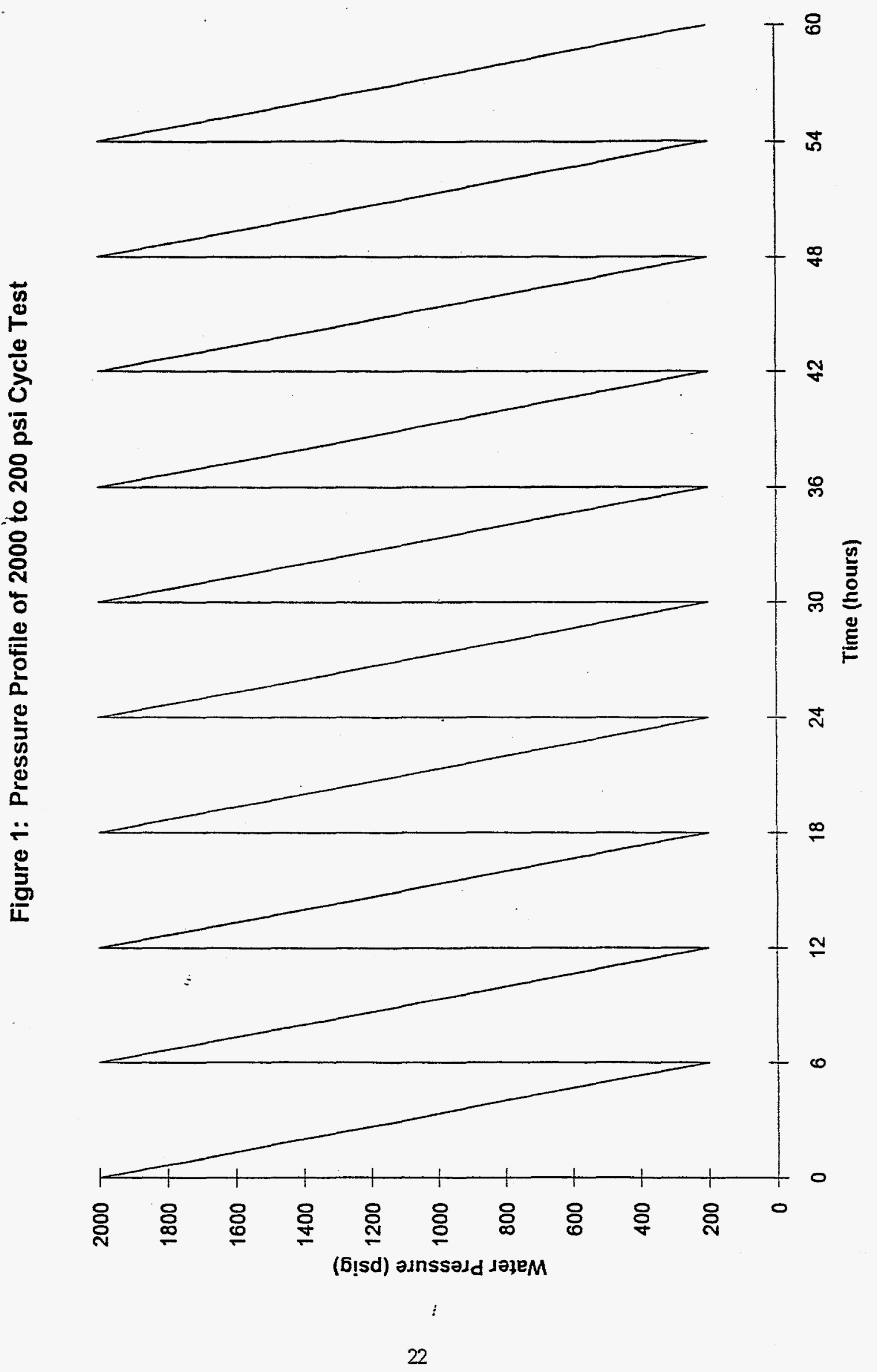



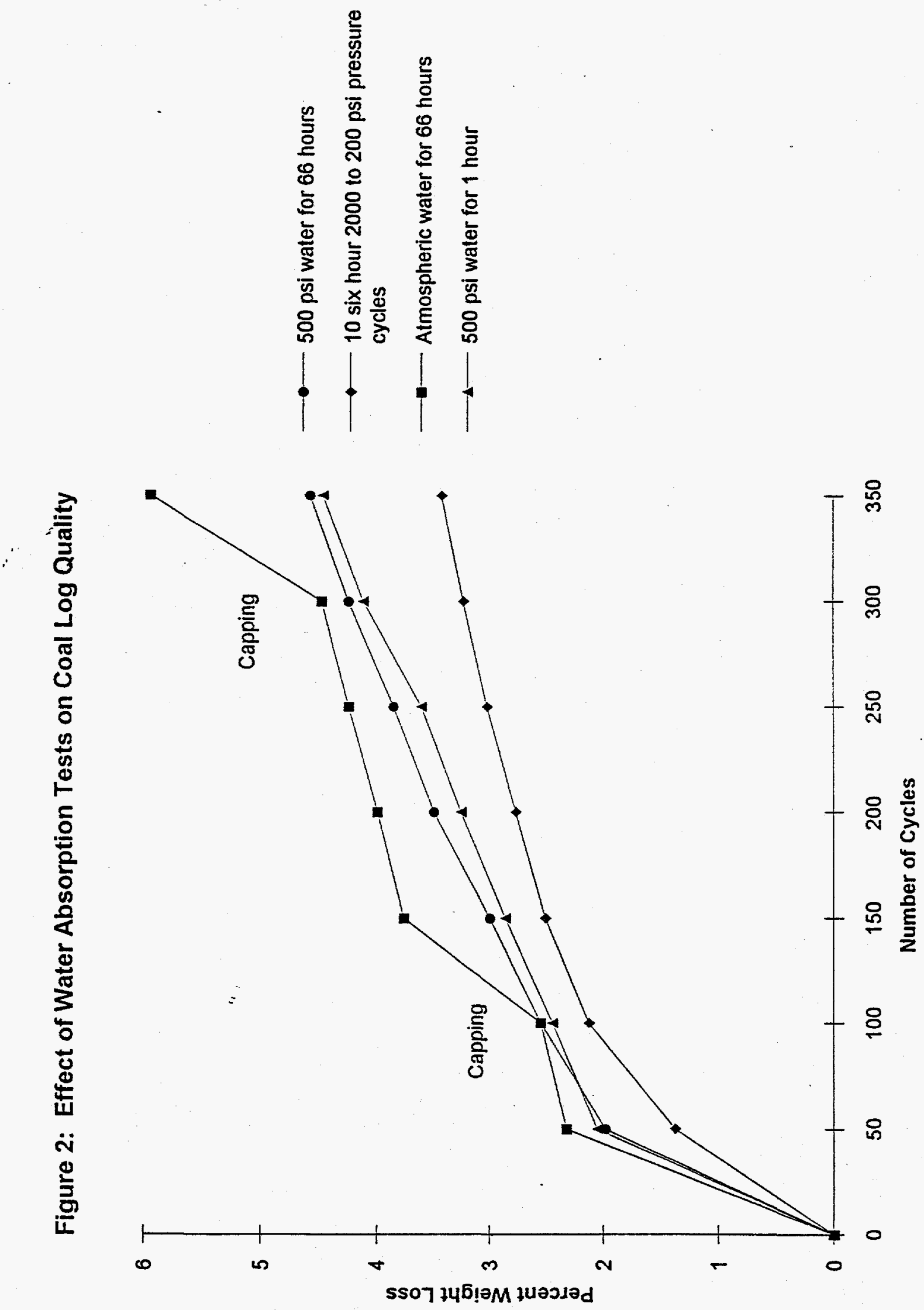
Figure 3: Effect of Multiple Pressure Cycling on Coal Loq"Quality

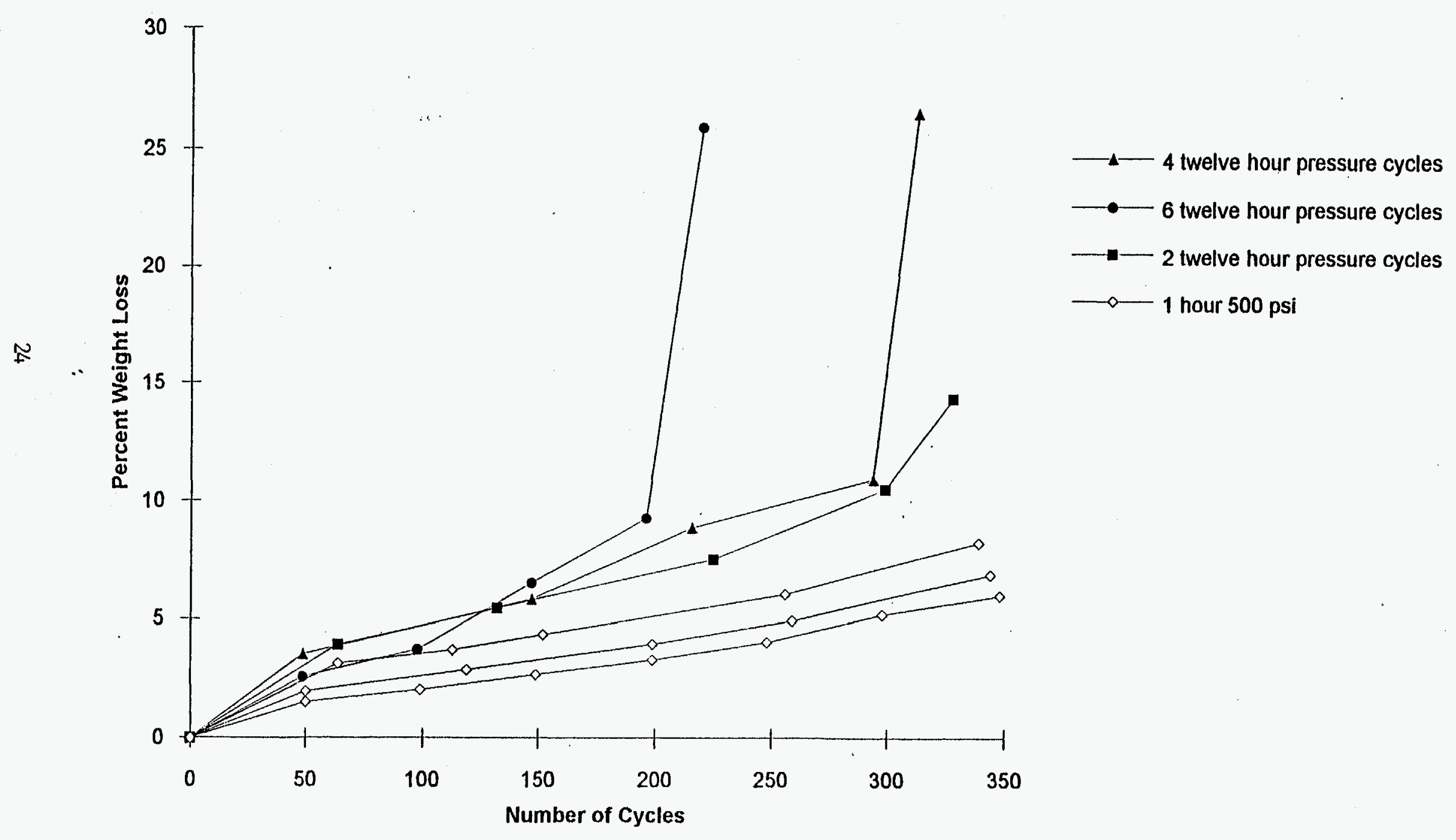




\title{
EFFECT OF MOLD TYPE ON COAL LOG QUALITY
}

\author{
Rebecca J. Smith \\ January 9, 1994
}

\section{Introduction}

Three types of compaction molds are compared in this study: single-piece mold, unṕlated split mold, and chrome-plated split mold.

The single-piece mold is constructed of stainless steel and is cylindrical in shape. Both split molds are rectangular pieces of mild steel with a cylindrical bore for log compaction. The surface of the boring is chrome plated in the chrome-plated split mold.

\section{Experimental Procedure}

Three logs were compacted by the procedure outlined in Table 1 in each of the three molds. Three batches of compaction feed were prepared. A total of nine logs were compacted.

Immediately after compaction the logs were placed in the 500 psi water absorption test for one hour. The logs then sat in water at atmospheric pressure until the circulation test. This duration did not exceed 24 hours.

All logs were circulated at capsule lift-off velocity during the circulation test. The velocity was monitored by a stopwatch. The velocity was approximately $6 \mathrm{ft} / \mathrm{s}$. 


\section{Results and Discussion}

Figure 1 presents the results of all nine circulation tests. Weight losses ranged from approximately $1.7 \%$ to $5.3 \%$ for the 350 cycle test.

The circulation performance of the single-piece mold logs had a large variation, with weight losses ranging from $1.7 \%$ to $5 \%$ in 350 cycles. In contrast, the split mold logs only lost 2 to $3 \%$ in 350 cycles. The chrome-plated split mold logs averaged $2.5 \%$ weight loss while the unplated split mold logs averaged $2.96 \%$ weight loss.

From these experiments it appears that both split molds consistently produced coal logs that passed the 350 cycle circulation test. The reason for the widespread results of the single-piece mold logs is unknown at this time. One possible cause is the cooling rate of the mold.

Table 2 presents the masses of each of the molds and the time required for cooling from 97 to $32^{\circ} \mathrm{C}$. The cooling of the molds was achieved by using a fan to blow directly on the mold. The low mass of the single-piece mold resulted in a significantly faster cooling rate. The single-piece mold log that lost 1.7 weight percent during the circulation test was cooled without a fan. The length of cooling for this log was roughly 90 minutes. Nonuniform cooling by the fan may also damage the coal log. When cooled by a fan, the temperature of the log may differ between upwind and downwind sides of the mold. Further investigation into log cooling rates should be done before concluding that the single-piece mold produces a less durable log.

Note: Many developments have arose since the completion of this study. Experiments suggest that one end of the coal log is stronger than the other. Failure to consistently put the same end (compacted top or bottom) of the coal log into the direction of flow can produce erratic circulation results. Recently, the single-piece mold was treated with a surface lubricant. Initial results indicate this lubricant improves log quality at high compaction temperatures and pressures. 


\section{Table 1: Procedure for Log Compaction}

Type of Coal

Particle Size Distribution

Type of Binder

Moisture Content

of Coal Mixture

Compaction Process

Compaction Molds

Log Curing Time
Powder River Basin - North Antelope mine

Maximum Density (through 30 mesh)

SS-1H (emulsified aspahlt)

$3 \%$ (aspahlt and water) by dry weight of coal

$38 \%$ by total weight

Empty mold heated to $97^{\circ} \mathrm{C}$ and then filled with coal $6 \mathrm{~min} 40 \mathrm{sec}$ loading to $20,000 \mathrm{psi}$

5 minute hold

$6 \mathrm{~min} 40 \mathrm{sec}$ unloading

Cooled to $32^{\circ} \mathrm{C}$

Unplated split mold with mild steel pistons Single-piece mold with stainless steel pistons Chrome-plated split mold with mild steel pistons All pistons were flat ended

None 


\section{Table 2: Compaction Mold Characteristics}

$\underline{\text { Mold }}$

Single-Piece

Single-Piece

Chrome-Plated

Unplated
Mass of Mold and Pistons

$16,285 \mathrm{~g}$

$16,285 \mathrm{~g}$

$19,092 \mathrm{~g}$

$17,634 \mathrm{~g}$
Cooling Time to $32^{\circ} \mathrm{C}$

25 minutes (fan)

90 minutes (no fan)

45 minutes (fan)

35 minutes (fan) 
Figure 1: Circulation Tests of PRB Coal Logs

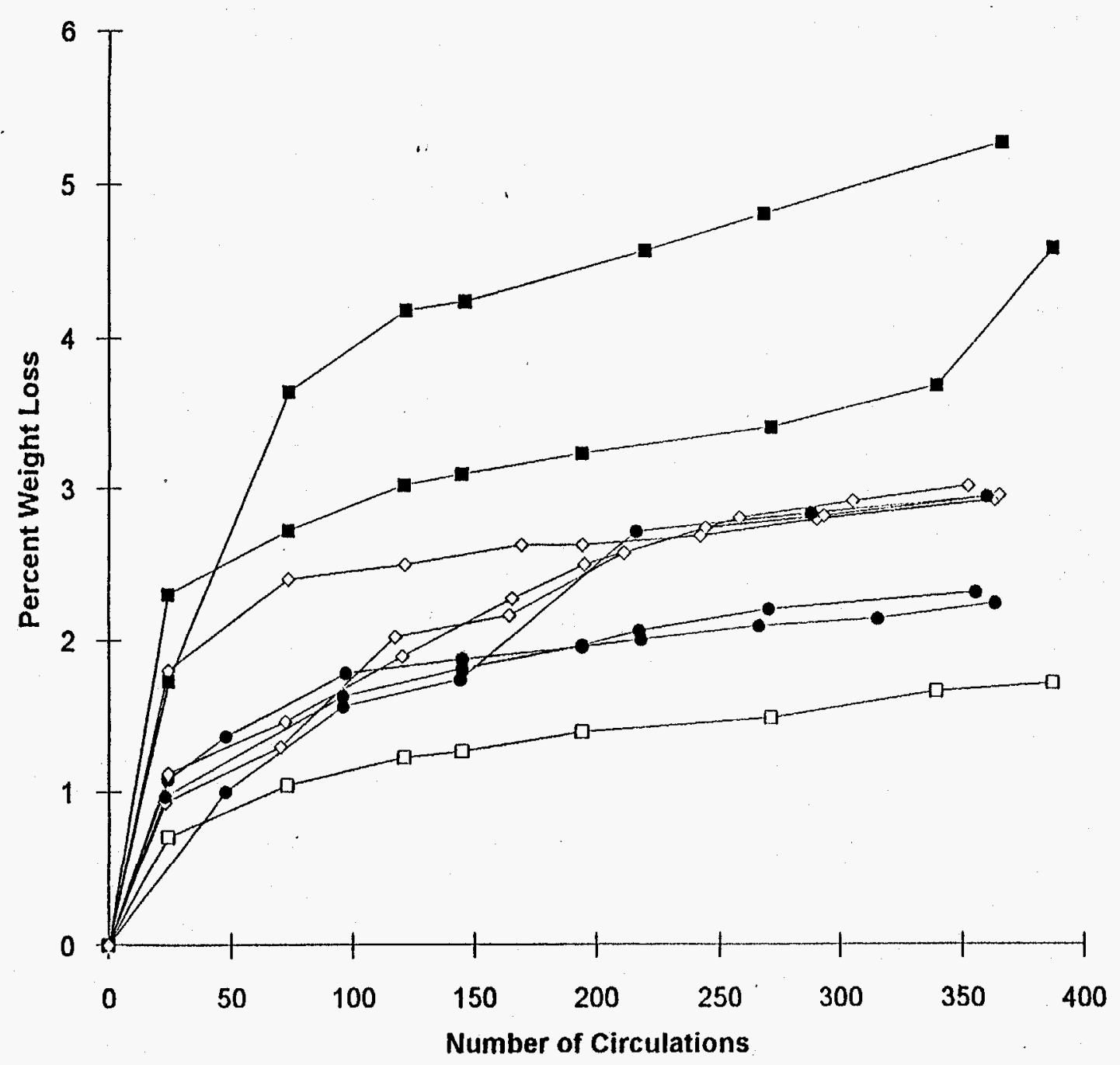

$\longrightarrow$ - Single-Piece Mold - Cooled without Fan

$\longrightarrow$ Single-Piece Mold - Cooled with Fan

- Chrome Plated Split Mold

$\multimap$ Unplated Split Mold 


\section{FAST PRODUCTION OF COALL LOGS \\ Capsule Pipeline Research Center}

Principal Investigator: Richard H. Luecke

Research Associate: Rebecca J. Smith

Research Assistant: Marcus J. Bahr

\section{INTRODUCTION}

One of the major cost components of a CLP is making the log. This step starts with raw coal, pulverizes it to the necessary particle size, and then compacts the coal with a high pressure ram into a cylindrical log for transit in the pipeline. This step involves a number of expenses for materials such as binders, but a major component of the costs are investment related fixed charges. Since a huge amount of coal needs to be formed into logs, the length of time involved in producing each log needs to be small to reduce the capital investment for compaction machinery. Table 1 summarizes the "standard" conditions for manufacture of coal logs. These conditions produce logs that pass the pipeline endurance tests. The work described in this report was initiated to reduce compaction time in order to improve pipeline economics while producing logs of similar quaiity.

\section{DisCUSSION}

In early compaction investigations at elevated temperatures, a smooth rate of increase and decrease in pressure was observed to produce logs of acceptable quality with greater consistency. Procedures were developed at that time to proportion the rate of pressure increase and decrease to the rate of temperature change. The compaction cycle consisted of 8-12 minutes loading time, 5-10 minutes at full pressure, and 5-15 minutes unloading. The soaking period at full pressure was intended to ensure better performance of the log in the pipeline. A typical pressure vs. time curve used previously for compaction is diagrammed in Figure 1.

This compaction cycle was developed for high temperature compaction partly as 
a result of suggestions in the literature that indicated that extended duration at pressure improved log quality, and partiy from compaction equipment limitations that precluded very rapid compaction.

These techniques were believed to provide "equilibration" time for plastic flow and for the particle-to-particie bonds to form, but it now seems more likely that water of equilibration and release of differential thermal stresses were having a greater effect. Improved mold designs have been found to counteract some of the factors that reduce the quality of logs if compaction rates are too rapid. For room temperature compactions, questions about thermal stresses are moot.

\section{Western Coal}

Since there was extensive background available, Western (Powder River Basin) coal was used for the initial exploration of fast compaction. The standard conditions for this coal included compaction with $3 \%$ binder (SS-1H), $97^{\circ} \mathrm{C}$ and maximum pressure of 20,000 psi. Typical "slow" compaction was 6 minutes loading, 5 minutes hold (at 20,000 psi) and 6 minutes unloading (Figure 1). For the fast compaction experiments, these were changed to 2 minutes loading, 1 minute unloading and no holding time at pressure.

The results of the circulation tests in the steel test pipeline are shown in Figure 2. The speed of these and other logs in this report was calculated by Dr. Liu's equation for lift-off velocity. The "slow" compactions show the best performance with losses less than $0.5 \%$ after 300 cycles of circulation. The "fast" compacted logs more than meet the performance criteria of $3 \%$ loss in 350 cycles.

One of the fast compacted logs matches the slow compaction for the first 200 cycles. Both the fast compacted logs seem to have good wear characteristics except for several episodes of losses of chunks. These two sets of logs were tested in the pipeline at the same time and the loss of chunks seems to occur at the same time.

\section{Eastern Coal}

The promising results with Western coal encouraged formulation of an experimental design to explore conditions for fast compaction using Eastern (MAPCO) 
coal. The proposed experiments included fast compaction at $90-97^{\circ} \mathrm{C}$ and at room temperature. These latter were referred to "Rolia" conditions since that is where the buik of the development for low temperature compaction had been carried out.

"Standard" coal log compaction conditions for this coal are shown in Table 1. Logs made at these conditions marginally meet the circulation performance criteria so that for this work, "good" logs were defined as having less than $10 \%$ weight loss after 300 cycles in the test pipe line. Note that the principal objective in this work was to evaluate difference between "siow" and "fast" compaction rather than to necessarily produce logs that themselves pass the criteria. Extensive other work is in progress to improve overall log performance.

The "slow" compaction cycle is (approximately) defined graphically in Figure 1 and a "fast" compaction cycle from a typical experiment is shown in Figure 3. (A simplified schematic of the pressure-release cycle is shown in the inset diagram.) This cycle is about as fast as compaction can be accomplished with the equipment that was used. Logs were produced using the rapid compaction cycle that were very similar in appearance to those produced by the "slow" cycle. The density and moisture range appeared to be not significantly different between the two manufacturing methods.

Initial Results

At $90-97^{\circ} \mathrm{C}$, several logs were produced with fast compaction with moderate weight loss in the test pipeline. Pipeline test results are compared for a fast compacted coal log and a slow compacted coal log in Figure 4. Both logs were compacted at $90^{\circ} \mathrm{C}$. Curing (storing the $\log$ for one to three days at room temperature before the high pressure water immersion test) did not affect the performance of these logs.

At room temperature, fast compaction produced only unsatisfactory logs, with or without curing. A check of the same procedures using siow compaction also yieided unsatisfactory logs however and failed to reproduce the results reported for low temperature compaction. Several key differences were found to account for the poorer performance:

a. The most important difference was that the Rolla experiments were 
made with smaller particle sizes. The smaller particle size distribution was used in all subsequent evaluations.

b. Another significant difference was that the Rolla logs were made with a larger aspect ratio (length-to-diameter). Subsequent work (at Rolia) established that larger aspect ratios gave better performance (in the test pipeline). The difference in performance due to aspect ratio shouid be considered in the evaluation of results in this work.

c. Evaluation of performance is sometimes clouded when large pieces of log were lost rather than "normal" wear. This "capping" has not been observed in large logs and may be caused by the specific steel test pipeline that is used. In their evaluations, the Rolla group often reported when end "caps" were lost but then restarted the analysis discounting the "abnormal" losses. In the subsequent discussions here, all losses including the "abnormal" losses are shown. Performance of logs looks much better, of course, if loss of end "caps" or "abnormal" large chunks is discounted.

When these differences were removed, we confirmed that logs made with slow compaction at room temperature using $3 \%$ orimulsion could pass the required circulation specifications in the test pipeline if they were cured for $2-4$ days. If the logs were made at high temperature $\left(90-95^{\circ} \mathrm{C}\right)$, curing was not required. Intermediate temperatures $\left(50^{\circ} \mathrm{C}\right)$ appeared to be very little better than room temperature.

\section{Fast Compaction - Room Temperature}

\section{Methods}

A complete set of experiments was designed to evaluate fast compaction at room temperature. The experimental design was to test one and three cycles of rapid compaction. Variation of the initial (excess) water level was included since it was possible that dewatering rate during compaction could affect log quality. All logs in the experiments described here were compacted at the "standard" conditions of Table 1 except: 
1. Compaction rates were either "slow" or "fast", with the latter being as fast as the equipment allowed,

2. The amount of water added (before compaction) was varied, along with the mixing process.

3. Compaction temperature was room temperature $\left(22-25^{\circ} \mathrm{C}\right)$,

4. Compacted logs were "cured" for two to three days.

For "slow" compaction, the diagram shown in Figure 1 was followed with a maximum compaction pressure of 10,000 psi. The compaction cycle consisted of 3 minutes of loading time, 5 minutes at full pressure, and 3 minutes unloading.

For "fast" compaction, the diagram shown in Figure 3 was used as the template with maximum compaction pressure being 20,000 psi. In this particular experiment, the time for the compaction stroke for crushed (MAPCO) coal at room temperature from atmospheric pressure to 20,000 psi was 27 seconds. This varied between about 20 to 30 seconds for all the experiments. Pressure release time, 11 seconds on this run, varied from about 8-14 seconds. The total cycle varied from about 30 to 40 seconds.

The minimum cycle time was limited, not by some performance criteria of the coal logs, but by physical capability of the compaction machine and in particular by the maximum ram speed at pressure. The compression stroke is controlled by manual adjustment of a needle valve that meters the rate of flow of hydraulic fluid to the press. The maximum pump output flow is limited and also careful control is needed to avoid over-pressure in the lines. Pressure decrease time is controlled by opening the valve and here again hydraulic fluid flow rate is limiting.

Fast compaction could be either single stroke or triple stroke; for the single stroke, the last two puises in Figure 3 are omitted. In the second and third compaction strokes, there is very little (or no) change in log density (volume) and the rate of pressure increase is limited primarily by our ability to manually throttle the rate of hydraulic oil flow to the press.

The levels of experiments were as follows:

Compaction: Slow compaction and fast compaction with one and three strokes. 
Water added: 16,21 and $30 \%$ by dry weight.

The sequence of the permutation of six conditions was randomized to eliminate systematic error. Replications of state were also programmed. Evaluation of the logs was in the steel test pipeline. The rate of weight loss as well as the total integrity of the log was used in the evaluation.

\section{Results}

The key findings of this work are:

1. Good quality logs can be made with the rapid compaction.

2. Logs made with rapid strokes perform almost as well as logs made under (nearly) identical conditions with extended period $(5 \mathrm{~min})$ strokes. During the first 150 cycles of circulation, there is little if any difference in performance between fast and slow compaction. After that time, the fast compaction logs tend to perform more poorly than the slowly compacted logs. These failures tend to be due to loss of relatively large chunks as discussed above.

3. A single fast compression stroke is as effective as two or three. The data is scattered but a difference between one and three strokes cannot be found.

4. Improved log quality was not observed at lower initial water contents. Instead log performance was adversely affected by reduction of initial water. The adverse effect was, however, apparently due to poorer mixing of coal, water and orimulsion at the lower water levels. Additional experiments showed that good quality logs could be obtained at lower water levels if mixing effort was greatly increased. This result led to conclusion number 5 .

5. Mixing of orimulsion (asphalt emulsion in water) with the coal was established as potentially an important variable. It is possible that inadequate mixing of the binder accounts for much of the observed variation in performance of logs made at low temperature. In this work, serious problems were encountered when the amount of water in the initial mix was reduced to near equilibrium values. Mixing of the orimulsion with coal is more difficult at low water levels. With more intensive mixing, logs were made at lower water levels that matched or 
exceeded the performance of previous logs at higher water leveis.

Discussion

$30 \%$ initial Moisture

A comparison of logs made with $30 \%$ initial water content is shown in Figure 5. The logs made with slow compaction performed better in the steel loop than did the rapidly compacted logs. The weight loss for slowly compacted logs averaged about $10 \%$ after 300 circulations while the rapidly compacted logs reached $10 \%$ loss after 200 circulations. At 150 circulations, the slow and rapidly compacted logs had similar weight losses averaging about $5 \%$.

In these as in other tests, there is little consistent difference between one and three strokes.

It is noted that one of the logs made with three strokes suffered a large weight loss after a short circulation time (at about 75 circulations). One of the single stroke logs had a similar occurrence but at a later time, i.e., at about 210 cycles. This indicates that a single large "chunk" broke loose. In previous work, loss of these large pieces was considered to be atypical and if sufficient log remained, the slope of the rate of the subsequent weight loss was taken to be more representative of the log quality. In this limited series of experiments, optimal compaction .conditions obviously were not determined. The objectives were to compare fast compaction with slow compaction. We can conclude that logs made with slow compaction may be more consistent but those from fast compaction can certainly compete with the slowly compacted logs.

\section{Reduced Initial Water}

Excess moisture in the initial powder mixture must be pressed out of the mold during compaction. With fast compaction, much less time is available for this process than in slow compaction. It was expected that reducing the amount of water in the initial powder mixture would improve log quality.

As shown in Figure 6, the opposite was found ... log performance was much poorer with lower initial moistures. Discussions indicated that mixing was more difficult 
at lower moisture levels.

The normal mixing procedure was to add half of the water to the coal and mix. Then the remaining half of the water and the orimulsion were combined and added to the coal and mixed. Mixing was accomplished with a handheld kitchen-type mixer for 4-8 minutes.

Two experiments were carried out at the lower moisture level $(16 \%)$ in which all of the orimulsion and water were combined before adding to the coal. Mixing then was extended to 30 minutes rather than 8 minutes.

The results, shown in Figure 7, showed that performance of the log with intense mixing was vastly improved. It was as good, but not better, than the performance with higher initial moistures.

It is apparent that good mixing is vital for good log performance. It even suggests that performance of logs in other experiments may be affected by inadequate mixing. 
Table 1 - Common Characteristics of Coal Logs

\begin{tabular}{|c|c|}
\hline Characteristic & Description \\
\hline Type of Coal & Mapco - Metikki mine \\
\hline Particle Size Distribution & $\begin{array}{lc}\text { Use Gundlach 30M when available, } & \text { use } M U \text { hammermill until then } \\
\text { Gundlach 30M } & \text { MU hammermill } \\
\# 30<\mathrm{d}-3 \% & \# 50<\mathrm{d}<\# 30-30 \% \\
\# 50<\mathrm{d}<\# 30-6 \% & \# 100<\mathrm{d}<\# 50-28 \% \\
\# 100<\mathrm{d}<\# 50-14 \% & \# 200<\mathrm{d}<\# 100-21 \% \\
\text { Pan }-77 \% & \mathrm{Pan}-21 \% \\
\end{array}$ \\
\hline Type of Binder & Orimulsion (if not available, use SS-1H asphalt emulsion) \\
\hline Amount of Binder & $3.0 \%$ Orimulsion (by dry weight of coal) \\
\hline Mixing process & $\begin{array}{l}\text { Grind, sieve and weigh coal (for } L / D=1.6 \text { ) } \\
\text { Measure moisture content and calculate dry weight of the coal } \\
\text { Add water so the sum of existing water and added water is } 25 \% \text { by dry weight. } \\
\text { Soak for } 1 \text { hr minimum } \\
\text { Measure Orimulsion ( } 3.0 \% \text { by dry weight of coal) } \\
\text { Dilute Orimulsion with water ( } 5 \% \text { by dry weight of coal) } \\
\text { Thoroughly mix coal and diluted Orimulsion }\end{array}$ \\
\hline Compaction Process & $\begin{array}{l}\text { Heat coal filled mold to compaction temperature } \\
\text { Loading time: } \approx 1 \text { minute } \\
\text { Peak load holding time: } 5 \text { minutes } \\
\text { Unloading time: } \approx 1 \text { minute } \\
\text { Remove log when mold cools down to room temperature } \\
\text { Do not apply pressure when log is cooling }\end{array}$ \\
\hline Compaction Pressures & 20,000 psi $(10,0008,000$ or 6,000 psi if other pressures are used) \\
\hline Compaction Temperatures & Room Temperature, $50^{\circ} \mathrm{C}, 90^{\circ} \mathrm{C}$ ( 1 or more of these three) \\
\hline Compaction mold & Mild steel split mold (floating cylinder) -- Flat-ended pistons (not beveled) \\
\hline Log curing (setting) time & $\begin{array}{l}\text { Absorption testing should begin within } 4 \text { hours after log is removed from mold. } \\
\text { After absorption testing logs can be stored underwater or in sealed plastic zip } \\
\text { lock bags. }\end{array}$ \\
\hline Water Absorption & $500 \mathrm{psi}, 1$ hour \\
\hline Moisture Content & $\%$ of total wet weight \\
\hline Circulation Testing & $\begin{array}{l}\text { 2" steel pipe - Logs circulated at liftoff velocity as calculated using Liu } \\
\text { equation }\end{array}$ \\
\hline Aspect ratio (L/D ratio) & 1.6 \\
\hline Coal log measurements & $\begin{array}{l}\text { Pre-Compaction coal weight, weight of } \mathrm{H}_{2} \mathrm{O} \text { added to coal, Orimulsion weight, } \\
\quad \text { weight of } \mathrm{H}_{2} \mathrm{O} \text { added to Orimulsion } \\
\text { Pre-water absorption weight, length, diameter, } \\
\text { Post-water absorption weight, length, diameter, } \\
\text { Weight loss as a function of \# of circulation cycles } \\
\text { Record and describe coal log breakage in pipe, if it occurs } \\
\text { Post-circulation tensile strength (psi) } \\
\text { Post-circulation moisture content (\% of total wet weight) }\end{array}$ \\
\hline $\begin{array}{l}\text { Calculated coal log } \\
\text { properties }\end{array}$ & $\begin{array}{l}\text { Pre-water absorption specific gravity, moisture content } \\
\text { Post-water absorption specific gravity, moisture content } \\
\text { (assume post-circulation M.C. = post-water adsorption M.C.) } \\
\text { Volumetric expansion due to water absorption } \\
\text { (\% of pre-water absorption volume) }\end{array}$ \\
\hline
\end{tabular}




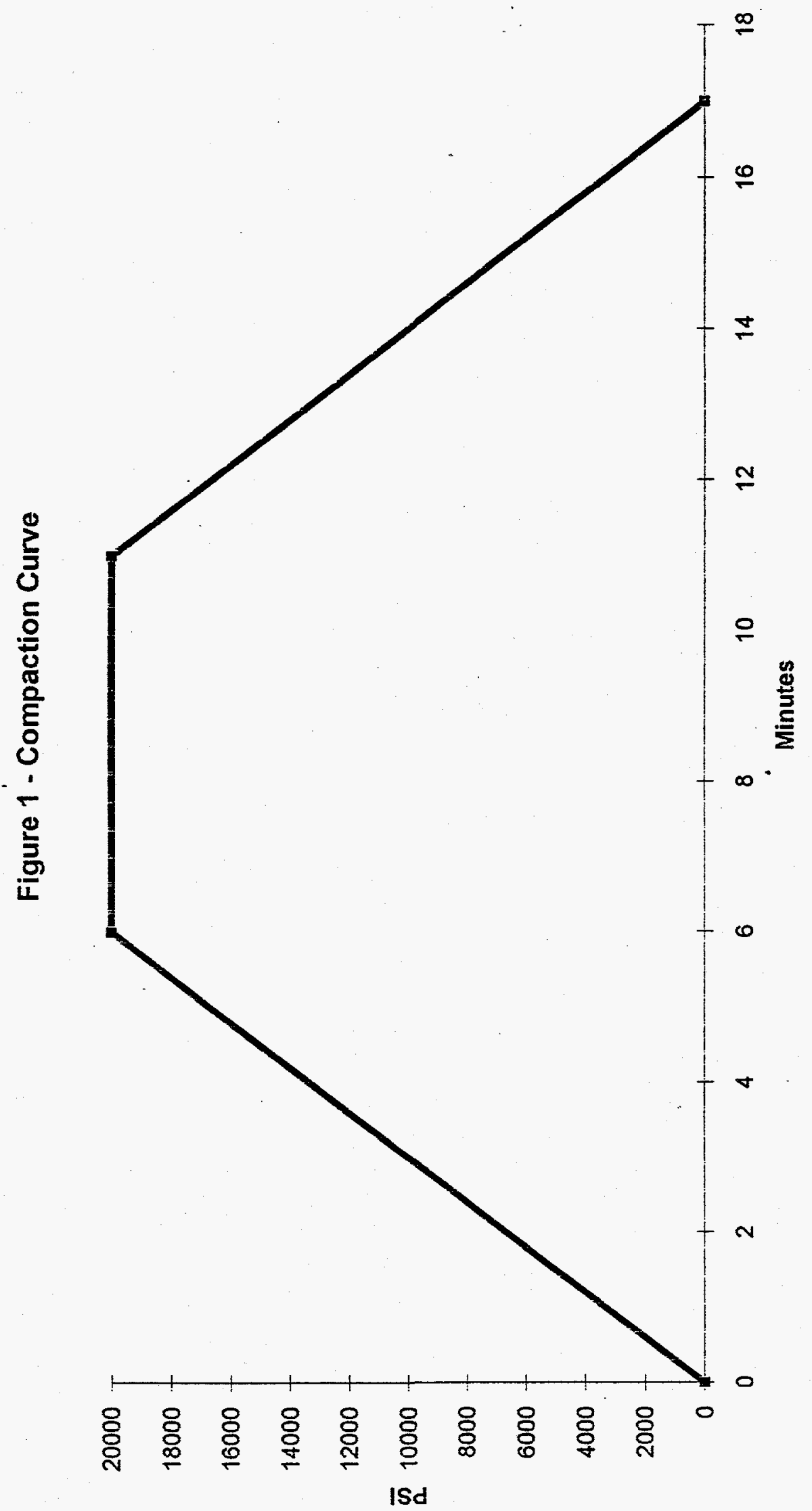


Figure 2: Comparison of Wear Tests of Fast and Slow Compacted of PRB Coal Logs

$\delta$

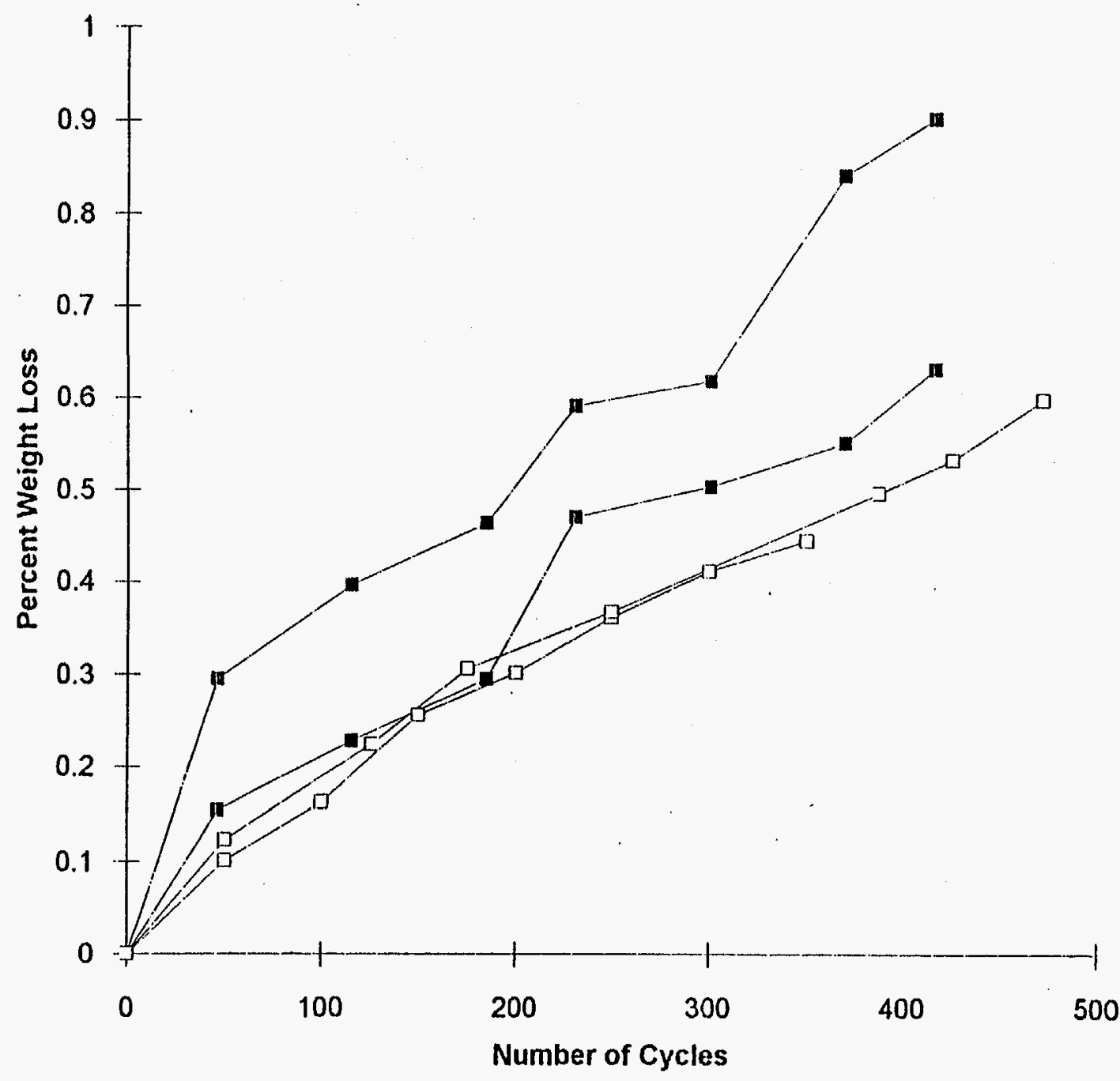

- Fast Compacted - 2 min loading, 1 min unloading

- Slow Compacted - 6 min loading $5 \mathrm{~min}$ hold, $6 \mathrm{~min}$ unloading 


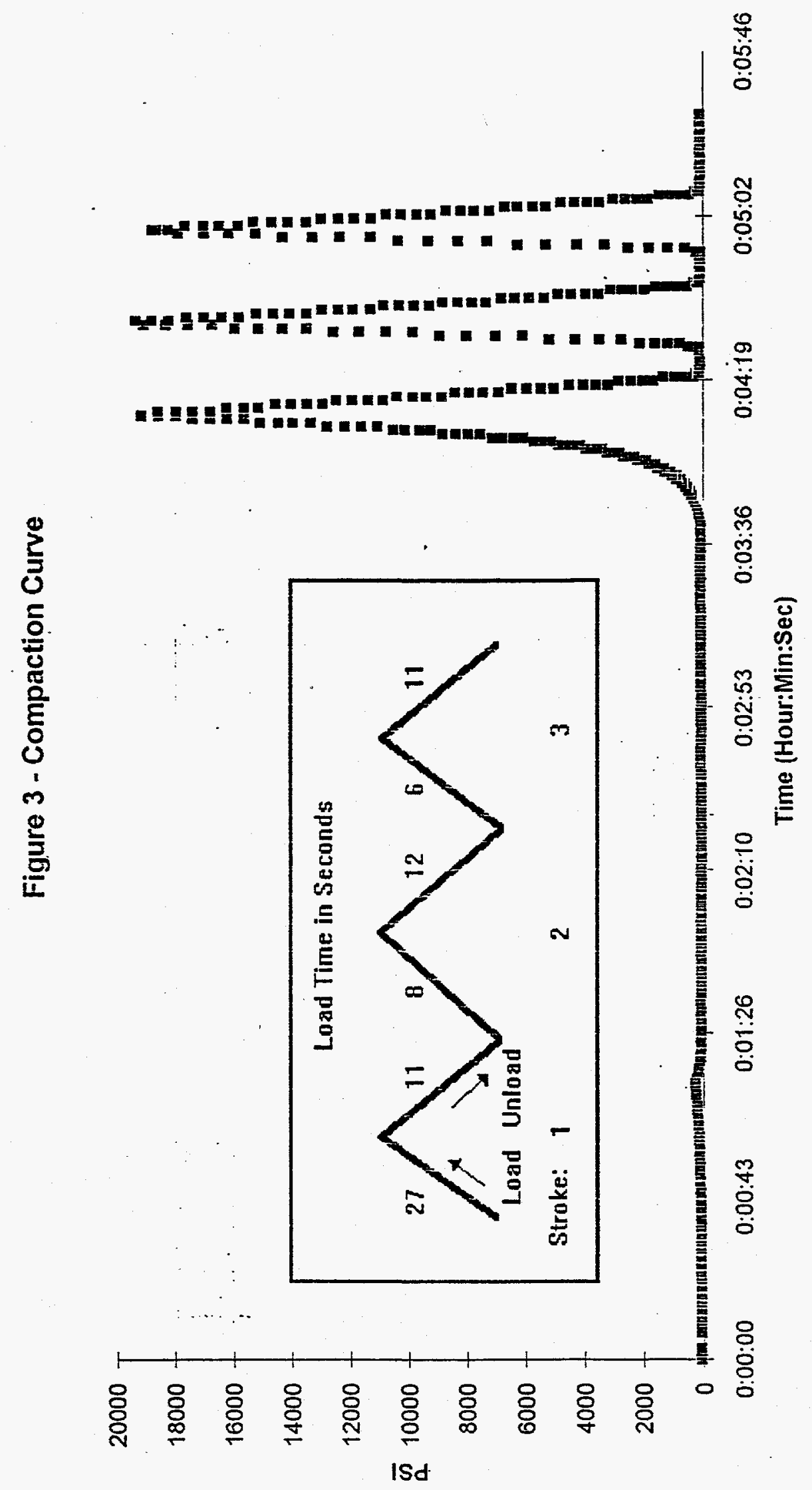


Figure 4: Fast Compaction vs. Slow Compaction at $90 \mathrm{C}$

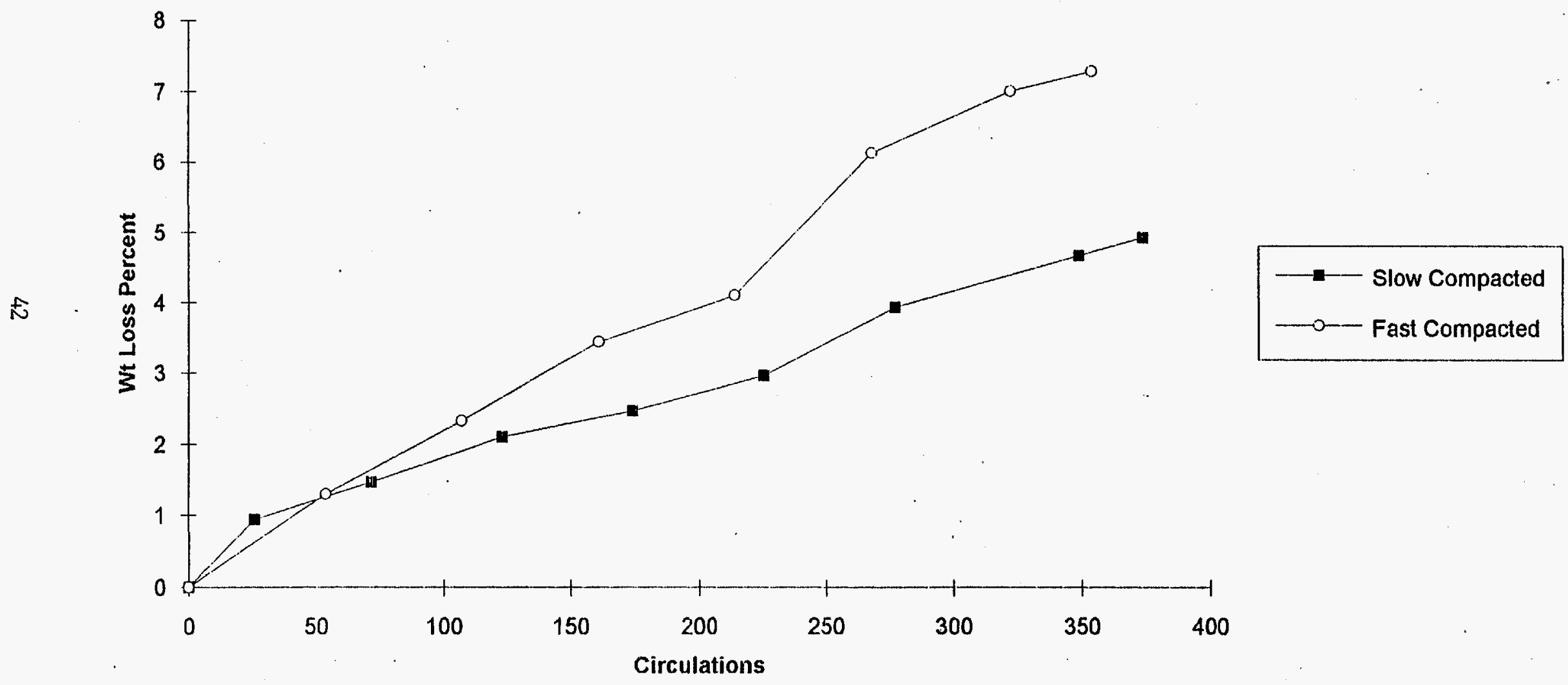



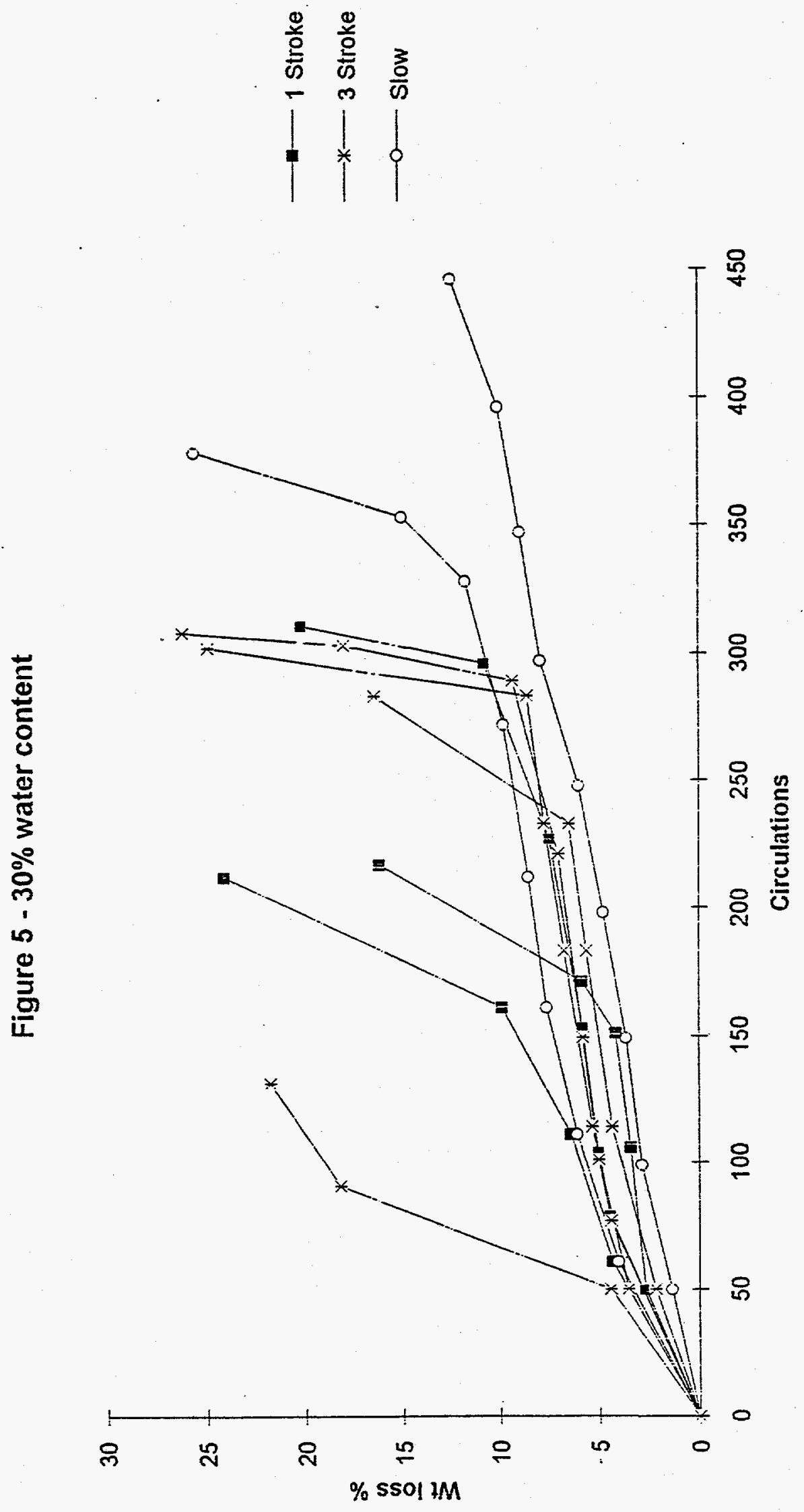

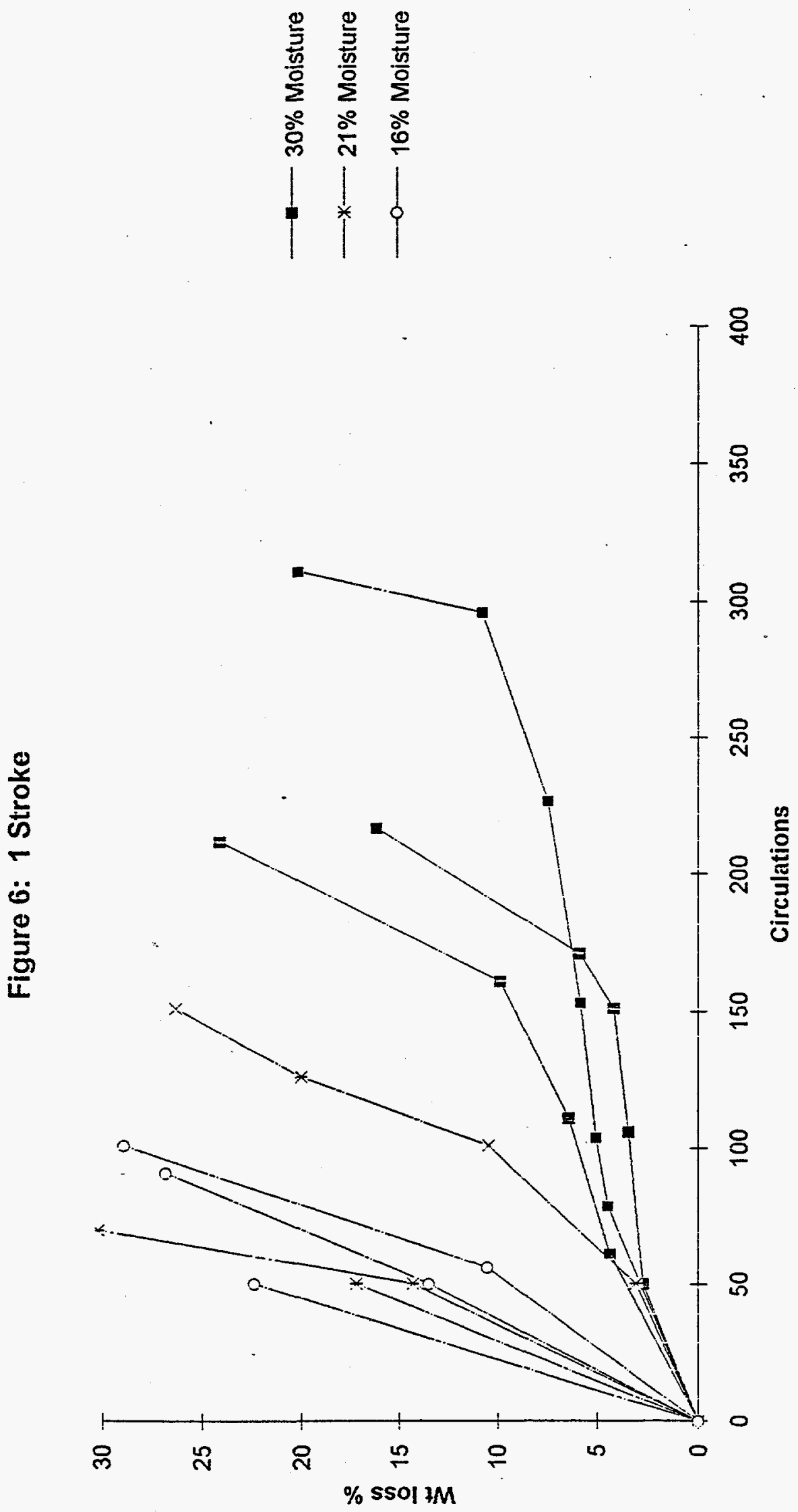

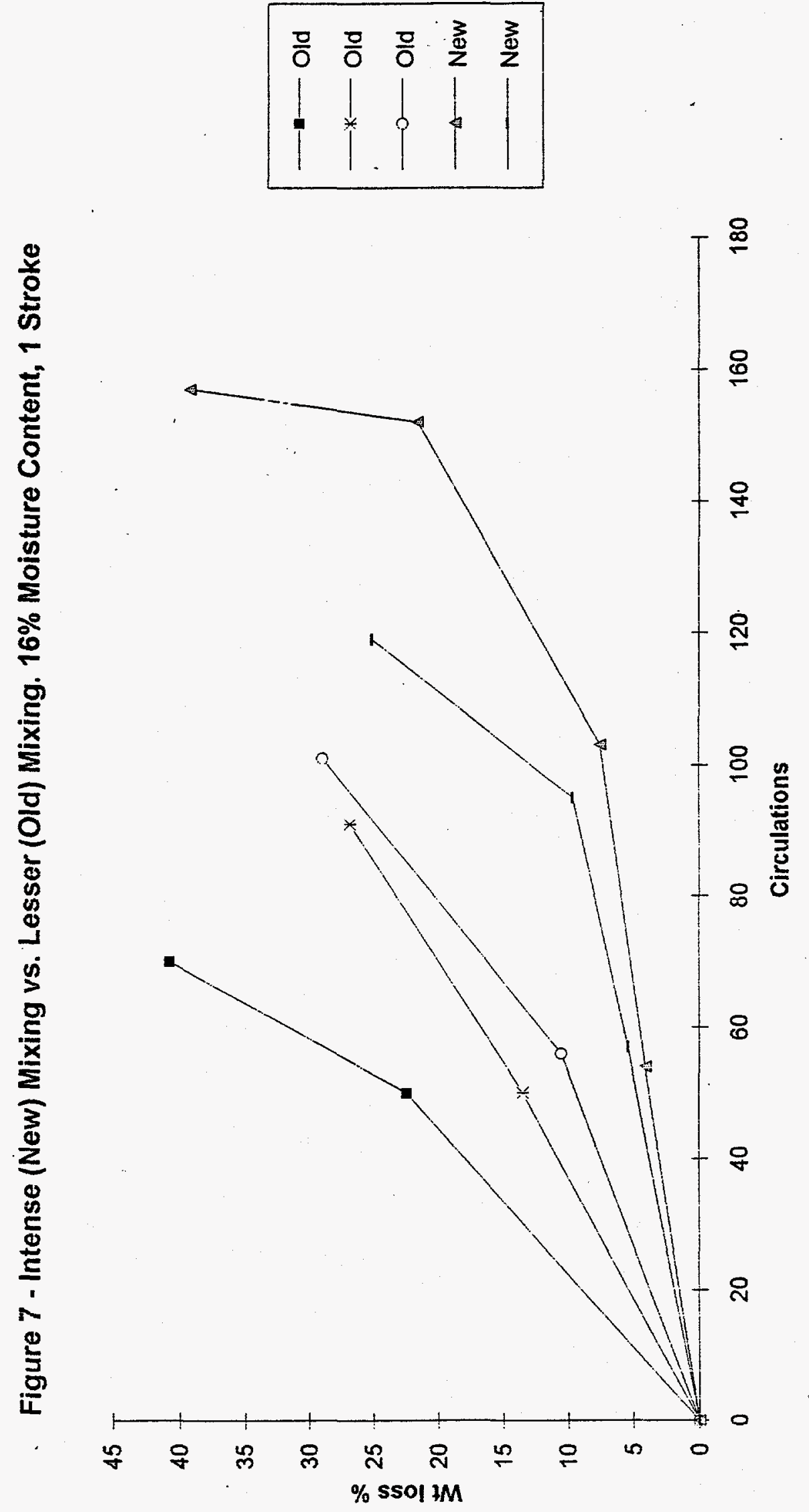


\title{
LUBRICANT EFFECTS ON COAL LOG COMPACTION
}

\author{
Project Completion Report \\ YIN LI, Post Doctoral Fellow
}

January 1995

\section{PRINCIPAL INVESTIGATOR: Dr. Henry Liu \\ RESEARCH ASSISTANT: Andrew Rockabrand}

Purpose: To test two lubricants, one oil based and the other solid based, for their effectiveness in enhancing coal log quality.

Lubricants: The oil-based lubricant was selected to be SAE $40 \mathrm{~W}$ motor oil and the solid lubricant was calcium stearate powder. The selection was based on commercial availability and low costs.

Test Plan:

1. Variable Test Conditions

1). Binder concentration: 0 and $3 \%$ Orimulsion (water included)

2). Temperature: Room temperature (RT) and $90^{\circ} \mathrm{C}$

3). Lubrication of mold: No lubricant (NL), SAE 40W motor oil (OL), and calcium stearate (CS)

\section{Fixed Test Parameters}

1). Coal type: MAPCO

2). Particle size distribution: -30 mesh (please see Table 1 for detail)

3). Initial moisture content: $20 \%$ by weight

4). Peak Pressure: 20,000 psi

5). Loading speed: $8,000 \mathrm{lb} / \mathrm{min}$ (see Figure 1) 
6). Mold type: single-piece mold with a beveled exit (unchrome-plated).

7). Piston type: flat ended

8). Mixing: hand mixer (about $5 \mathrm{~min}$ )

9). Wear test velocity $\left(V_{L}\right): 1.76-1.924 \mathrm{~m} / \mathrm{s}$ (see Appendix for detail)

Table 1. Coal particle size distribution

\begin{tabular}{|c|c|}
\hline Particle size (mech) & Percentage \\
\hline $30-60$ & 45.2 \\
\hline $60-120$ & 23.5 \\
\hline $120-200$ & 19.6 \\
\hline Pan & 11.7 \\
\hline
\end{tabular}

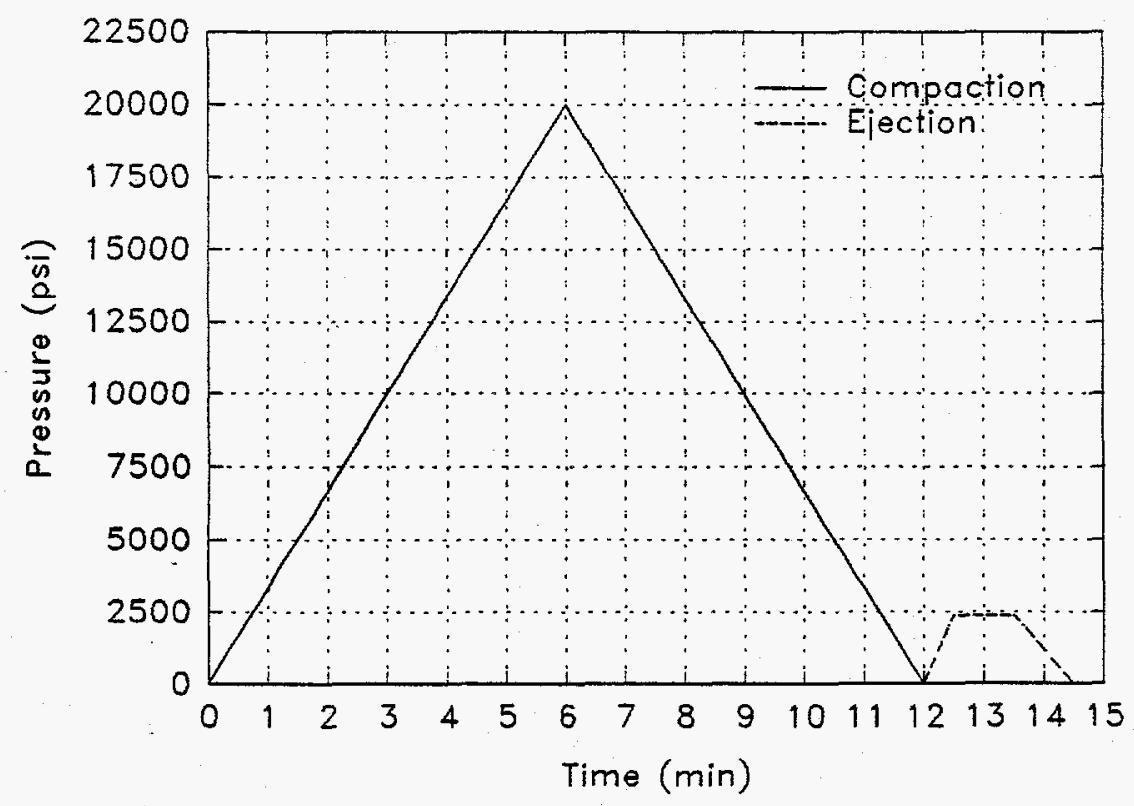

Figure 1. Typical coal log compaction and ejection patterns for the study of lubricant effects 


\section{Experiment Design:}

Table 2 lists the experiment design including $2 \times 2 \times 3=12$ treatments.

Table 2. Design of experiments

\begin{tabular}{|c|c|c|c|c|c|}
\hline $\begin{array}{l}\text { Run } \\
\text { No. }\end{array}$ & unlubricated mold & $\begin{array}{l}\text { Run } \\
\text { No. }\end{array}$ & oil lubricated & $\begin{array}{l}\text { Run } \\
\text { No. }\end{array}$ & $\begin{array}{l}\text { calcium stearate } \\
\text { lubricated }\end{array}$ \\
\hline NLR3 & $3 \%$ Orimulsion, RT & OLR3 & $3 \%$ Orimulsion, $\mathrm{RT}$ & CSR3 & $3 \%$ Orimulsion, RT \\
\hline NLR0 & $0 \%$ Orimulsion, RT & OLRO & $0 \%$ Orimulsion, RT & CSRO & $0 \%$ Orimulsion, RT \\
\hline NLH3 & $\begin{array}{l}3 \% \text { Orimulsion, } \\
90^{\circ} \mathrm{C}\end{array}$ & OLH3 & $\begin{array}{l}3 \% \text { Orimulsion, } \\
90^{\circ} \mathrm{C}\end{array}$ & CSH3 & $\begin{array}{l}3 \% \text { Orimulsion, } \\
90^{\circ} \mathrm{C}\end{array}$ \\
\hline NLHO & $\begin{array}{l}0 \% \text { Orimulsion, } \\
90^{\circ} \mathrm{C}\end{array}$ & OLHO & $\begin{array}{l}0 \% \text { Orimulsion, } \\
90^{\circ} \mathrm{C}\end{array}$ & CSHO & $\begin{array}{l}0 \% \text { Orimulsion, } \\
90^{\circ} \mathrm{C}\end{array}$ \\
\hline
\end{tabular}

\section{Dependent Variables}

1). Density before and after water absorption

2). Moisture content before and after water absorption

3). Porosity before and after water absorption

4). Weight loss due to wear in pipe

\section{Status of Research:}

Lubrication effects of SAE $40 \mathrm{~W}$ motor oil and calcium stearate have been

investigated. A total of 42 logs were compacted under twelve treatment conditions and tested for water absorption, weight loss and tensile strength. Log density, moisture content, porosity and water holding capacity before and after water absorption were determined. Compaction work and compressibility were calculated based on force - displacement curves. Data needed for compaction modeling were recorded during compaction and ejection of logs. The force displacement history, transmitted force ratio, characteristic length and ejection force were also analyzed. 
Results and Discussion:

1. Effects of lubricants on density of coal logs before water absorption

The densities of coal logs with $0 \%$ Orimulsion and compacted under three lubrication conditions -- no lubricant, SAE 40W motor oil and calcium stearate -- are compared in Figure 2. At room temperature, calcium stearate lubrication produced the highest density but the largest within-treatment variation while the unlubricated mold produced the lowest density. At $90^{\circ} \mathrm{C}$, the unlubricated mold and SAE $40 \mathrm{~W}$ lubricated mold did not show any difference in density while the calcium stearate lubricated mold generated higher density. It was notice that logs with a very large variation of density had severe cracks and broke-up during circulation tests. Therefore, cracking before water absorption may be one of the causes for such a large within-treatment variation of density.

The densities of coal logs with $3 \%$ Orimulsion and compacted without lubricant, with SAE $40 \mathrm{~W}$ motor oil and with calcium stearate lubricated molds, respectively, are compared in Figure 3. Interestingly, coal logs with 3\% Orimulsion had lower density than their binderless counterparts. This is due to a lower density of Orimulsion than coal particles, which causes the density of the total solids or coal-Orimulsion mixture to decrease. This argument was supported by the calculated solid density (see Appendix). This result should bring cautions when comparing the density of the logs with and without Orimulsion. Because logs with $3 \%$ Orimulsion, although had lower densities, actually had lower total porosities than binderless logs that had higher densities. Please see page 5 for more detail. At $90^{\circ} \mathrm{C}$, the lubricated molds did not produce logs as dense as those produced by the unlubricated mold. The logs compacted at $90^{\circ} \mathrm{C}$ and with the unlubricated mold had very obvious cracks before 


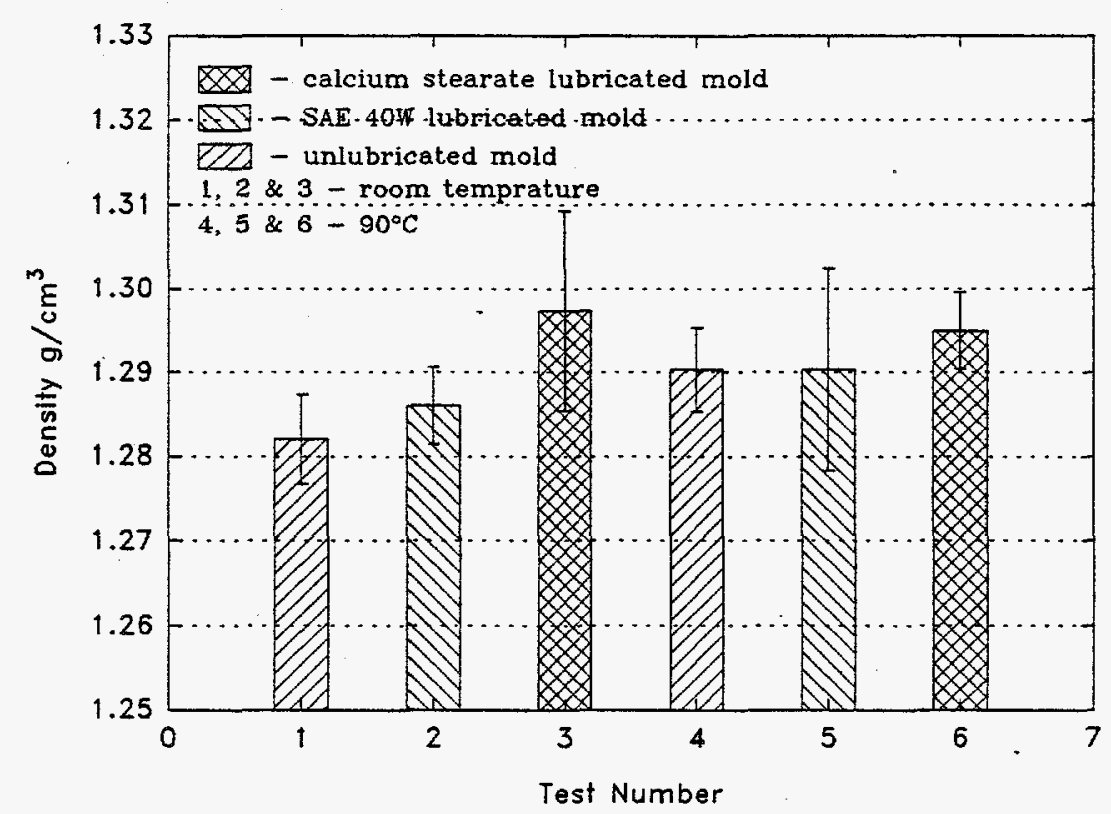

Figure 2. Density of coal logs having $0 \%$ Orimulsion before water absorption

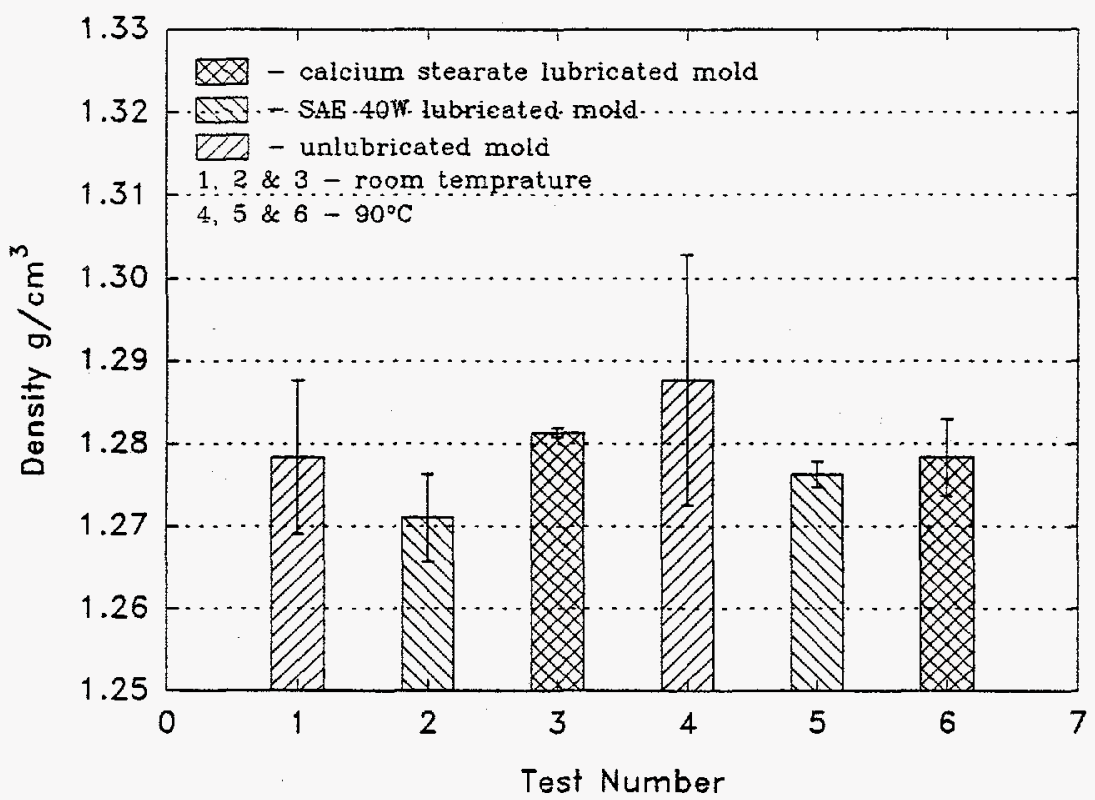

Figure 3. Density of coal logs having $3 \%$ Orimulsion before water absorption 
water absorption. In contrast to binderless logs, the size of the cracks of $3 \%$ Orimulsion logs was small and did not expand during circulation tests. The cracks of the $90^{\circ} \mathrm{C}$ logs compacted with lubricated molds were significantly reduced, especially with the mold lubricated by calcium stearate.

\section{Effects of lubricants on moisture content of coal logs before water absorption}

Figures 4 and 5 give moisture content of logs with 0 and $3 \%$ Orimulsion before water absorption. Under the same compaction conditions, logs with $3 \%$ Orimulsion resulted in lower moisture content than those binderless logs except for $90^{\circ} \mathrm{C}$ logs produced by a SAE 40W lubricated mold. In most of the cases, $90^{\circ} \mathrm{C}$ logs had lower moisture content than their room temperature counterparts. Calcium stearate was more effective than SAE $40 \mathrm{~W}$ in displacing water and producing denser logs except for $0 \%$ Orimulsion and $90^{\circ} \mathrm{C}$ group.

\section{Effects of lubricants on porosity of coal logs before water absorption}

Figures 6 and 7 give total porosity (porosity occupied by water and air before water absorption tests) of logs with 0 and $3 \%$ Orimulsion, respectively. Before the calculation of total porosity, the density of solids was determined based on the water absorption data:

$$
\rho_{s}=\frac{\text { mass of solids }}{\text { volume of solids }}=\frac{w_{2}}{V_{s}}=\frac{w_{i}\left(1-m_{i}\right)}{w_{1} / \rho_{1}-\left[w_{1}-w_{i}\left(1-m_{i}\right)\right] / \rho_{w}}
$$

where $\rho_{\mathrm{s}}$ is the density of the solids (coal/coal - Orimulsion mixture), $\rho_{1}$ is the density of the coal $\log$ after water absorption, $\rho_{w}$ is the density of water. $w_{2}$ is the weight of the solids, $V_{s}$ is the volume of the solids, $w_{1}$ is the weight of the coal log after water absorption, $w_{i}$ is the initial weight of the coal-Orimulsion-water mixture, $m_{i}$ is the initial moisture content of the 


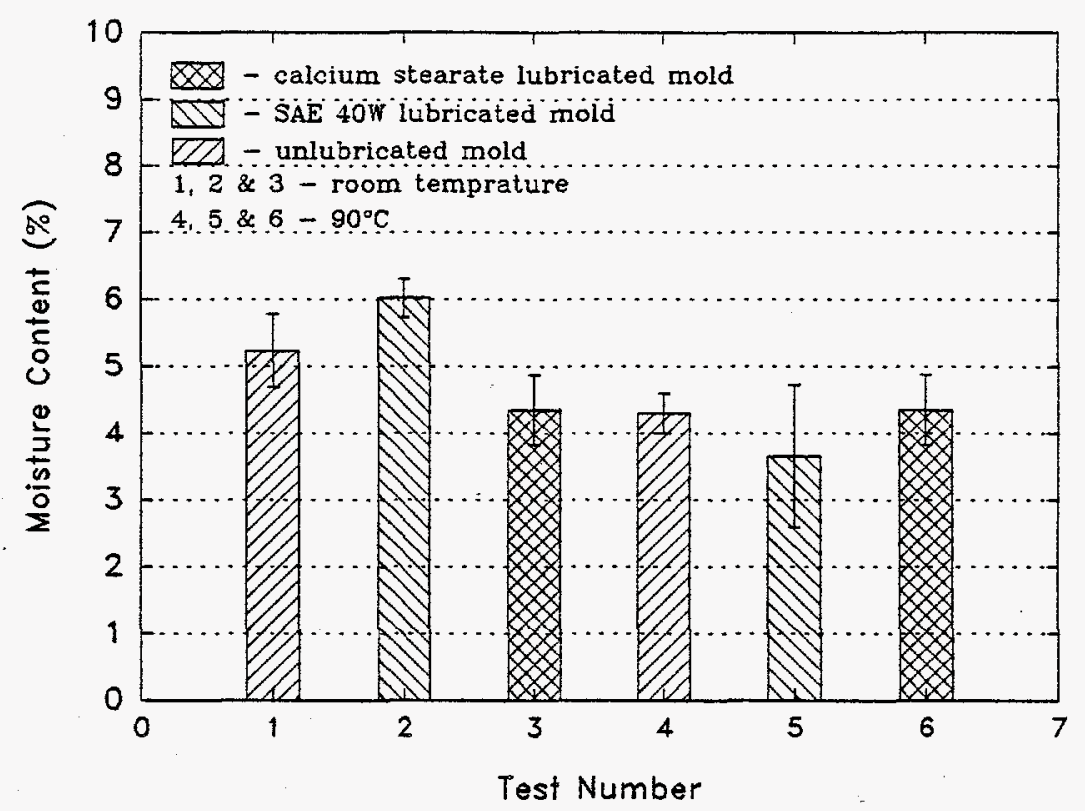

Figure 4. Moisture content of coal logs having $0 \%$ Orimulsion before water absorption

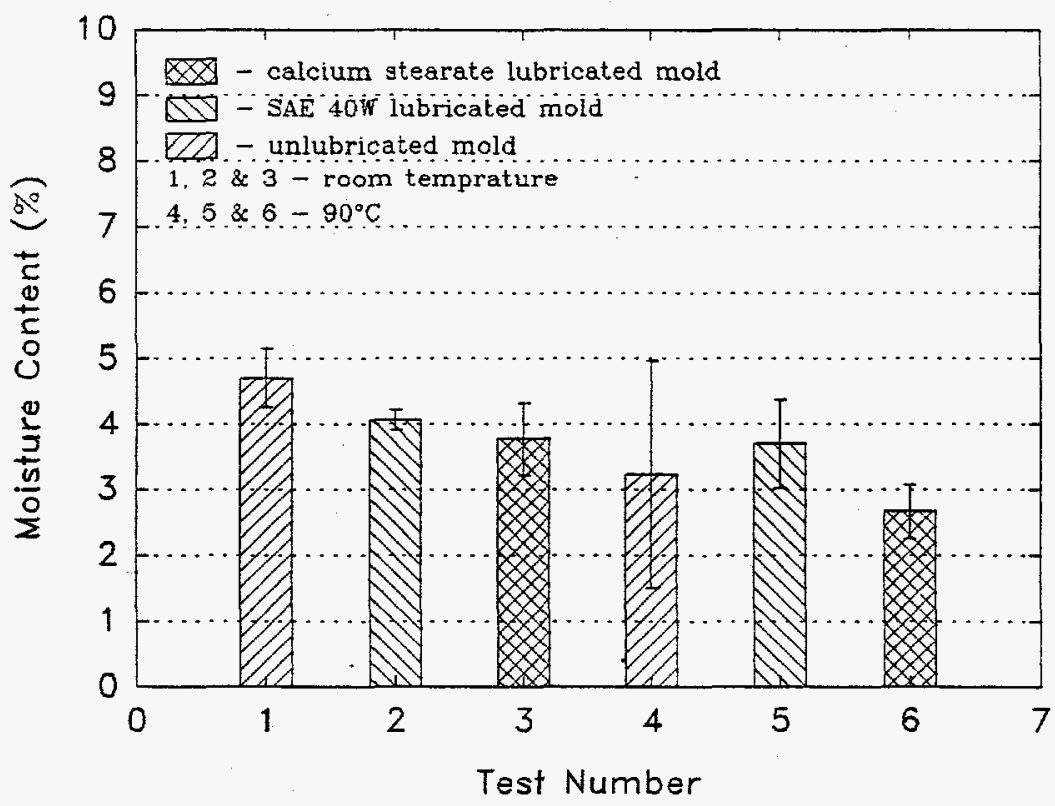

Figure 5. Moisture content of coal logs having 3\% Orimulsion before water absorption 


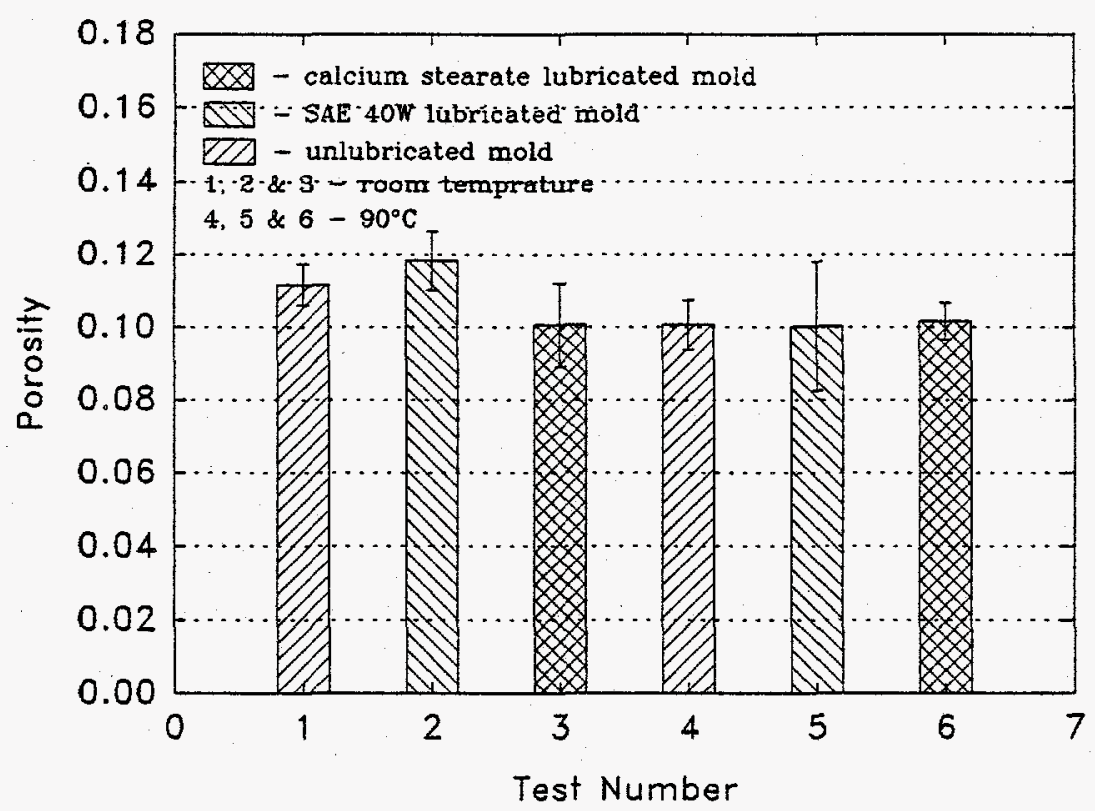

Figure 6. Total porosity of coal logs having $0 \%$ Orimulsion before water absorption

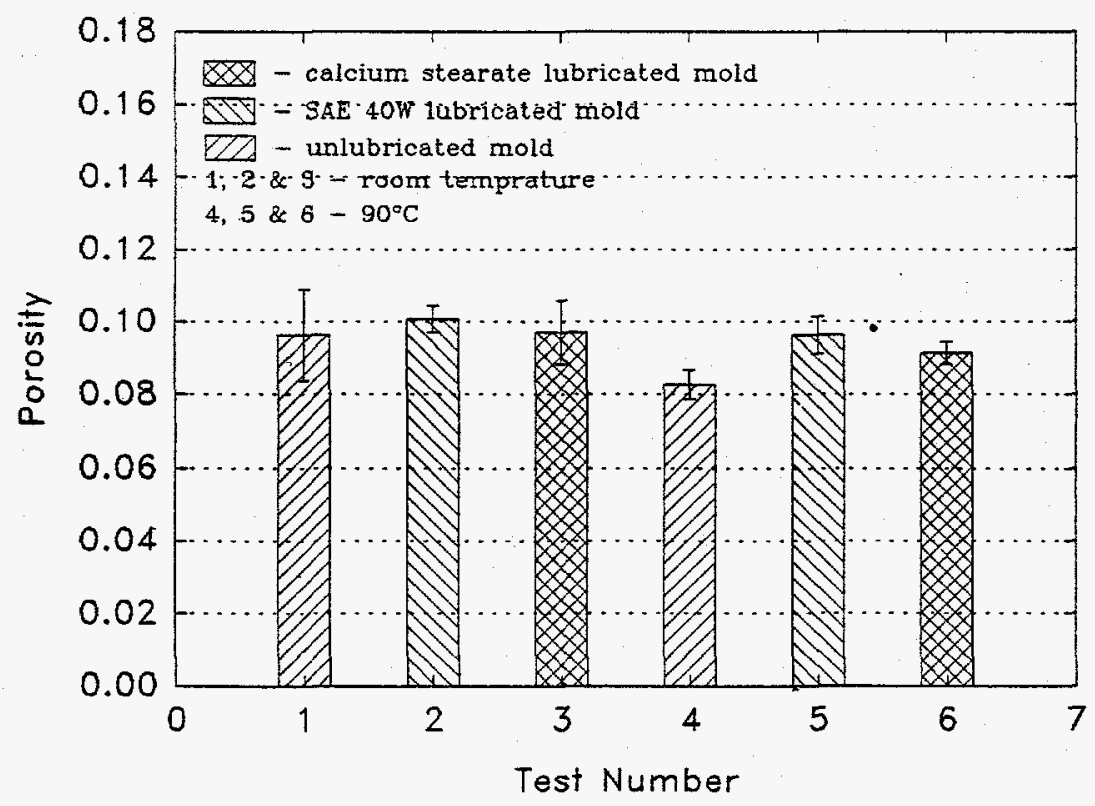

Figure 7. Total porosity of coal logs having $3 \%$ Orimulsion before water absorption 
coal-Orimulsion-water mixture. In above calculation, we assumed that no air was left in the $\log$ after water absorption. Then the total porosity was determined by the following equation:

$$
\epsilon_{0}=\frac{\text { volume of } \log -\text { volume of solids }}{\text { volume of } \log }
$$

It is shown that the $3 \%$ Orimulsion logs had a lower total porosity than the binderless logs, which is unexpected because these logs also had a lower density. However, if the total mass of solids was constant, which is relatively true for our case, the $3 \%$ Orimulsion logs would have a larger total volume due to a lower solid density than those binderless logs. At the same time, the $3 \%$ orimulsion logs had a lower total voids volume. Since porosity is presented in a fraction of the total volume, an increase in total volume and decrease in total voids should result in a lower porosity. High temperature logs had lower porosity than room temperature ones, and lubrication did not help to reduce total porosity in most of the cases.

\section{Effects of lubricants on weight loss of coal logs before water absorption}

The results of weight loss as a function of circulation cycles for logs with $3 \%$

Orimulsion are presented in Figures 8 and 9. Coal logs compacted with an unlubricated mold showed better wear resistance than those compacted with a SAE $40 \mathrm{~W}$ lubricated mold under both room temperature and $90^{\circ} \mathrm{C}$ conditions (Figure 8). Room temperature logs compacted with a calcium stearate lubricated mold showed lower weight loss than those room temperature logs produced by the control mold. Logs compacted at $90^{\circ} \mathrm{C}$ with calcium stearate lubrication had higher'weight loss than $90^{\circ} \mathrm{C}$ logs without lubrication (Figure 9).

For binderless logs (Figures 10 and 11), both lubricants showed a obvious reduction on weight loss and an increase in circulation time. In contrast to coal logs with $3 \%$ 
Orimulsion, increasing compaction temperature of binderless logs did not indicate any obvious beneficial effects on the weight loss reduction except for the calcium stearate lubricated mold.

Generally speaking, the $90^{\circ} \mathrm{C}$ coal logs compacted in an unlubricated mold with $3 \%$ Orimulsion had the lowest weight loss while the $90^{\circ} \mathrm{C}$ coal logs with $3 \%$ Orimulsion compacted in a calcium stearate lubricated mold had the second lowest weight loss.

During wear tests, it was noticed that the worn surface of the logs with $3 \%$

Orimulsion was smooth and the damage was due to abrasion. Binderless logs compacted at room temperature showed very rough worn surface and poor binding and the wear was due to chipping, tearing and/or flushing away by the water. However, binderless logs compacted with both lubricants had smooth worn surface and improved binding (coal particles were not easily to be scrubbed off by using fingers).

\section{Comparison of the maximum ejection force}

The maximum ejection forces (dynamic) are compared in Table 3. Both room temperature and $90^{\circ} \mathrm{C}$ logs were ejected immediately after compaction. In the case of SAE 40W lubricant, the maximum ejection forces were significantly reduced. For binderless logs compacted at $90^{\circ} \mathrm{C}$, the unlubricated mold had the highest ejection force, the calcium stearate lubricated mold had the second highest, and the oil lubricated mold had the lowest.

Comparing the ejection forces in each column in Table 3, the unlubricated and oil lubricated mold had the highest values at $0 \%$ Orimulsion and $90^{\circ} \mathrm{C}$. With calcium stearate lubrication, the highest ejection force was at $3 \%$ Orimulsion and $90^{\circ} \mathrm{C}$. 


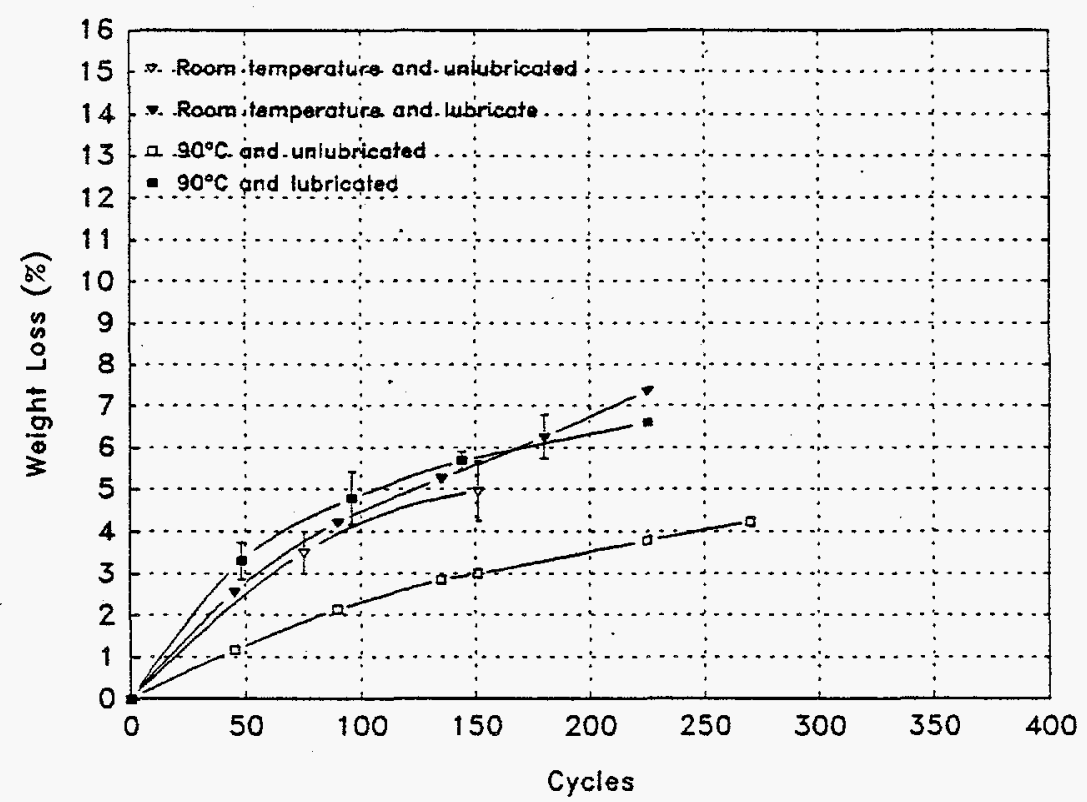

Figure 8. Effects of SAE 40W lubrication on weight loss of logs with $3 \%$ Orimulsion

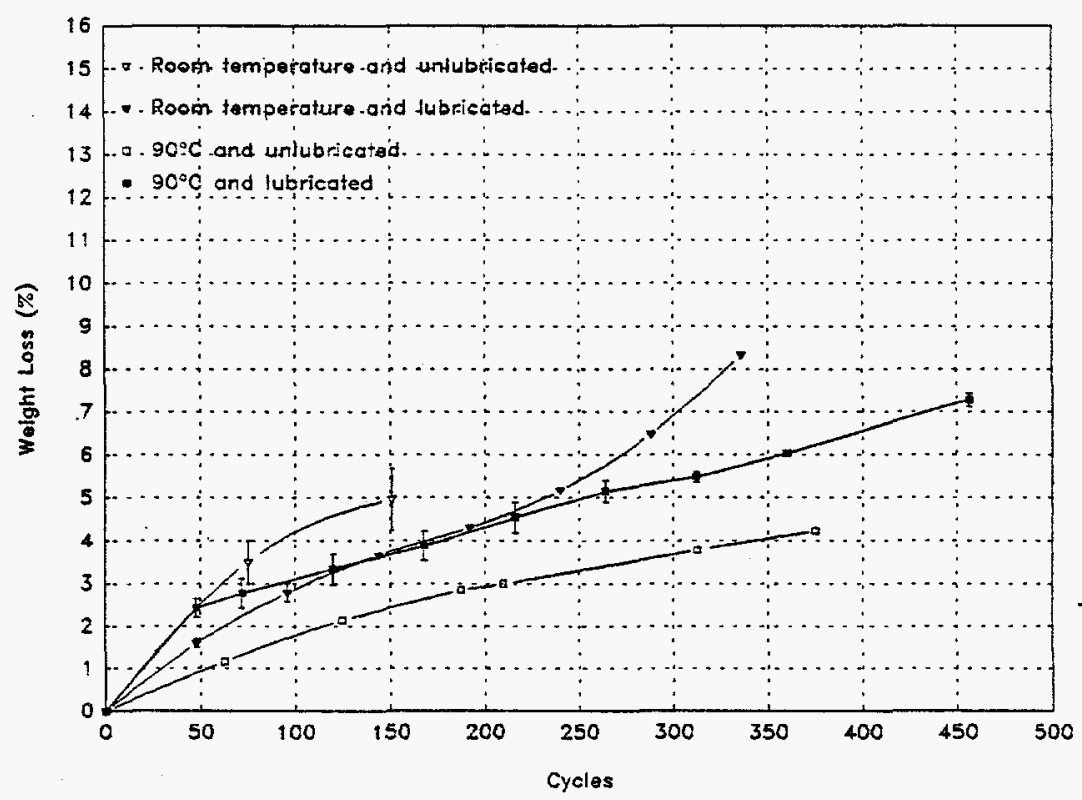

Figure 9. Effects of calcium stearate lubrication on weight loss of logs with $3 \%$ Orimulsion 


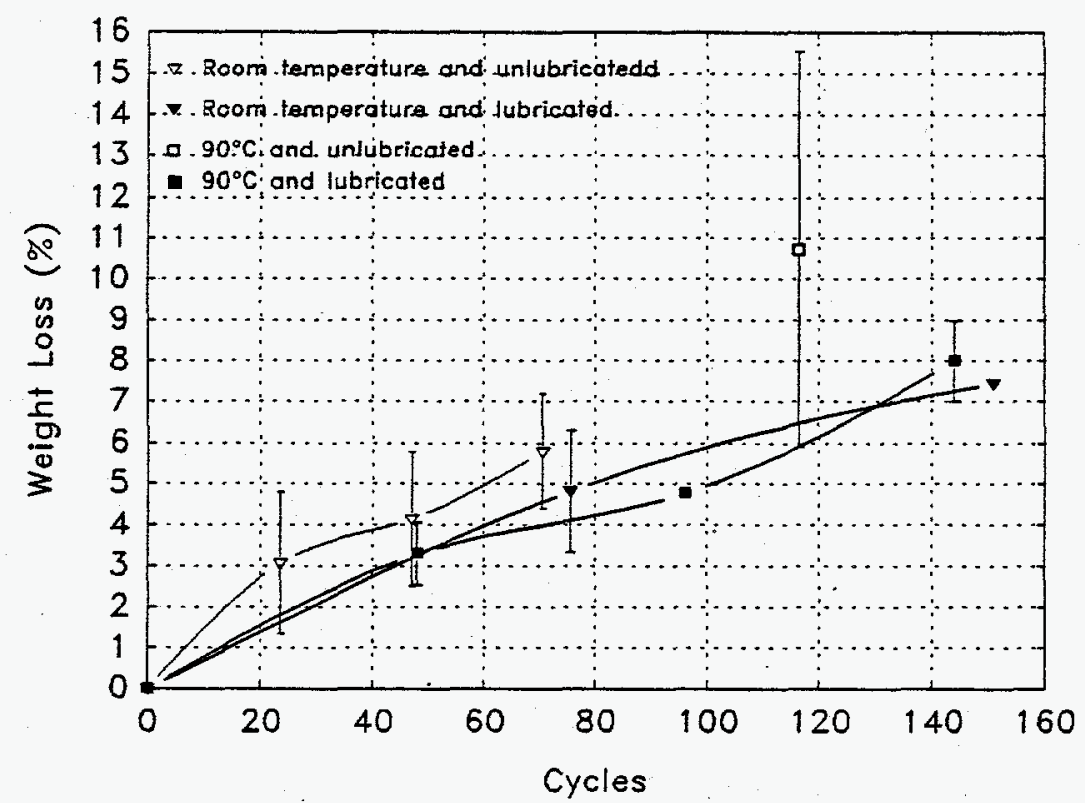

Figure 10. Effects of SAE $40 \mathrm{~W}$ lubrication on weight loss of logs with $0 \%$ Orimulsion

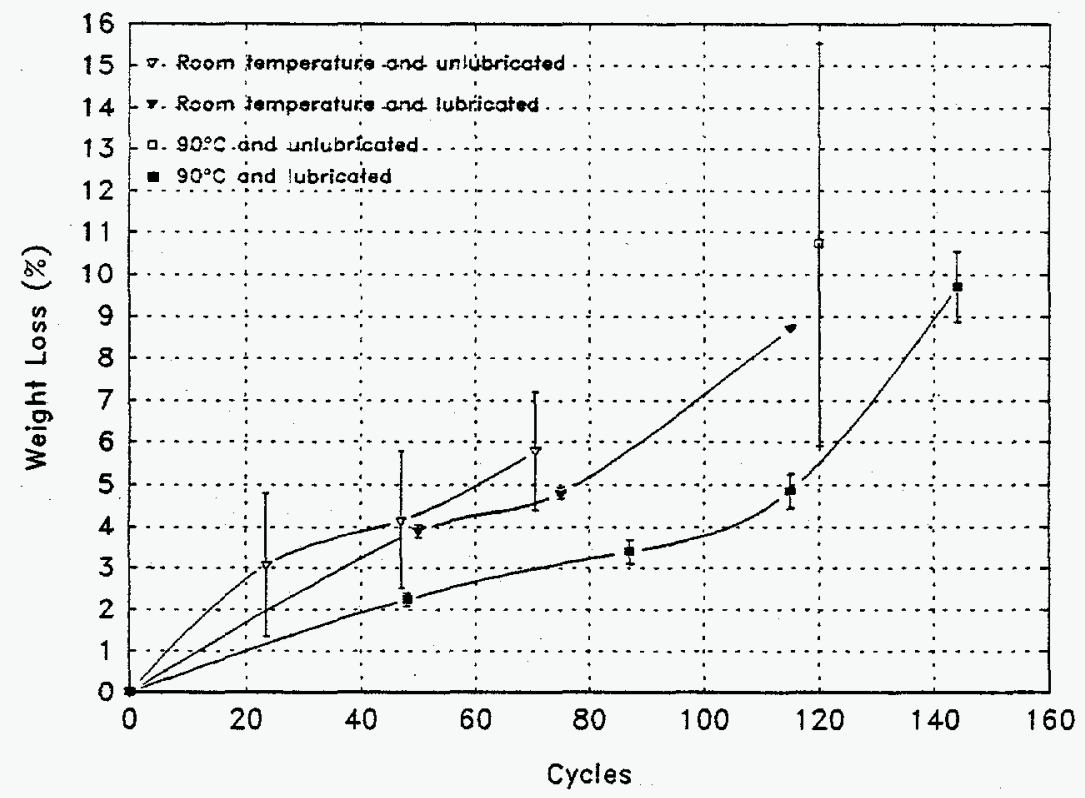

Figure 11. Effects of calcium stearate lubrication on weight loss of logs with $0 \%$ Orimulsion 
Table 3 Comparison of the maximum ejection force

\begin{tabular}{||l|c||l|l||l|c|}
\hline unlubricated mold & $\begin{array}{l}\mathrm{F}_{\text {emex }} \\
(\mathrm{kN})\end{array}$ & $\begin{array}{l}\text { SAE 40W motor } \\
\text { oil }\end{array}$ & $\begin{array}{l}\mathrm{F}_{\text {emax }} \\
(\mathrm{kN})\end{array}$ & calcium stearate & $\begin{array}{c}\mathrm{F}_{\text {emax }} \\
(\mathrm{kN})\end{array}$ \\
\hline $3 \%$ binder \& RT & 17 & $3 \%$ binder \& RT & 12 & $3 \%$ binder \& RT & 10 \\
\hline $0 \%$ binder \& RT & 18 & $0 \%$ binder \& RT & 11 & $0 \%$ binder \& RT & 13 \\
\hline $3 \%$ binder \& $90^{\circ} \mathrm{C}$ & 18 & $3 \%$ binder \& $90^{\circ} \mathrm{C}$ & 11 & $3 \%$ binder \& 90 C & 22 \\
\hline $0 \%$ binder \& $90^{\circ} \mathrm{C}$ & 21 & $0 \%$ binder \& $90^{\circ} \mathrm{C}$ & 16 & $0 \%$ binder \& 90 C & 19 \\
\hline
\end{tabular}

\section{Compressibility}

The relationship between the volume and applied force during coal log compaction was investigated. The typical relationship between the volume of a coal log and the applied compaction force can be expressed as:

$$
V=\frac{C}{F_{a}^{1 / K}} \quad\left(F_{a}>100 \mathrm{kN}\right)
$$

where $\mathrm{V}$ is the volume of the compact, $\mathrm{F}_{\mathrm{a}}$ is the applied force (force on the top piston) and $\mathrm{C}$ is a constant. The constant $\mathrm{C}$ and the slope $(1 / \mathrm{K})$ of the plot were determined by a linear regression method (see Figure 12). The $r^{2}$ of the regression was above 0.999 for all the conditions tested. The above equation has a resemblance to the following equation derived by Adams et al. (1994) and can be used to correlate the constant $C$ to the agglomerate shear strength $\tau_{0}$ :

$$
V=V_{0}\left(\frac{\tau_{0}}{K P}\right)^{L / E}
$$

where $V_{0}$ is the initial volume and $P$ is the applied compaction pressure. The compressibility 
factor $\mathrm{K}$ is defined as the inverse of the slope of the logarithm of bulk density of the compact versus the logarithm of the applied pressure. This factor is basically constant for most solids within the typical briquetting pressure range of 1,000 to 70,000 psi. This factor is commonly used in briquetting industry for the determination of power requirements. Small $\mathrm{K}$ indicates larger force and power requirements for obtaining the same density change (Johanson, 1969). By comparing of Eqs. (3) and (4) and using the following relationship:

$$
P=\frac{4 F_{\alpha}}{\pi D^{2}}
$$

we can obtain the constant $\mathrm{C}$ as:

$$
C=V_{0}\left(\frac{\pi D^{2} \tau_{0}}{4 K}\right)^{1 / K}
$$

In the case of coal log compaction reported here, the compressibility factor was determined based on volume change of the compact instead of bulk density. The reason for this modification was due to water displacement from the log during compaction which made the bulk density difficult to be determined. The compressibility factor in our case was found to be within a range of 13 to 16 . I am still trying to locate references on the typical values of compressibility factor of different coals. 


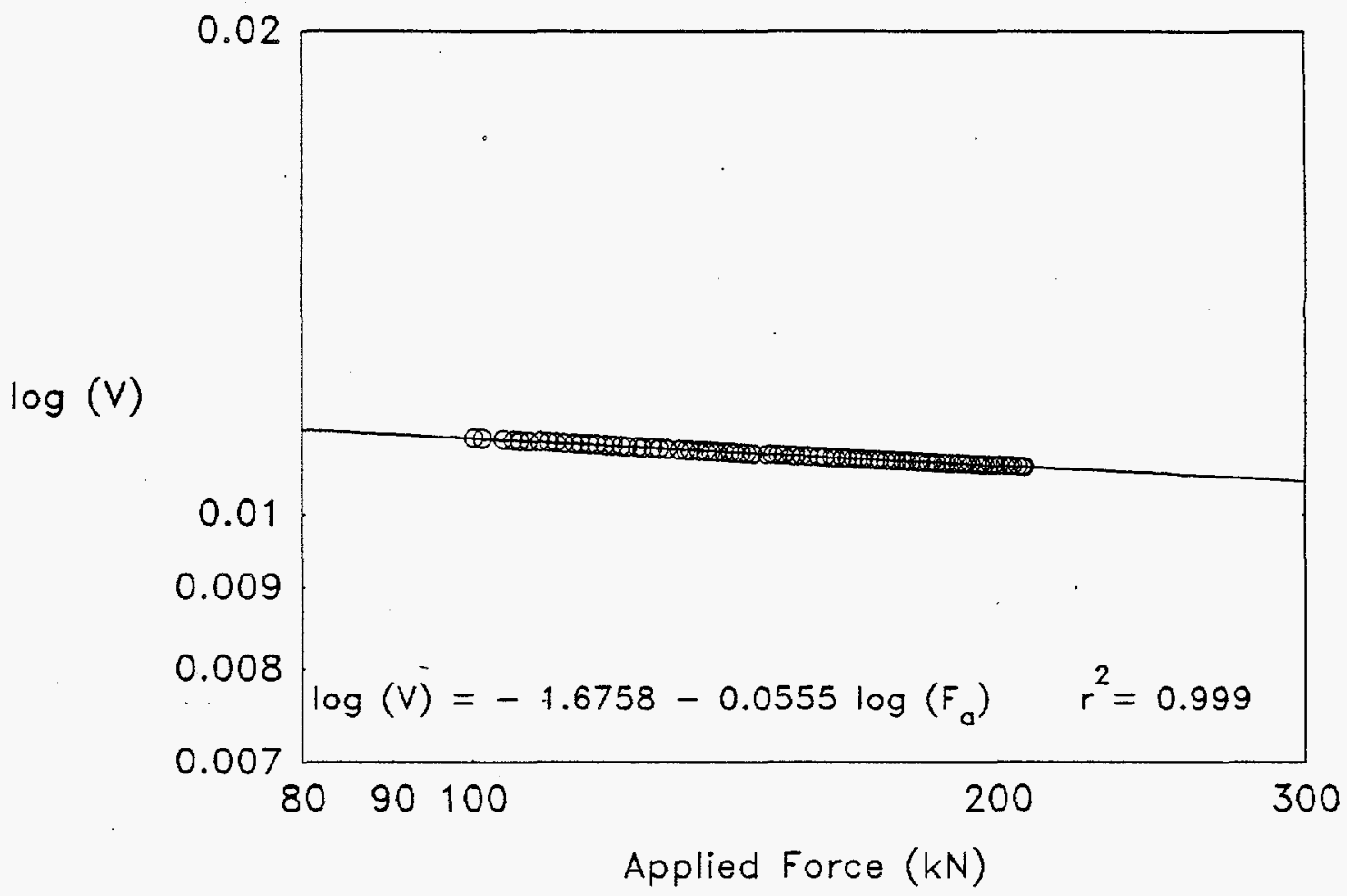

Figure 12. The typical relationship between the volume of logs (NLH3) and applied force. 


\section{Conclusions}

1. Calcium stearate as a solid lubricant is effective in increasing density, minimizing cracks and reducing of the weight loss of logs with or without Orimulsion. When compared with the unlubricated mold (control mold) and/or the SAE 40W motor oil lubricated mold, the weight losses of the logs compacted with the calcium-stearatelubricated mold have a much smaller within-treatment variation, especially for logs compacted with $0 \%$ Orimulsion. This indicates that the calcium stearate can produce logs with more uniform quality than the control mold and oil-lubricated mold.

2. SAE 40W lubricant can help to reduce weight loss of binderless logs but not logs with $3 \%$ Orimulsion. Lubrication of the mold with SAE $40 \mathrm{~W}$ can reduce friction loss, increase the transmitted force and reduce the ejection force significantly.

3. Orimulsion has major contribution on increasing wear resistance which may be due to stronger chemical bond (adhesiveness) and larger contact area among particles.

4. Increasing compaction temperature helps to remove more water, reduce total porosity, produce more compact logs and improve wear resistance of logs with Orimulsion addition. The results of density, moisture content, total porosity and weight loss indicate a clear association between Orimulsion and temperature.

5. Large within-treatment variation of density may be an indication of cracking of the logs before water absorption tests.

6. The logarithm of volume versus the logarithm of applied force fitted to a straight line when the applied force was larger than $1000 \mathrm{kN}$. The compressibility factor ranged from 13 to 16 . 


\section{References:}

Adams, M. J., Mullier, M. A. and Seville, J. P. K. (1994). "Agglomerate strength measurement using a uniaxial confined compression test." Powder Technology, 78:5-13. Johanson, J. R. (1969). "The use of laboratory tests in the design and operation of briquetting presses." Preceedings of the 11th Briquetting Conference IBA. pp 
Table 1 Data for room temperature logs compacted with $3 \%$ Orimulsion in an unlubricated mold

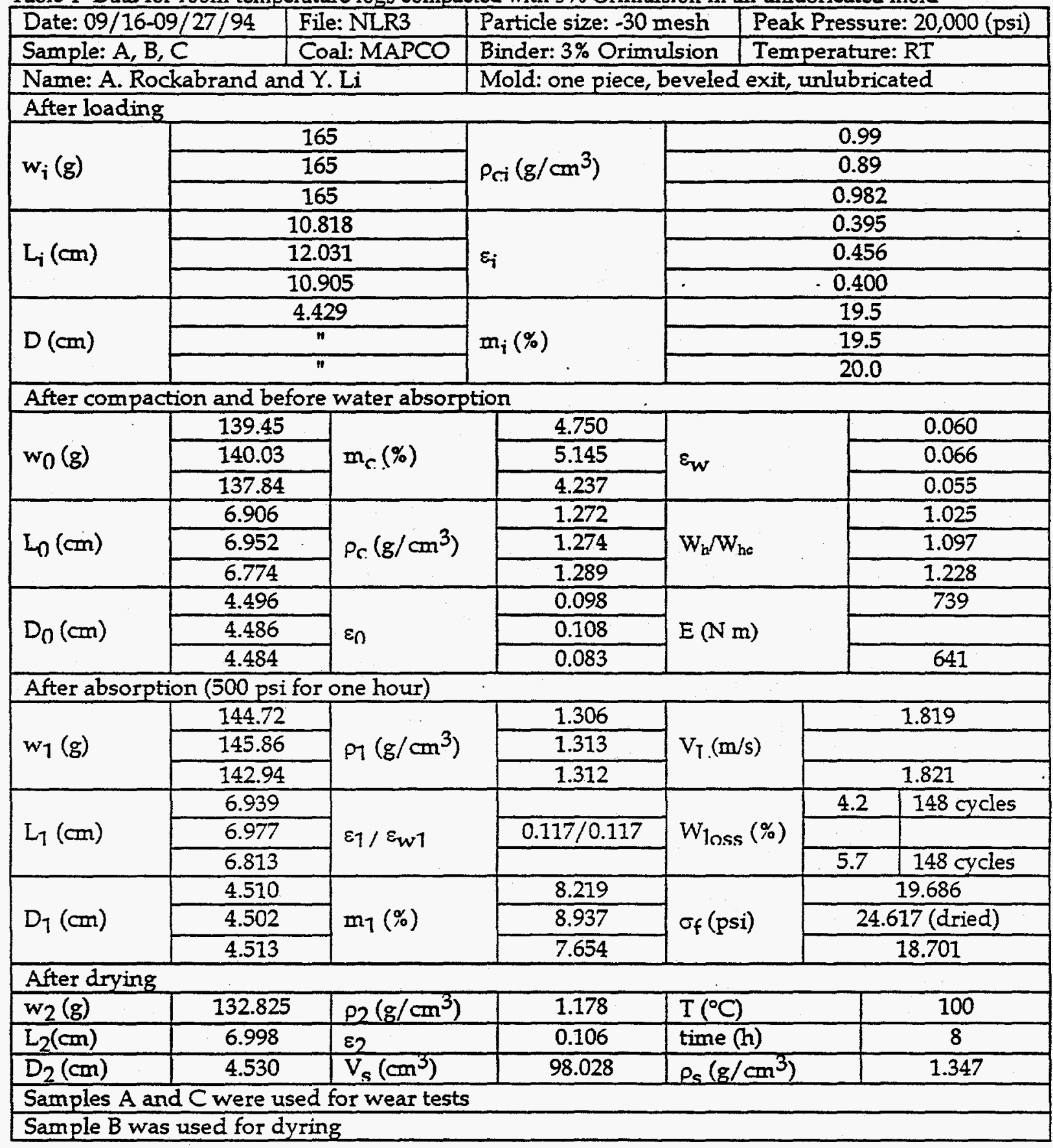


Table 2 Data for room temperature logs compacted with $0 \%$ Orimulsion in an unlubricated mold

\begin{tabular}{|c|c|c|c|c|c|c|c|}
\hline Date: $09 / 30 / 94$ & \multicolumn{2}{|c|}{ File: NLR0 } & \multicolumn{2}{|c|}{ Particle size: -30 mesh } & \multicolumn{3}{|c|}{ Peak Pressure: 20,000 (psi) } \\
\hline Sample: $A, B, C$ & Coal & MAPCO & Binder: $0 \%$ Orin & Alsion & Tem & ratur & RT \\
\hline \multicolumn{3}{|c|}{ Name: A. Rockabrand and Y. Li } & \multicolumn{5}{|c|}{ Mold: one piece, beveled exit, unlubricated } \\
\hline \multicolumn{8}{|c|}{ After loading } \\
\hline \multirow{3}{*}{$w_{\mathbf{i}}(\mathrm{g})$} & \multicolumn{2}{|c|}{165} & \multirow{3}{*}{$\rho_{\mathrm{ri}}\left(\mathrm{g} / \mathrm{cm}^{3}\right)$} & \multicolumn{4}{|c|}{1.101} \\
\hline & \multicolumn{2}{|c|}{165} & & \multicolumn{4}{|c|}{0.948} \\
\hline & \multicolumn{2}{|c|}{165} & & \multicolumn{4}{|c|}{1.161} \\
\hline \multirow{3}{*}{$\mathrm{L}_{\mathbf{i}}(\mathrm{cm})$} & \multicolumn{2}{|c|}{9.731} & \multirow{3}{*}{$\varepsilon_{\mathbf{i}}$} & \multicolumn{4}{|c|}{0.359} \\
\hline & \multirow{2}{*}{\multicolumn{2}{|c|}{$\frac{11.30}{9.227}$}} & & \multicolumn{4}{|c|}{0.448} \\
\hline & & & & \multicolumn{4}{|c|}{0.324} \\
\hline \multirow{3}{*}{$\mathrm{D}(\mathrm{cm})$} & \multicolumn{2}{|c|}{4.429} & \multirow{3}{*}{$\mathrm{m}_{\mathfrak{i}}(\%)$} & \multicolumn{4}{|c|}{19.5} \\
\hline & & & & & & 19.5 & \\
\hline & & & & & & 19.2 & \\
\hline After compactic & and befo & water absorp & tion & & & & \\
\hline & 141.03 & & 5.8 & & & & 0.081 \\
\hline$w_{0}(g)$ & 139.43 & $\mathrm{~m}_{\mathrm{C}}(\%)$ & 4.7 & $\varepsilon_{\mathrm{w}}$ & & & 0.061 \\
\hline & 140.60 & & 5.2 & & & & 0.066 \\
\hline & 6.962 & & 1.286 & & & & 1.103 \\
\hline $\mathrm{L}_{0}(\mathrm{~cm})$ & 6.870 & $\rho_{c}\left(\mathrm{~g} / \mathrm{cm}^{3}\right)$ & 1.284 & $W_{h} /$ & & & 1.061 \\
\hline & 6.935 & & 1.276 & & & & 1.018 \\
\hline & 4.479 & & 0.118 & & & & 683 \\
\hline $\mathrm{D}_{\mathrm{n}}(\mathrm{cm})$ & 4.487 & $\varepsilon_{n}$ & 0.107 & $E(N$ & & & 699 \\
\hline & 4.498 & & 0.110 & & & & \\
\hline After absorption & 500 psi fo & one hour) & & & & & \\
\hline & 147.12 & & 1.325 & & & & 1.840 \\
\hline$w_{1}(g)$ & 145.41 & $\rho_{1}\left(\mathrm{~g} / \mathrm{cm}^{3}\right)$ & 1.327 & $\mathrm{~V}_{\mathrm{T}}$ (I & & & 1.870 \\
\hline & 146.49 & & 1.323 & & & & \\
\hline & 6.984 & & 0.135 & & & 7.2 & 70.6 cycles \\
\hline $\mathrm{L}_{1}(\mathrm{~cm})$ & 6.911 & $\varepsilon_{1 / \varepsilon_{w 1}}$ & & $W_{\ln }$ & $(\%)$ & 4.5 & 70.6 cycles \\
\hline & 6.954 & & & & & & \\
\hline & 4.499 & & 10.2 & & & & 11.76 \\
\hline $\mathrm{D}_{1}(\mathrm{~cm})$ & 4.493 & $\mathrm{~m}_{1}(\%)$ & 9.2 & $\sigma_{f}(p$ & & & 14.55 \\
\hline & 4.503 & & 9.8 & & & & 99 (dried) \\
\hline After drying & & & & & & & \\
\hline$w_{2}(g)$ & 132.09 & $\rho_{2}\left(\mathrm{~g} / \mathrm{cm}^{3}\right)$ & 1.182 & $\mathrm{~T}\left({ }^{\circ} \mathrm{C}\right.$ & & & 100 \\
\hline $\mathrm{L}_{2}(\mathrm{~cm})$ & 7.015 & $\varepsilon_{2}$ & 0.141 & time & & & 8 \\
\hline $\mathrm{D}_{2}(\mathrm{~cm})$ & 4.504 & $V_{s}\left(\mathrm{~cm}^{3}\right)$ & 96.038 & $\overline{\rho_{s}(g}$ & $\left(\mathrm{cm}^{3}\right)$ & & 1.375 \\
\hline
\end{tabular}


Table 3 Data for room temperature logs compacted with $3 \%$ Orimulsion in a lubricated mold

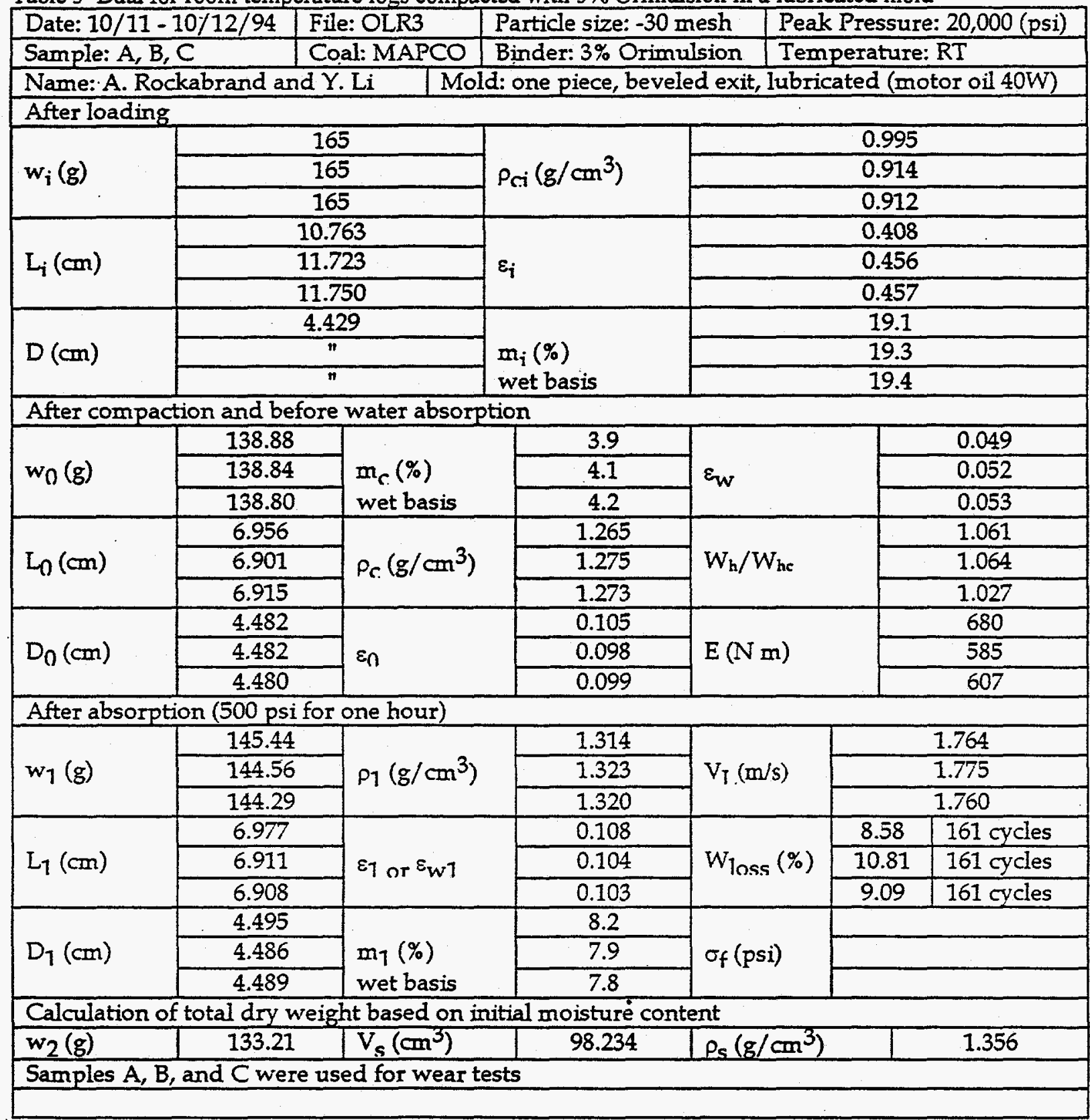


Table 4 Data for room temperature logs compacted with $0 \%$ Orimulsion in a lubricated mold

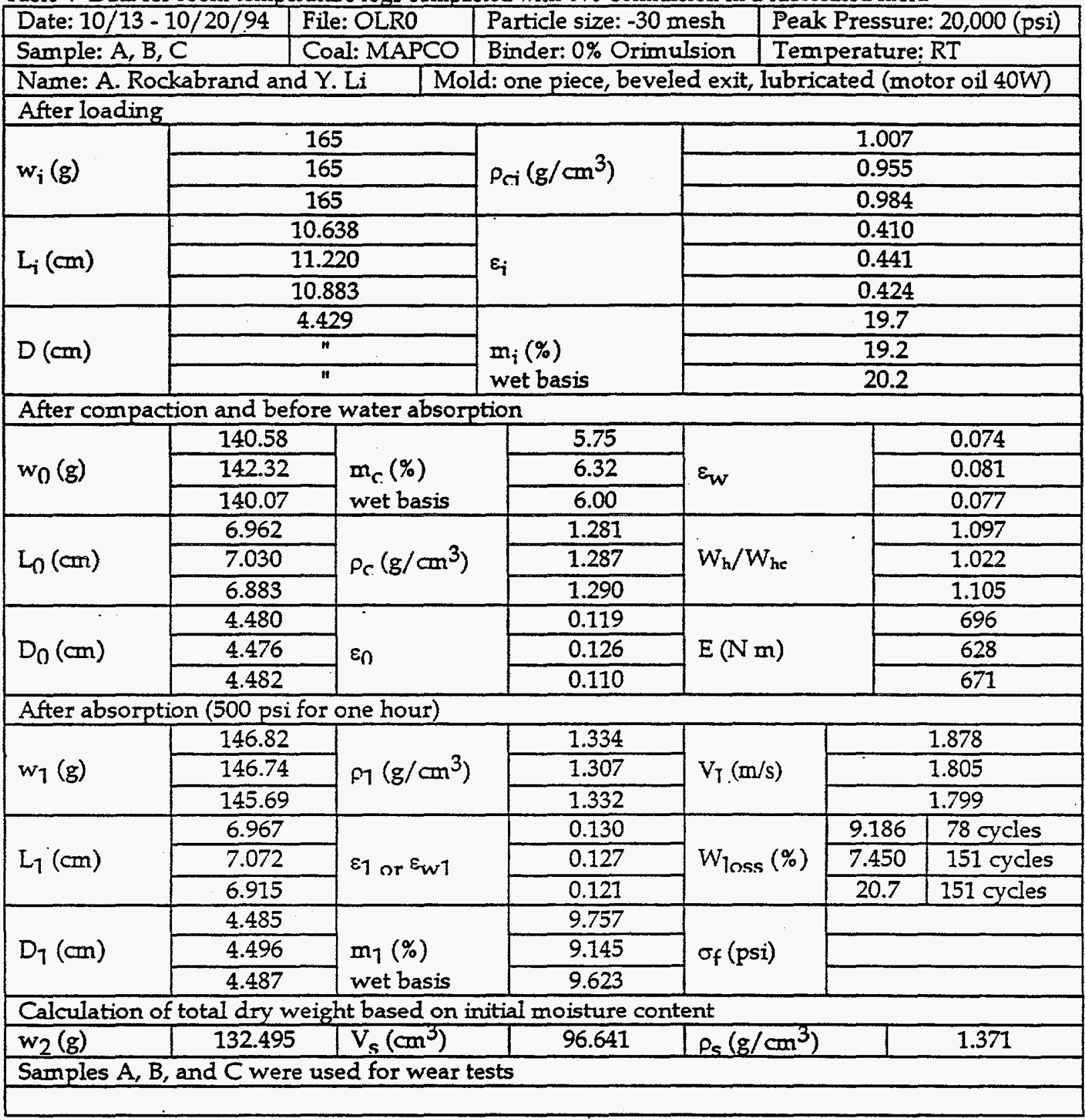


Table 5 Data for $90^{\circ} \mathrm{C}$ logs compacted with $3 \%$ Orimulsion in an unlubricated mold

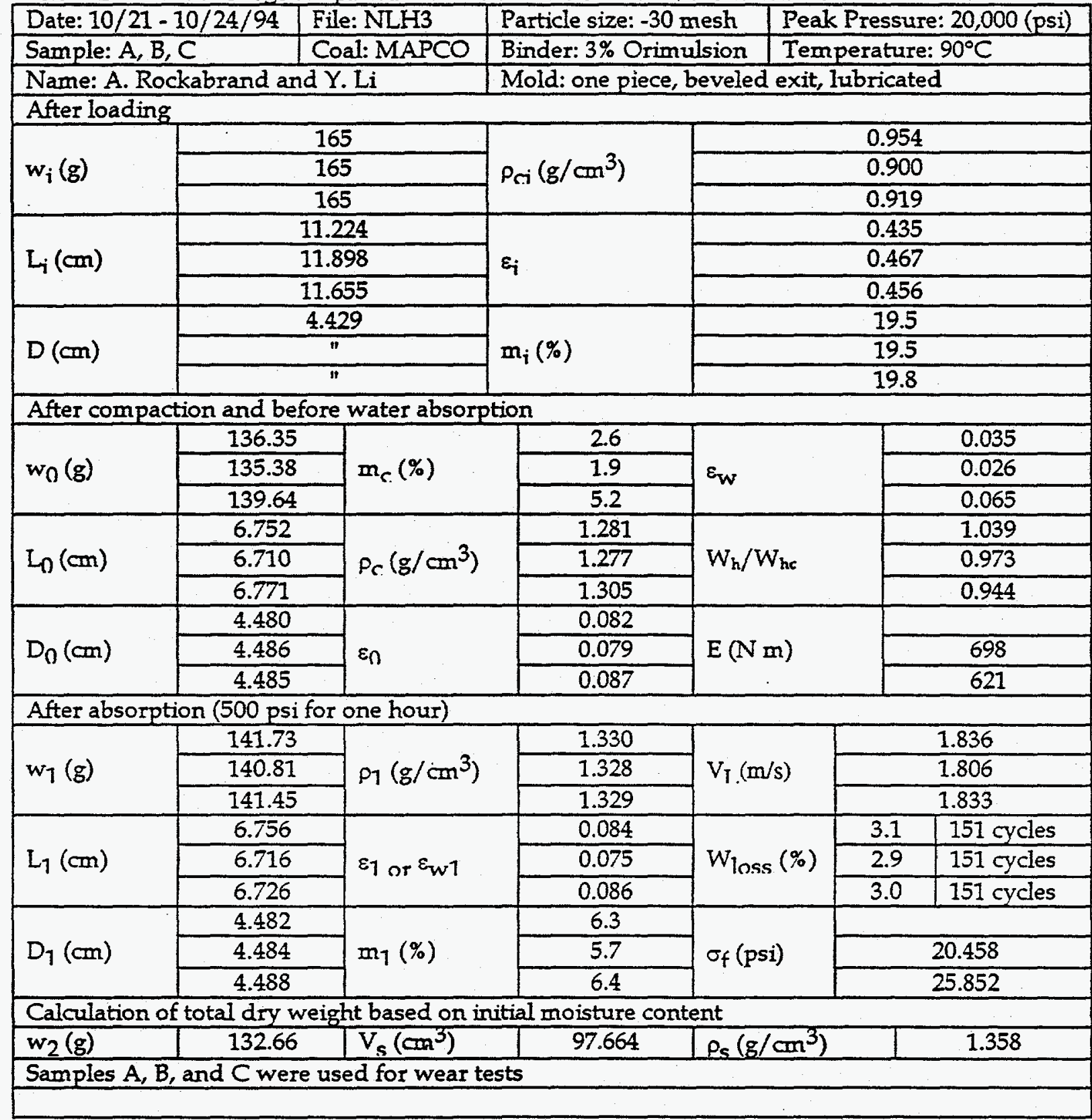


Table 6 Data for $90^{\circ} \mathrm{C}$ logs compacted with $0 \%$ Orimulsion in an unlubricated mold

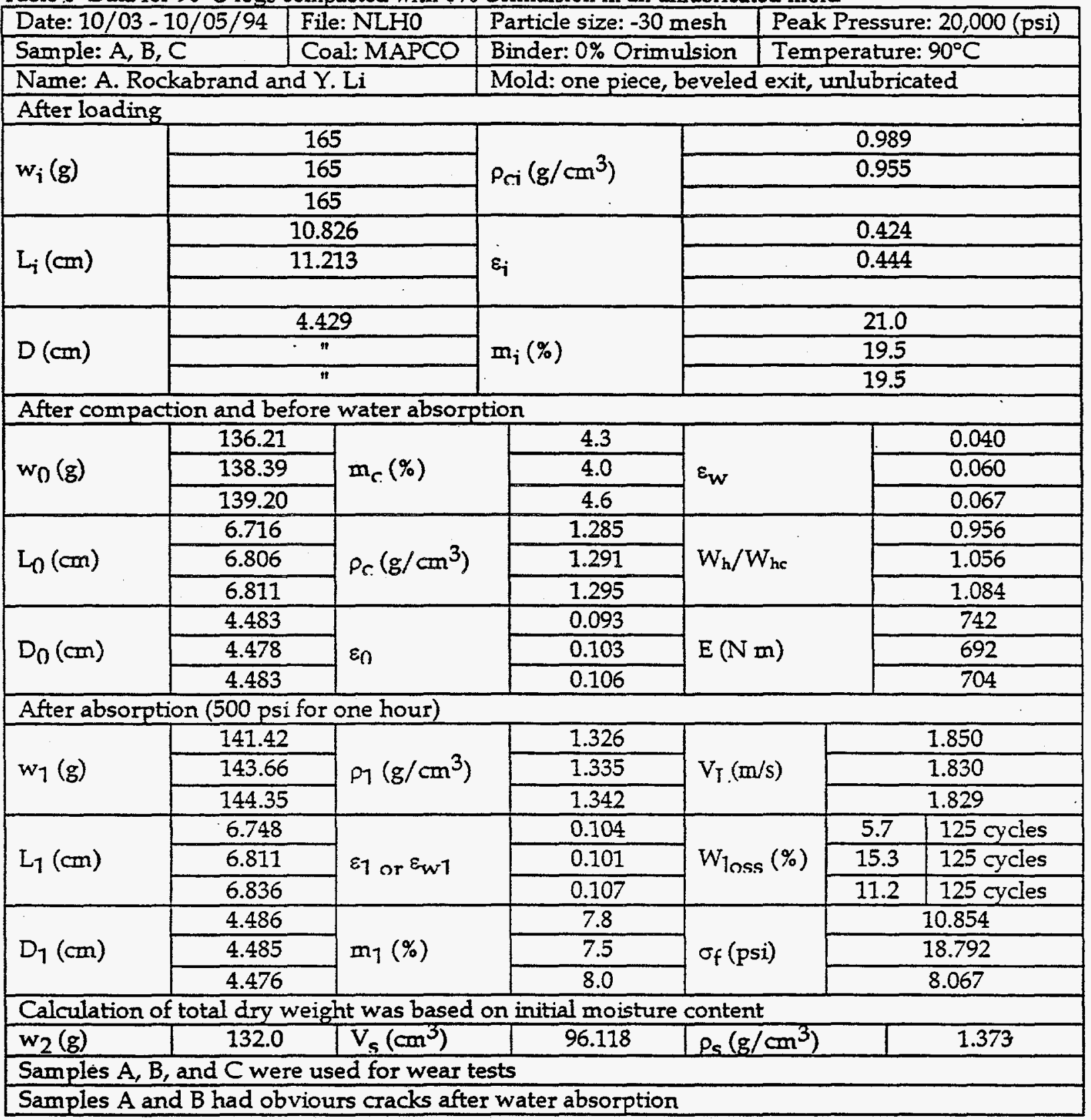


Table 7 Data for $90^{\circ} \mathrm{C}$ logs compacted with $3 \%$ Orimulsion in a lubricated mold

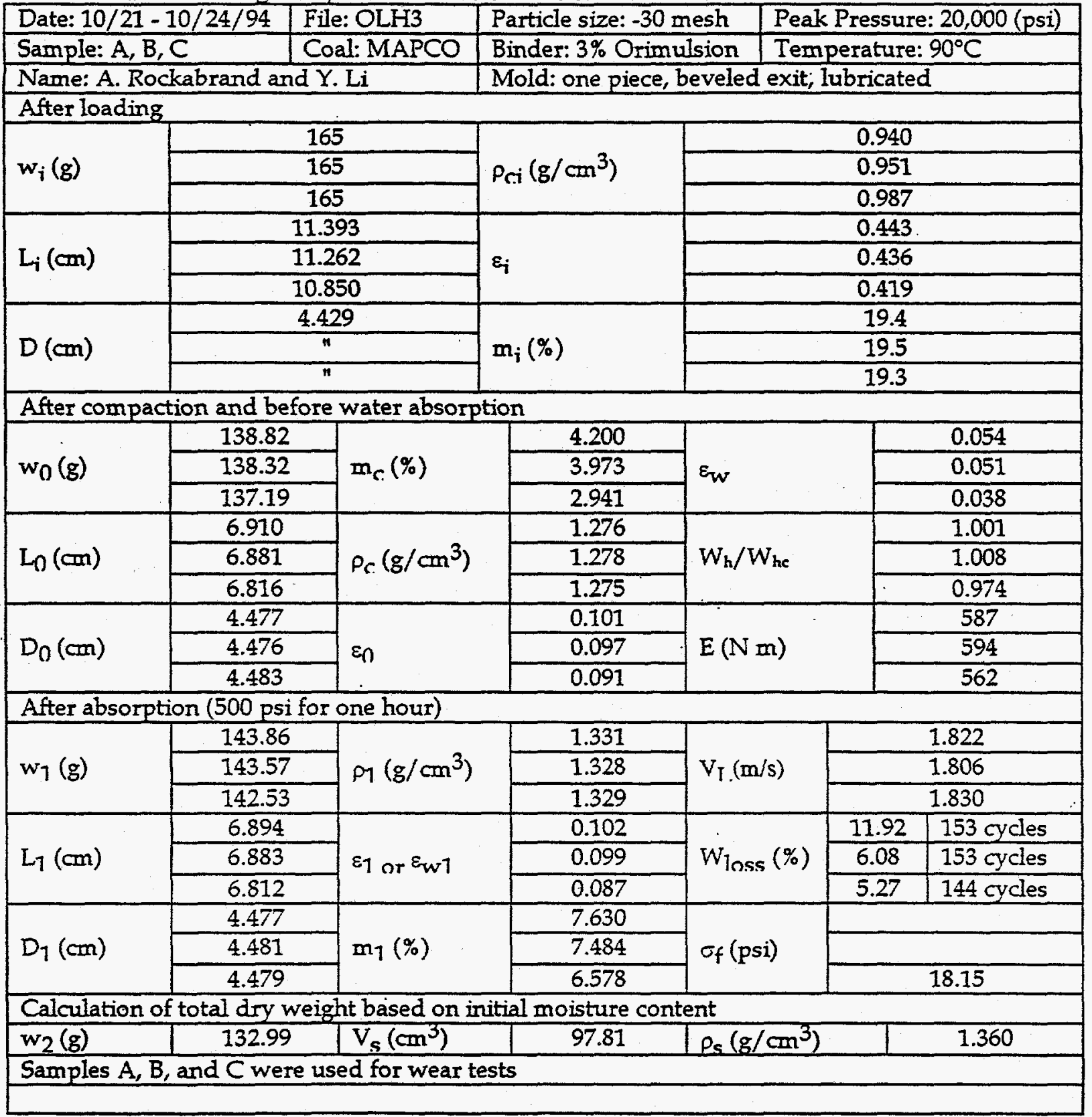


Table 8 Data for $90^{\circ} \mathrm{C}$ logs compacted with $0 \%$ Orimulsion in a lubricated mold

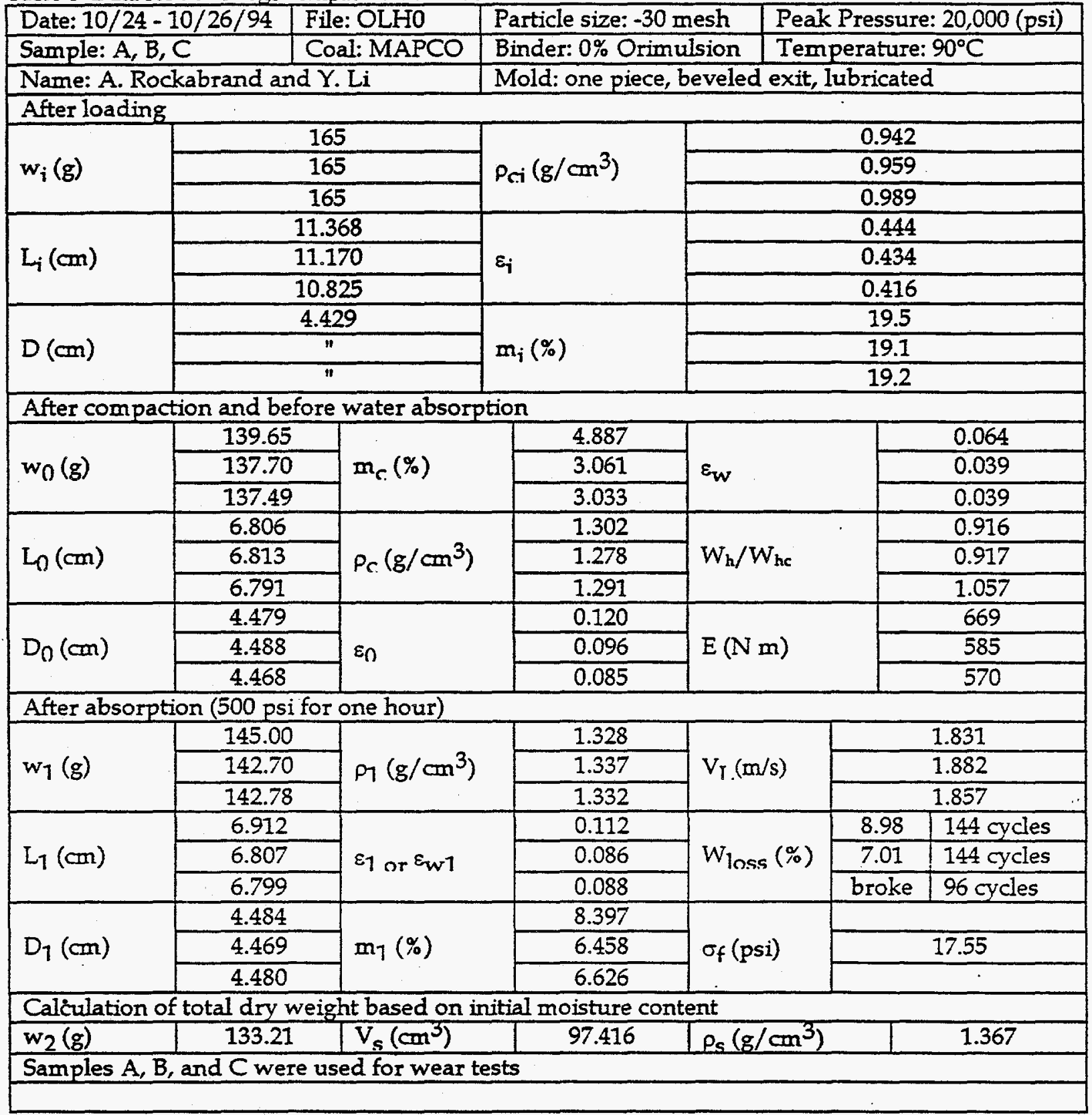


Table 9 Data for room temperature logs compacted with 3\% Orimulsion in a lubricated mold

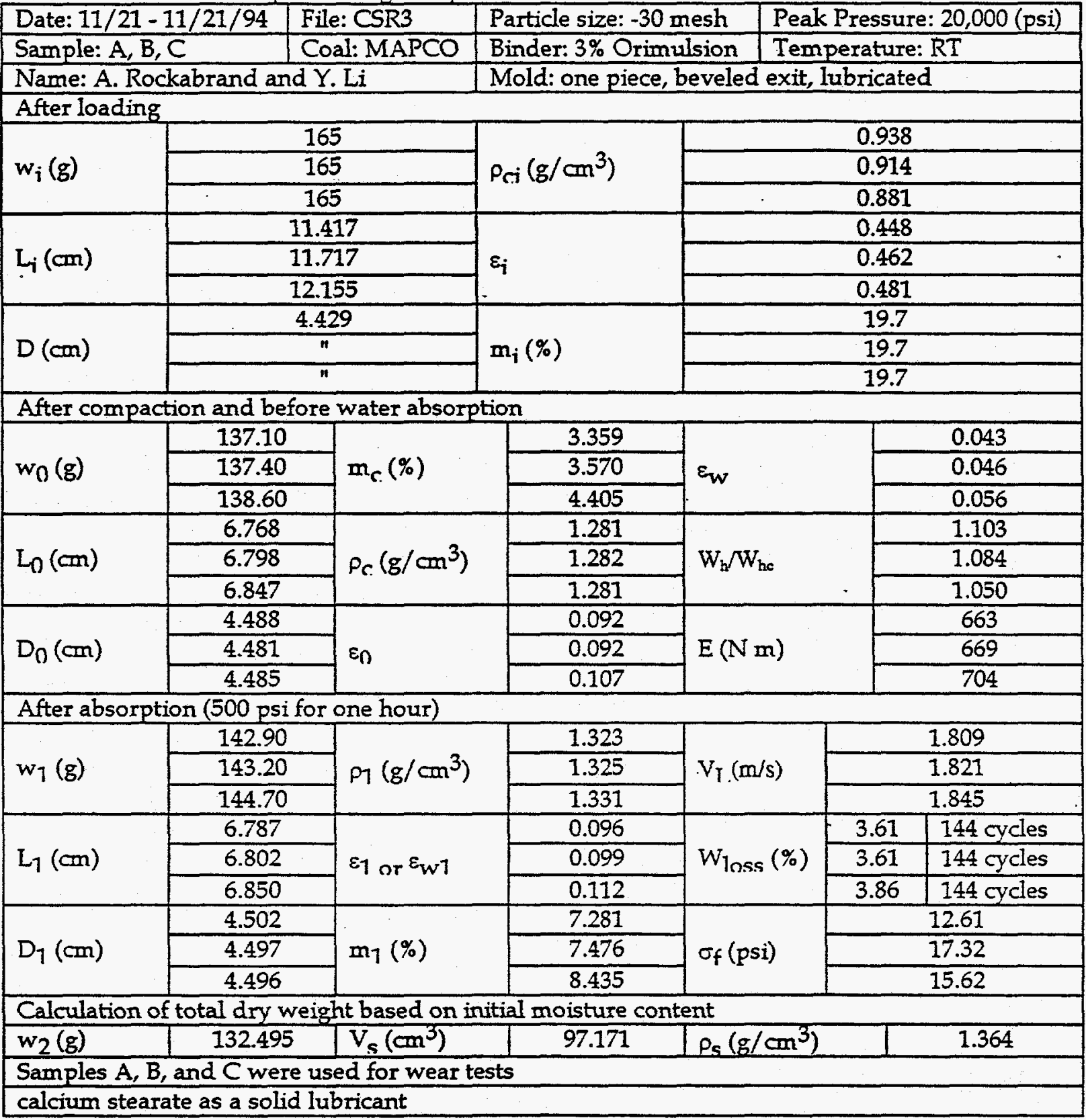


Table 10 Data for room temperature logs compacted with $0 \%$ Orimulsion in a lubricated mold

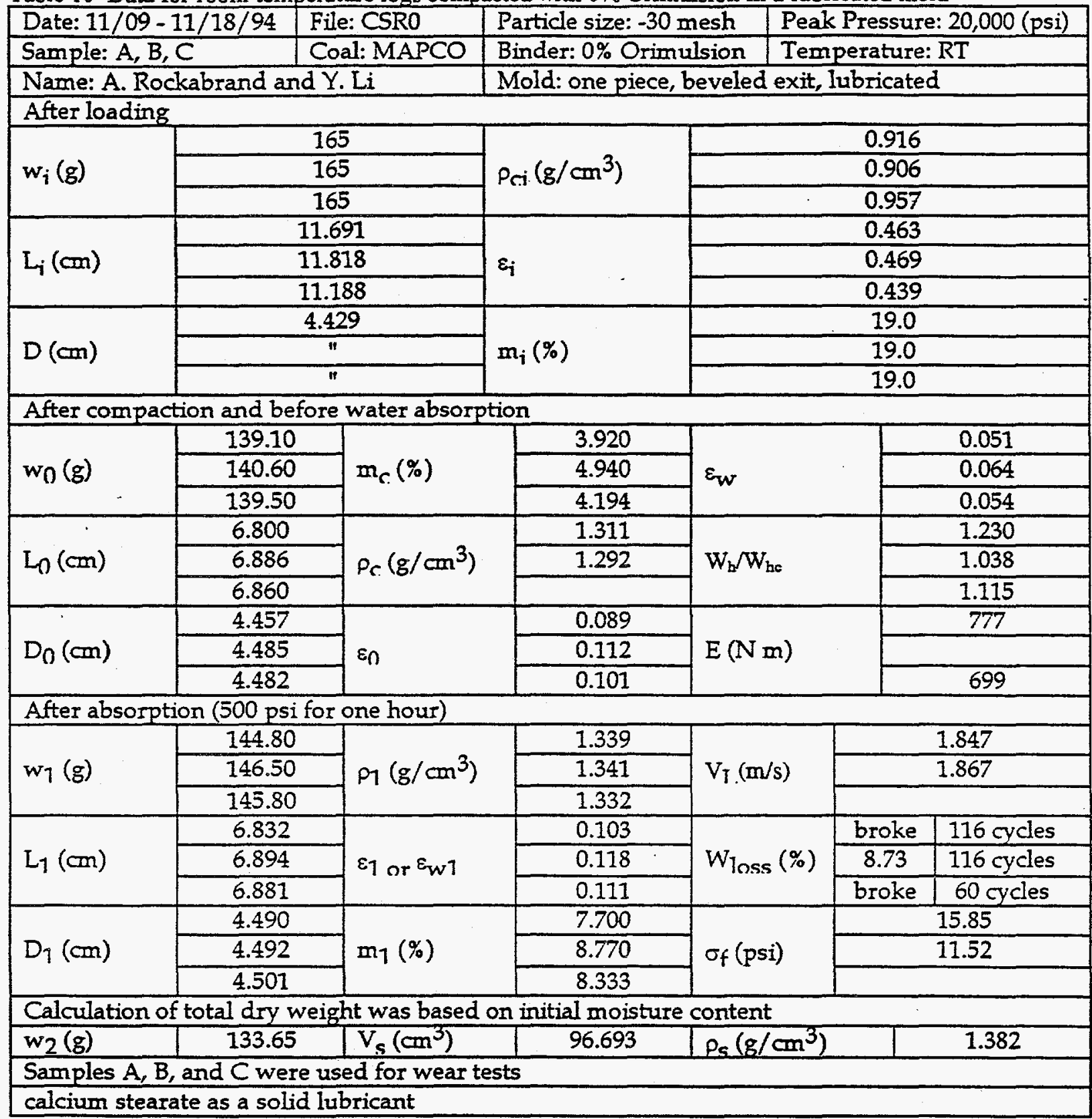


Table 11 Data for $90^{\circ} \mathrm{C}$ logs compacted with $3 \%$ Orimulsion in a lubricated mold

\begin{tabular}{|c|c|c|c|c|c|c|c|}
\hline \multicolumn{2}{|c|}{ Date: $11 / 22-11 / 22 / 94$} & File: $\mathrm{CSH} 3$ & \multicolumn{2}{|c|}{ Particle size: -30 mesh } & \multicolumn{3}{|c|}{ Peak Pressure: 20,000 (psi) } \\
\hline \multicolumn{2}{|c|}{ Sample: A, B, C } & Coal: MAPCO & \multicolumn{2}{|c|}{ Binder: $3 \%$ Orimulsion } & \multicolumn{3}{|c|}{ Temperature: $90^{\circ} \mathrm{C}$} \\
\hline \multicolumn{3}{|c|}{ Name: A. Rockabrand and Y. Li } & \multicolumn{5}{|c|}{ Mold: one piece, beveled exit, lubricated } \\
\hline \multicolumn{8}{|c|}{ After loading } \\
\hline \multirow{3}{*}{$w_{i}(g)$} & \multicolumn{2}{|r|}{165} & \multirow{3}{*}{$\rho_{\mathrm{Ci}}\left(\mathrm{g} / \mathrm{cm}^{3}\right)$} & & & & \\
\hline & \multicolumn{2}{|r|}{165} & & & & & \\
\hline & \multicolumn{2}{|r|}{165} & & & & & \\
\hline \multirow{2}{*}{$L_{i}(\mathrm{~cm})$} & & & \multirow{2}{*}{$\varepsilon_{i}$} & & & & \\
\hline & & & & & & & \\
\hline \multirow{3}{*}{$\mathrm{D}(\mathrm{cm})$} & \multicolumn{2}{|r|}{4.429} & \multirow{3}{*}{$m_{i}(\%)$} & \multicolumn{4}{|c|}{19.2} \\
\hline & \multirow{2}{*}{\multicolumn{2}{|c|}{ " }} & & \multicolumn{4}{|c|}{19.0} \\
\hline & & & & \multicolumn{4}{|c|}{19.0} \\
\hline \multicolumn{8}{|c|}{ After compaction and before water absorption } \\
\hline \multirow{3}{*}{$\mathrm{w}_{0}(\mathrm{~g})$} & 136.40 & & 2.258 & & & & 0.029 \\
\hline & 137.90 & $m_{c}(\%)$ & 3.082 & $\varepsilon_{w}$ & & & 0.039 \\
\hline & 137.30 & & 2.658 & & & & 0.034 \\
\hline & 6.796 & & 1.273 & & & & 0.930 \\
\hline$L_{0}(\mathrm{~cm})$ & 6.825 & $\rho_{c}\left(\mathrm{~g} / \mathrm{cm}^{3}\right)$ & 1.281 & $W_{b} / h$ & & & 0.991 \\
\hline & 6.800 & & 1.281 & & & & 1.040 \\
\hline & 4.481 & & 0.092 & & & & \\
\hline $\mathrm{D}_{0}(\mathrm{~cm})$ & 4.481 & $\varepsilon_{0}$ & 0.094 & $\mathrm{E}(\mathrm{N}$ & & & \\
\hline & 4.480 & & 0.088 & & & & \\
\hline After absorptic & 2(500 psi & for one hour) & & & & & \\
\hline & 142.50 & & 1.338 & & & & 1.895 \\
\hline$w_{1}(g)$ & 143.70 & $\rho_{7}\left(\mathrm{~g} / \mathrm{cm}^{3}\right)$ & 1.336 & $V_{T}$. & & & 1.896 \\
\hline & 143.50 & & 1.334 & & & & 1.905 \\
\hline & 6.752 & & 0.086 & & & 7.12 & 456 cycles \\
\hline $\mathrm{L}_{7}(\mathrm{~cm})$ & 6.807 & $\varepsilon_{1 \text { or }} \varepsilon_{w 1}$ & 0.093 & $W_{\text {los }}$ & $(\%)$ & 7.42 & 456 cycles \\
\hline & 6.842 & rin w & 0.092 & & & 5.63 & 264 cycles \\
\hline & 4.481 & & 8.621 & & & & 25.98 \\
\hline$D_{1}(\mathrm{~cm})$ & 4.485 & $m_{1}(\%)$ & 9.345 & $\sigma_{f}(\mathrm{p}$ & & & 25.08 \\
\hline & 4.474 & & 9.157 & & & & 27.97 \\
\hline Calculation of & tal dry $w$ & reight was based & on initial moisture & conter & & & \\
\hline \begin{tabular}{l|l}
$w_{2}(g)$ \\
\end{tabular} & 133.54 & \begin{tabular}{|l|l}
$V_{s}\left(\mathrm{~cm}^{3}\right)$ \\
\end{tabular} & \begin{tabular}{|l|}
97.505 \\
\end{tabular} & $p_{s}(g$ & $\left.\mathrm{cm}^{3}\right)$ & & 1.370 \\
\hline
\end{tabular}


Table 12 Data for $90^{\circ} \mathrm{C}$ logs compacted with $0 \%$ Orimulsion in a lubricated mold

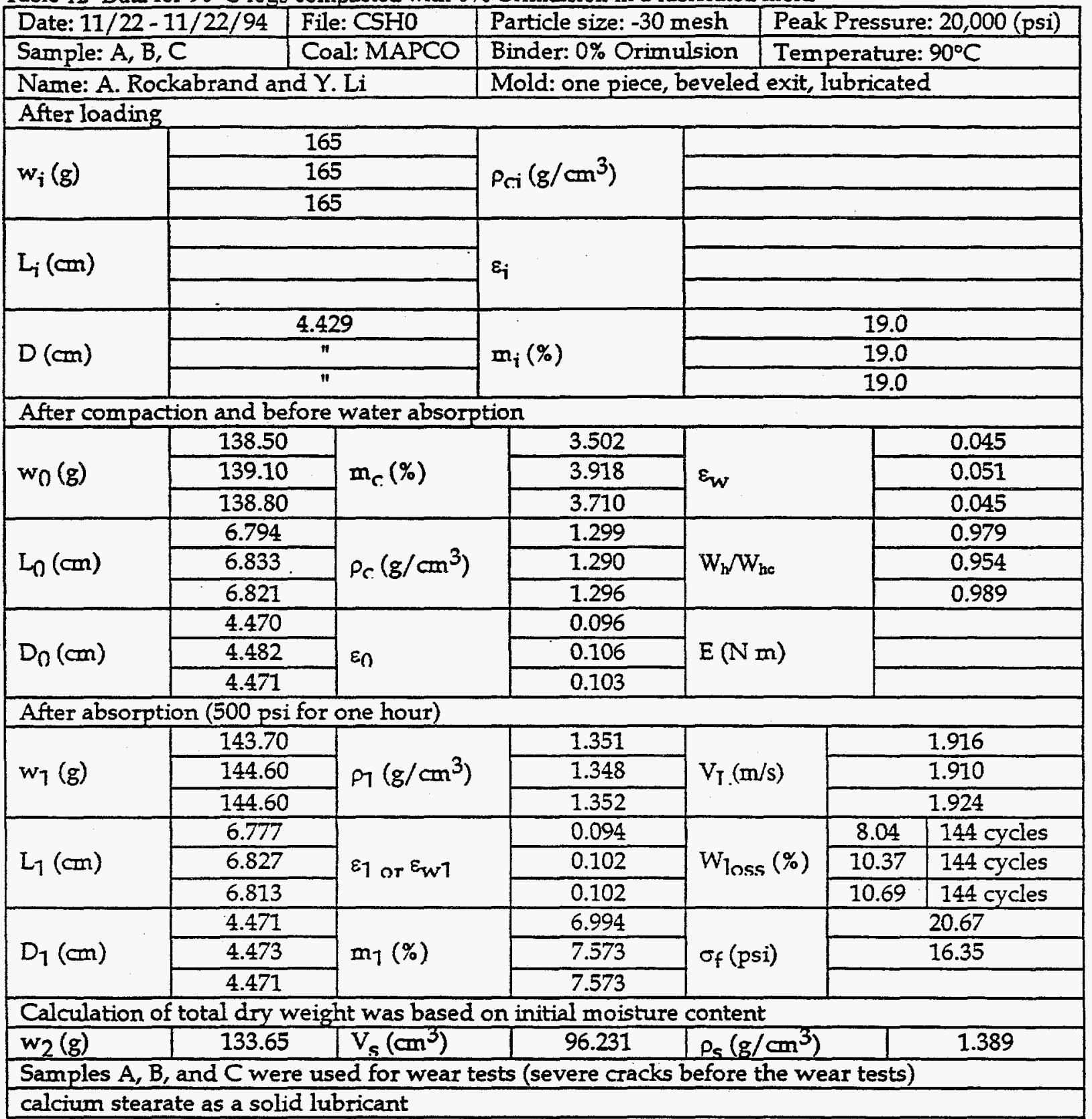




\title{
EFFECTS OF MILITEC-1 CONDITIONING ON COAL LOG QUALITIES
}

\author{
PROGRESS REPORT \\ YIN LI, Post Doctoral Fellow \\ January 15,1995
}

PRINCIPAL INVESTIGATOR: Dr. Henry Liu

RESEARCH ASSISTANT: Andrew Rockabrand

Purpose: To test the effectiveness of using a special surface conditioner (Militec-1) to enhance the quality of the coal logs.

Test Plan: To compare the qualities of the coal logs produced by the same mold before and after conditioning the mold surface with Militec-1.

\section{Variable Test Conditions}

1). Binder concentration: 0 and $3 \%$ Orimulsion (water included)

2). Temperature: Room temperature (RT) and $90^{\circ} \mathrm{C}$

3). Condition of mold: No lubricant (NL) and Militec-1 surface conditioned (SC)

\section{Fixed Test Parameters}

1). Coal type: MAPCO

2). Particle size distribution: -30 mesh (please see Table 1 for detail)

3). Initial moisture content: $20 \%$ by weight

4). Peak Pressure: 20,000 psi

5). Loading speed: $8,000 \mathrm{lb} / \mathrm{min}$ (see Figure 1 )

6). Mold type: unchrome-plated single-piece mold with a beveled exit (Figure 2).

7). Piston type: flat ended

8). Mixing: hand mixer (about $5 \mathrm{~min}$ ) 
9). Wear test velocity $\left(V_{L}\right): 1.852-1.899 \mathrm{~m} / \mathrm{s}$ (see Appendix for detail) Table 1. Coal particle size distribution

\begin{tabular}{|c|c|}
\hline Particle size (mech) & Percentage by weight \\
\hline $30-60$ & 49.31 \\
\hline $60-100$ & 31.89 \\
\hline $100-140$ & 12.96 \\
\hline $140-200$ & 3.27 \\
\hline$<200$ & 1.97 \\
\hline Total & 100 \\
\hline
\end{tabular}

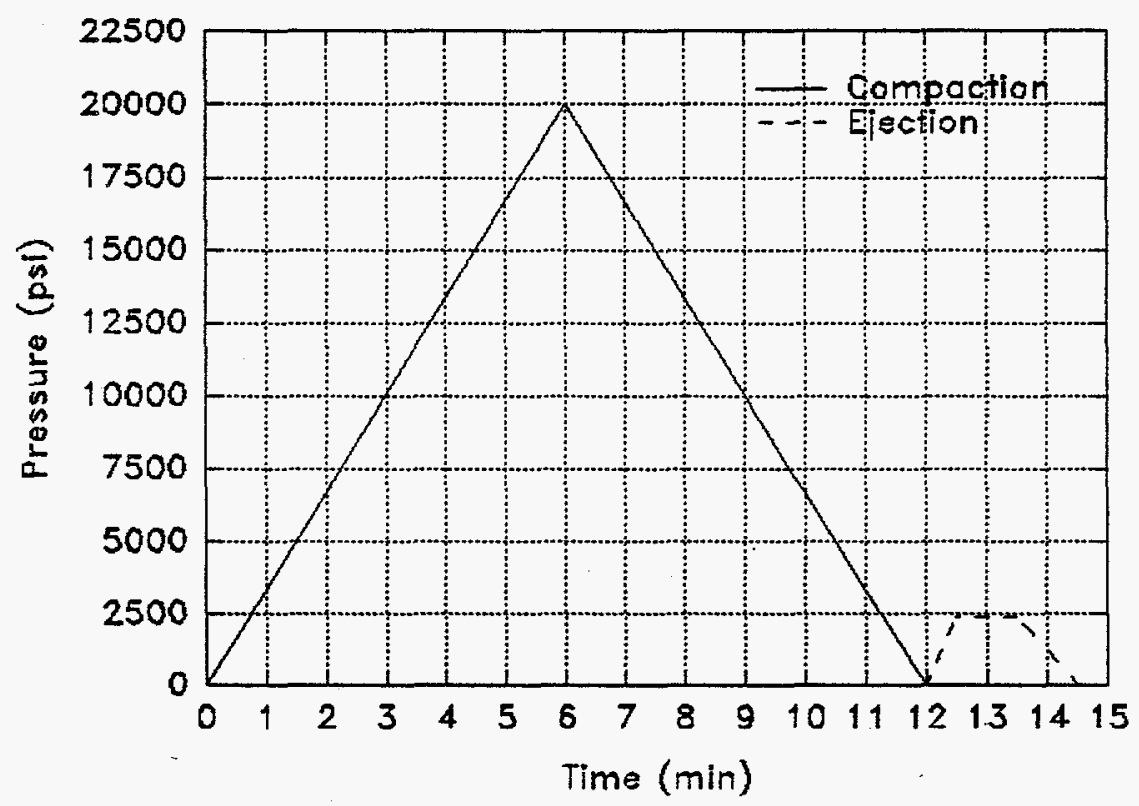

Figure 1. Typical coal log compaction and ejection patterns for the study of Militec-1 effects 


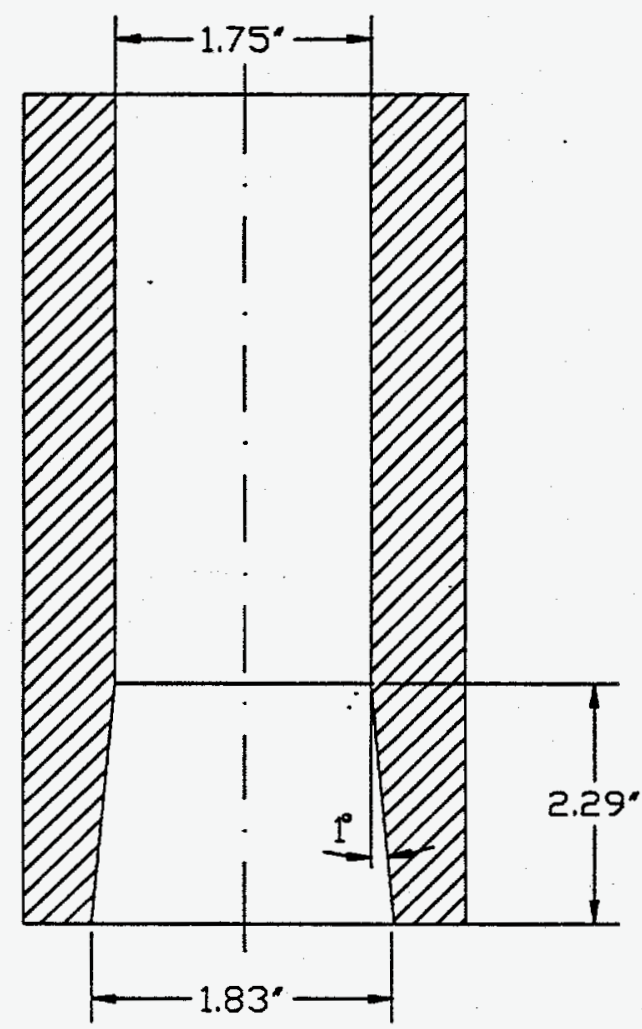

Figure 2 The compaction mold with a beveled end 


\section{Experiment Design:}

Table 2 list the experiment design for this part of the research. Other compaction parameters and dependent variables are the same as the study of the lubricant effect.

Table 2. Experiment design of mold conditioning effects

\begin{tabular}{||l|l||l|l||}
\hline Run No. & control & Run No. & Militec-1 conditioner \\
\hline NLR3 & $3 \%$ Orimulsion, RT & SCR3 & $3 \%$ Orimulsion, RT \\
\hline NLR0 & $0 \%$ Orimulsion, RT & SCR0 & $0 \%$ Orimulsion, RT \\
\hline NLH3 & $3 \%$ Orimulsion, $90^{\circ} \mathrm{C}$ & SCH3 & $3 \%$ Orimulsion, $90^{\circ} \mathrm{C}$ \\
\hline NLH0 & $0 \%$ Orimulsion, $90^{\circ} \mathrm{C}$ & SCH0 & $0 \%$ Orimulsion, $90^{\circ} \mathrm{C}$ \\
\hline
\end{tabular}

Data from lubrication effect experiments

\section{Militec-1 Conditioning of the Mold:}

1) A small cotton gauze pad was saturated with the Militec-1 oil with no carrier.

2) The inside of the mold was wiped with the saturated pad.

3) The mold was heated to $110^{\circ} \mathrm{C}$ and maintained there for 30 minutes.

4) 15 minutes after the mold had reached $110^{\circ} \mathrm{C}$ temperature, the mold was rewiped with the gauze pad.

5) After 30 minutes, the mold was allowed to cool and then the residual oil was wiped out.

Comments:

When the mold was wiped it apperas only wet, there was no excess oil. 
Research Status:

Eight logs were compacted with the Militec-1 conditioned mold under four treatment conditions ( 3 logs for SCR3, 3 logs for SCH3, $1 \log$ for SCR0 and $1 \log$ for SCH0) and tested for water absorption, weight loss and tensile strength. Log density, moisture content, total porosity and water holding capacity before and after water absorption were determined. Water hold capacity was defined as:

$$
\text { Water holding capacity }=(\text { volume of } \log -\text { Volume of solids }) \cdot p_{w}
$$

When compared with the density, moisture content, total porosity, water holding capacity and weight loss of the logs made with the control mold, the binderless logs compacted with the Militec-1 conditioned mold did not show any improvement on quality. Therefore, the results of those logs will not be showed and discussed here. No more attempt will be made to compact more binderless logs with the Militec- 1 conditioned mold due to the poor results obtained.

We recommend that more logs with $3 \%$ Orimulsion should be made using the conditioned mold to check the reproducibility of the results.

\section{Results and Discussion for Logs with 3\% Orimulsion:}

\section{Effects of Militec-1 on density of coal logs before water absorption}

Figure 3 gives the comparison of densities of coal logs made with an unconditioned, calcium stearate lubricated, and Militec-1 conditioned mold, respectively. Room temperature logs produced using the Militec-1 conditioned mold had the same density as those made using 
the calcium stearate lubricated mold. However, the calcium stearate lubricated mold showed a very small density variation within treatment. At $90^{\circ} \mathrm{C}$, logs produced by Militec-1 conditioned mold had higher densities than those compacted with calcium stearate lubricated mold and had the smallest density variation within treatment. However, the untreated mold had the highest density and the largest density variation within $90^{\circ} \mathrm{C}$ group.

\section{Effects of Militec-1 on moisture content of coal logs before water absorption}

Figure 4 gives the moisture content of the logs before water absorption. When compared with the other two mold conditions, logs produced with the Militec-1 conditioned mold had the lowest moisture content for both the room temperature and $90^{\circ} \mathrm{C}$ conditions. Those $90^{\circ} \mathrm{C}$ logs had significantly lower moisture content than their room temperature counterparts.

\section{Effects of Militec-1 on porosity of coal logs before water absorption}

Figure 5 gives the comparison of the total porosity of logs made with the three mold conditions. Room temperature logs made with Militec-1 conditioned mold had the highest total porosity but smallest variation. The $90^{\circ} \mathrm{C}$ logs compacted with Militec-1 conditioned mold had higher porosity than the unconditioned mold but lower porosity than the calcium stearate lubricated mold.

\section{Effects of Militec-1 conditioning on weight loss of coal logs}

Weight losses of four coal logs having 3\% Orimulsion (two for room temperature and two for $90^{\circ} \mathrm{C}$ ) produced with the Militec-1 conditioned mold are compared in Figure 6. Logs made at room temperature using the Militec-1 conditioned mold showed slight reduction 


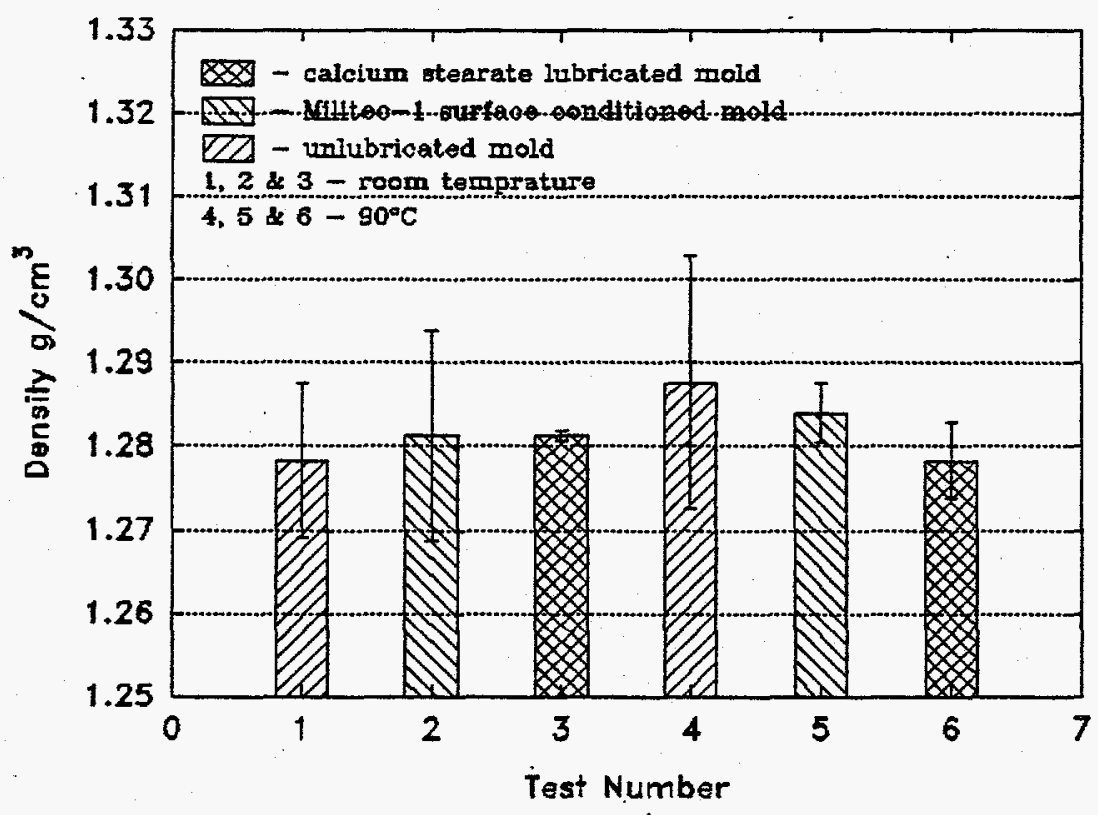

Figure 3. Densities of coal logs having 3\% Orimulsion before water absorption

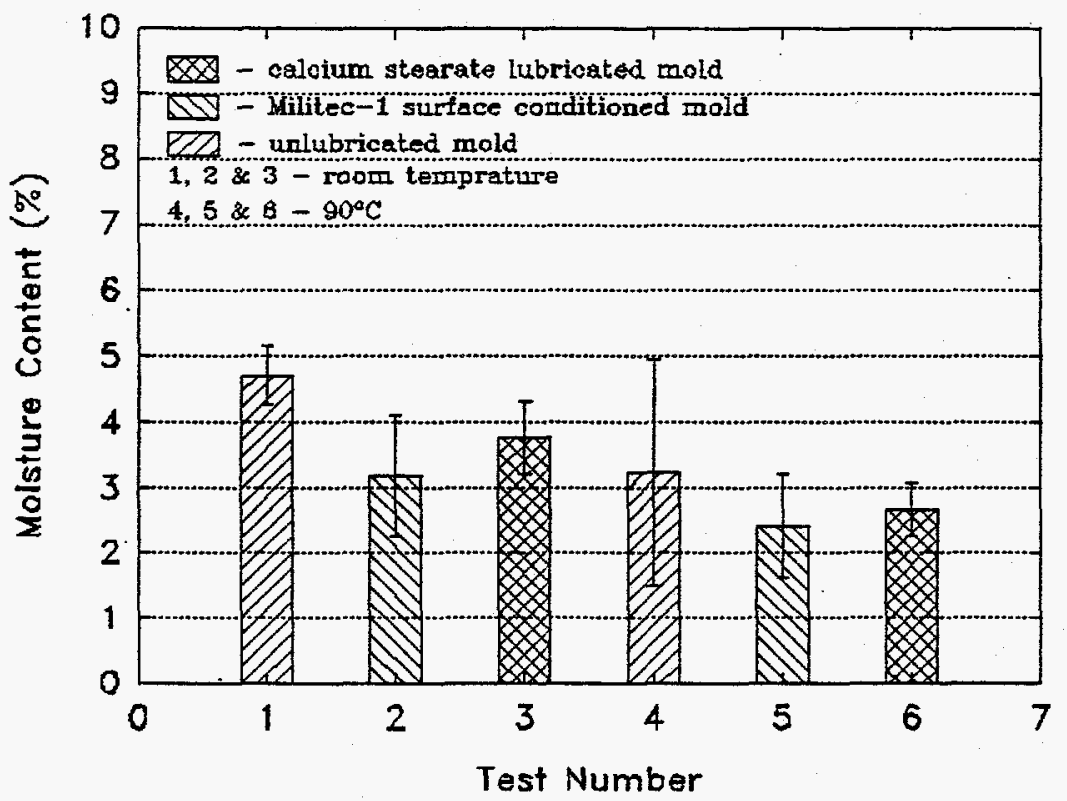

Figure 4. Moisture content of coal logs having 3\% Orimulsion before water absorption 


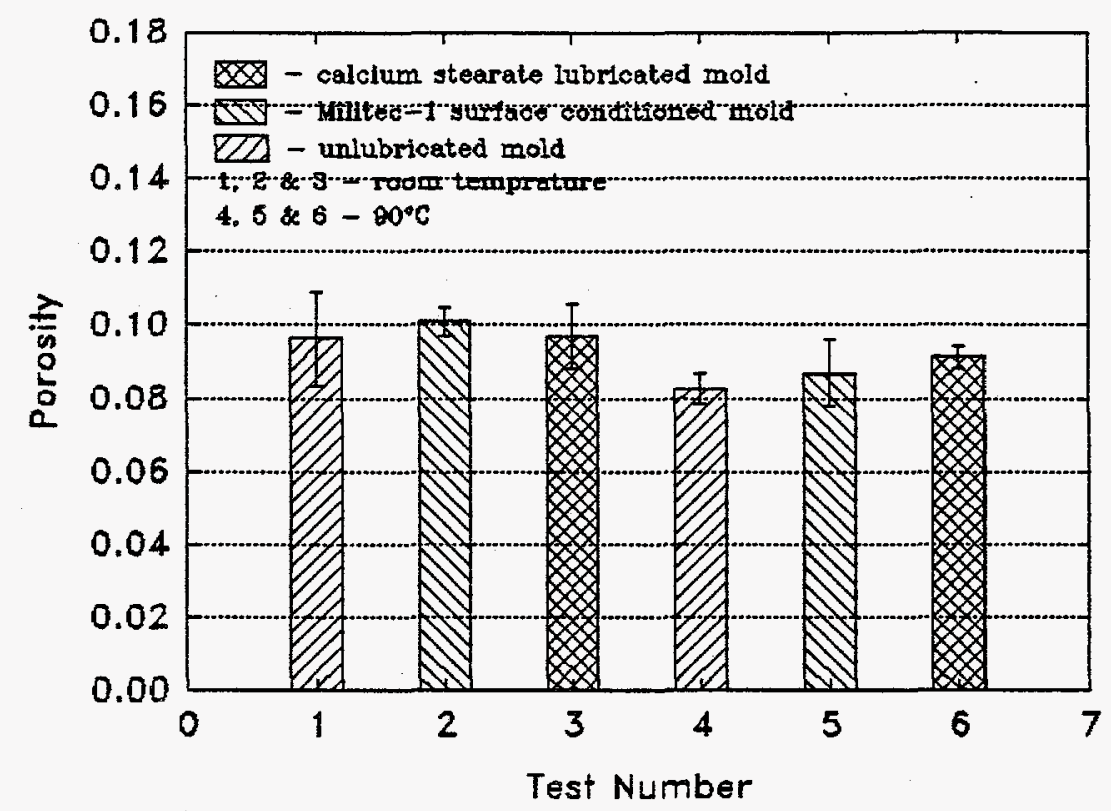

Figure 5. Total porosity of coal logs having 3\% Orimulsion before water absorption

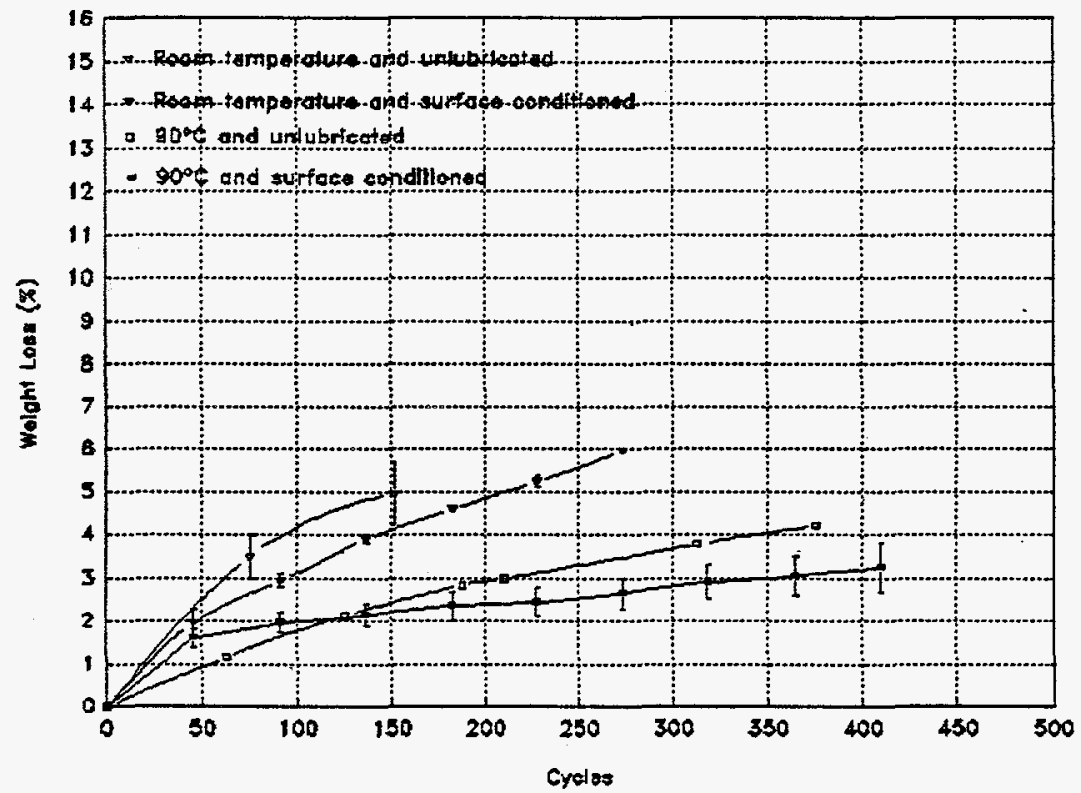

Figure 6. Effects of surface conditioning with Militec-1 on weight loss of logs having $3 \%$ Orimulsion 
on weight loss and extension in circulation time. The $90^{\circ} \mathrm{C}$ logs produced using the Militec-1 conditioned mold showed substantial improvement on wear resistance and circulation time. These logs passed the criterion of $3 \%$ weight loss during 350 cycle circulation.

During circulation tests, it was noticed that log orientation had an effect on weight loss (Figure 7). During compaction, the top piston applied a higher force than the bottom piston due to the wall friction of the mold. Therefore, the top side of the $\log$ had higher density than the bottom side. If a $\log$ is circulated with the top side at the back and bottom a unison de.sit. log. side in the front, the $\mathrm{N}$ og will tilt more than larger weight loss due to increased wall contacts and more opportunities of hitting the top of reanohery

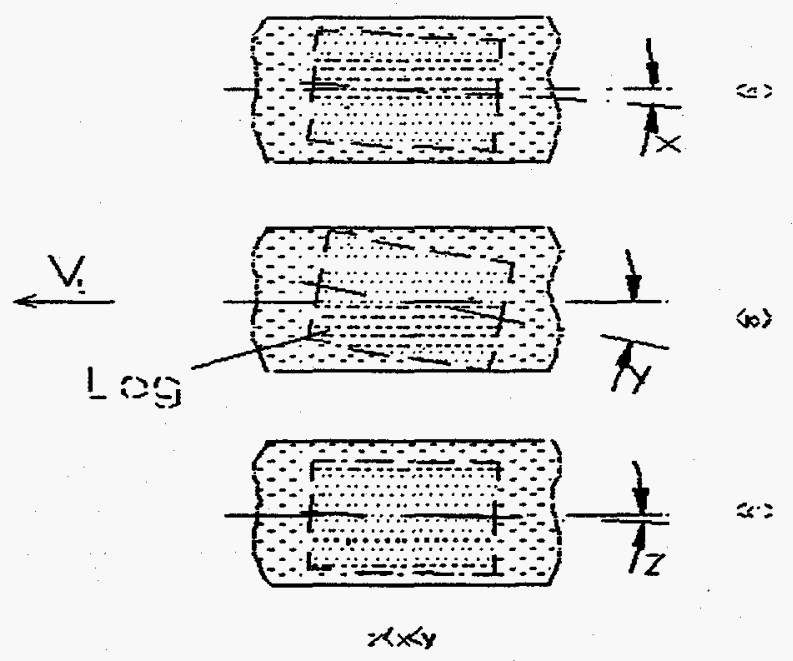

Figure 7. Log tiling angle during circulation: (a) uniform density, (b) when the dense end of a $\log$ facind, and (c) when the dense end of a $\log$

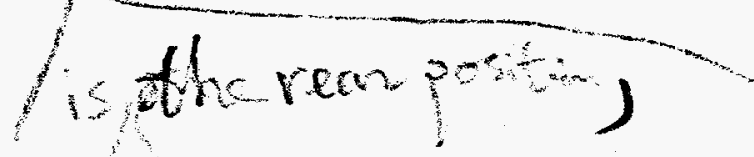

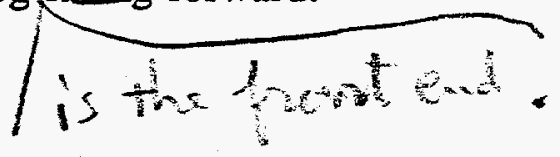


the pipe. If a $\log$ is circulated with the light side at the back and the dense side in the front, the tiling will be reduced. Under such a condition, the weight loss will be reduced. The results given in Figure 6 are for logs circulated with the light side at the back.

\section{Comparison of the maximum ejection force}

The maximum ejection forces (dynamic) of coal logs with $3 \%$ Orimulsion are compared in Table 3. At room temperature, the maximum ejection force with a Militec-1 conditioned mold was slightly lower than that of the control mold while at $90^{\circ} \mathrm{C}$, the maximum ejection force is slightly larger. The reason for higher ejection force at $90^{\circ} \mathrm{C}$ was expected to be due to increased radial stress. Further investigation is needed to confirm this.

Table 3. Comparison of the maximum ejection forces

\begin{tabular}{|l|c|c|c|c|}
\hline \multirow{2}{*}{ Run No. } & \multicolumn{4}{|c|}{$\mathrm{F}_{\text {emax }}(\mathrm{kN})$} \\
\cline { 2 - 5 } & unlubricated & SAE 40W & calcium stearate & Militec-1 \\
\hline $3 \%$ binder, $\mathrm{RT}$ & 17 & 12 & 10 & 16 \\
\hline $3 \%$ binder, $90^{\circ} \mathrm{C}$ & 18 & 11 & 22 & 19 \\
\hline
\end{tabular}

\section{Conclusions:}

The Militec-1 conditioned mold was more effective than the calcium stearate lubricated mold in reducing the weight loss of coal logs with $3 \%$ Orimulsion. Those $90^{\circ} \mathrm{C}$ coal logs compacted with $3 \%$ Orimulsion in the Militec-1 conditioned mold have passed the criterion of $3 \%$ weight loss in 350 cycles. Wear test results indicated that log orientation during circulation tests had an effect on weight loss. Logs circulated with the high density end (the top side) at the back and the low density end (the bottom side) in front may cause 
more weight loss due to greater tilting at the lift-off velocity. Further experiments are needed to check the reproducibility of the results. 
Table 1 Data for room temperature logs compacted with $0 \%$ Orimulsion in a surface conditioned mold

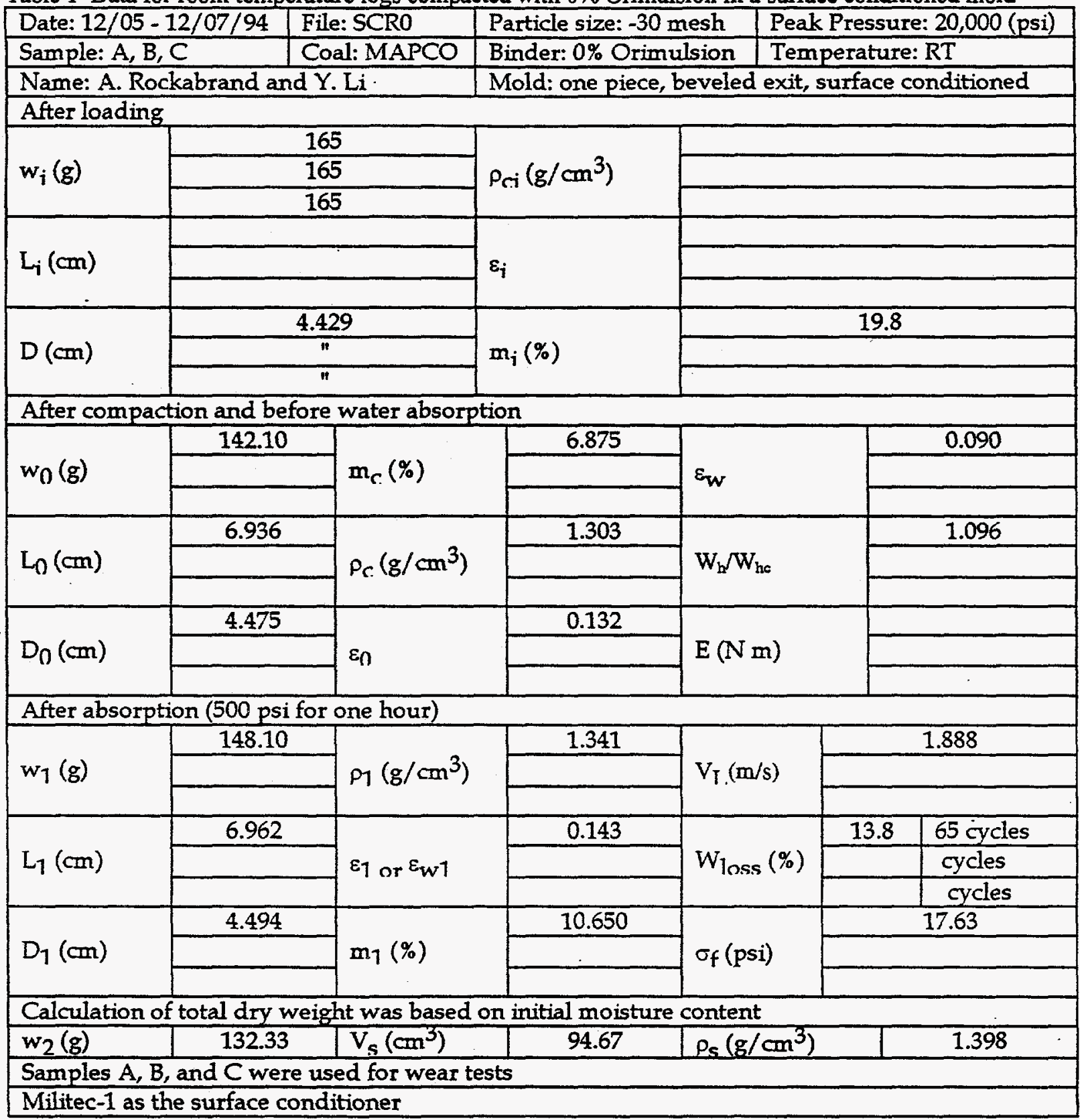


Table 2 Data for room temperature logs compacted with $3 \%$ Orimulsion in a surface conditioned mold

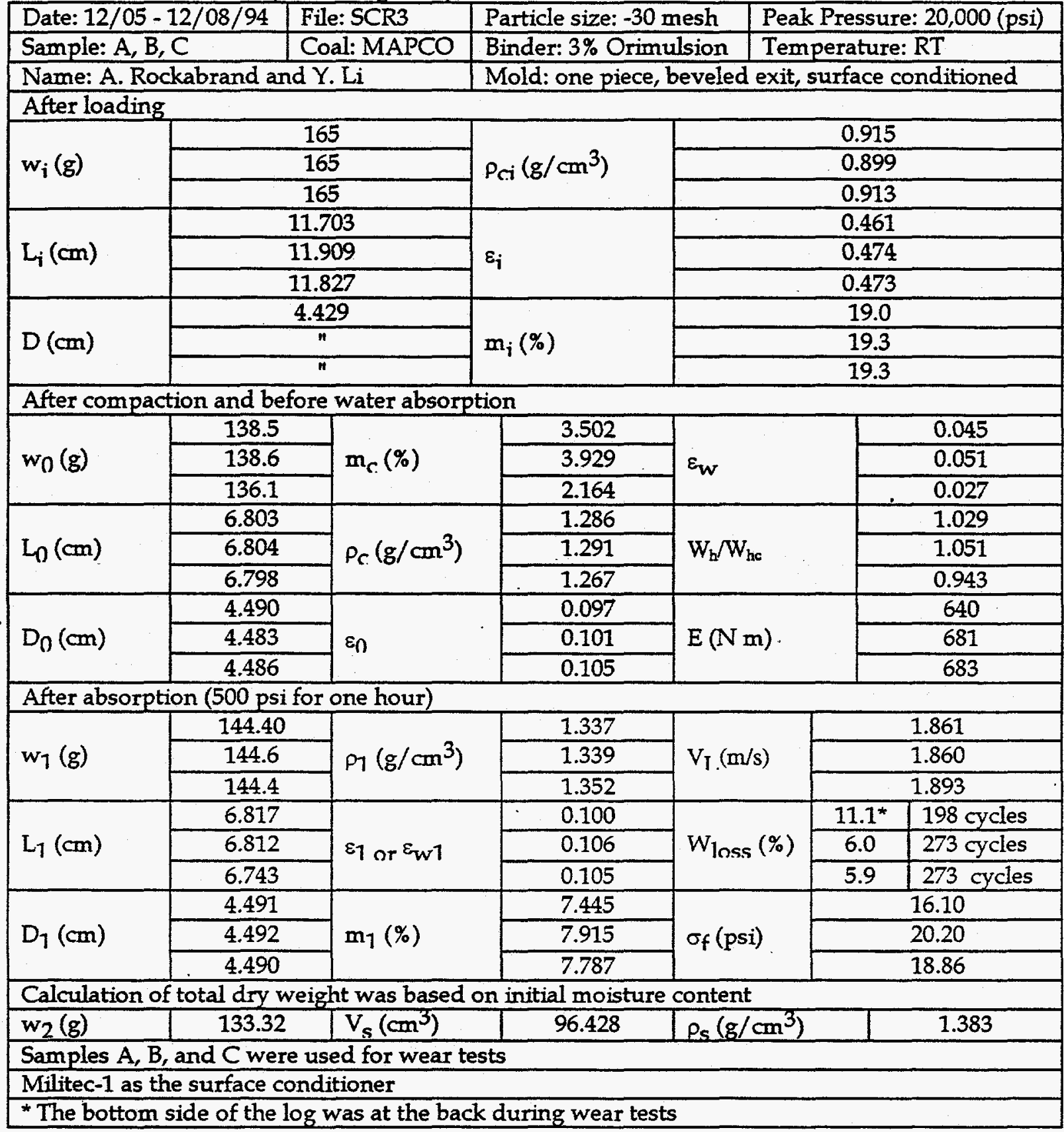


Table 3 Data for $90^{\circ} \mathrm{C}$ logs compacted with $0 \%$ Orimulsion in a surface conditioned mold

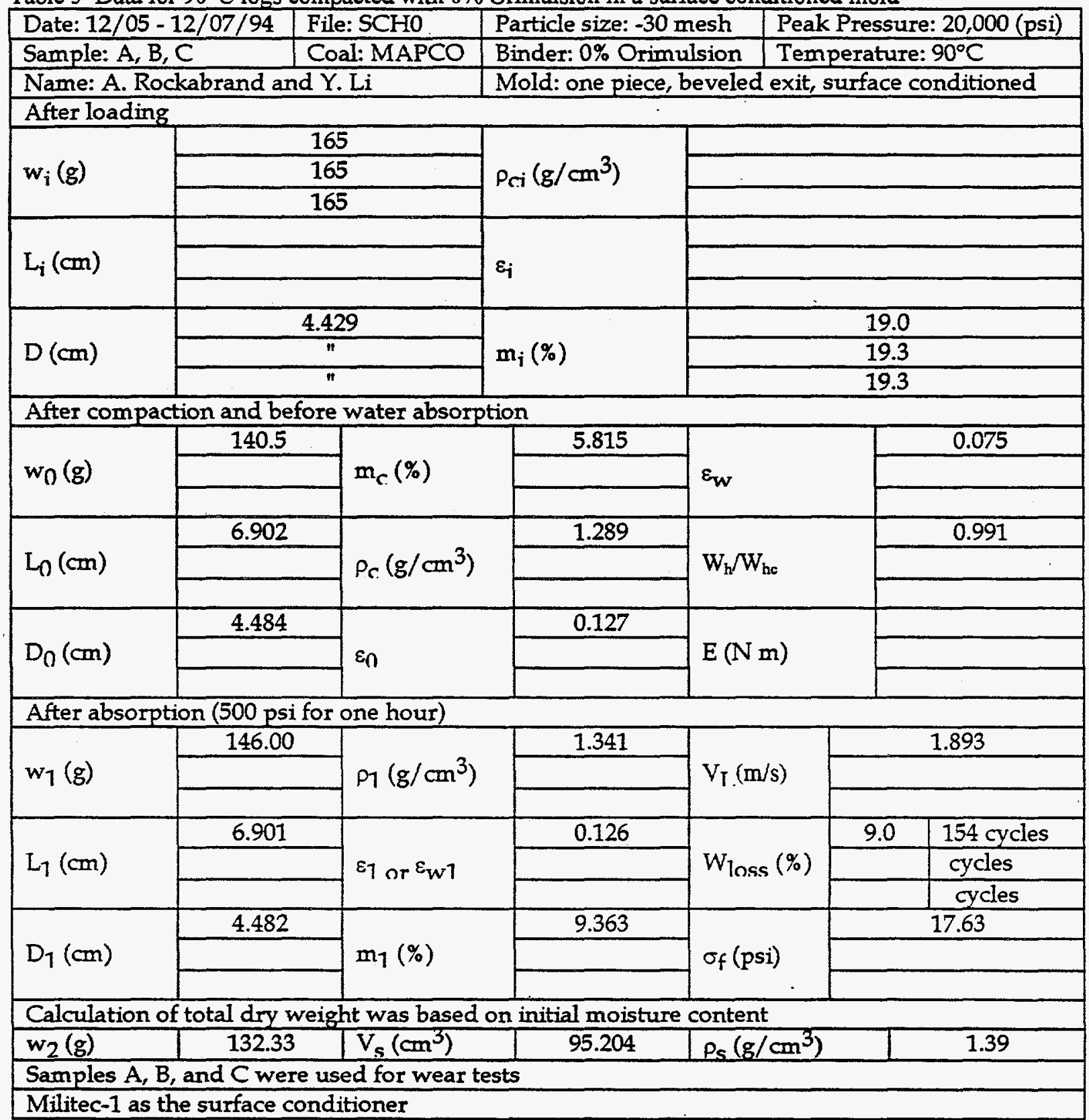


Table 4 Data for $90^{\circ} \mathrm{C}$ logs compacted with $3 \%$ Orimulsion in a surface conditioned mold

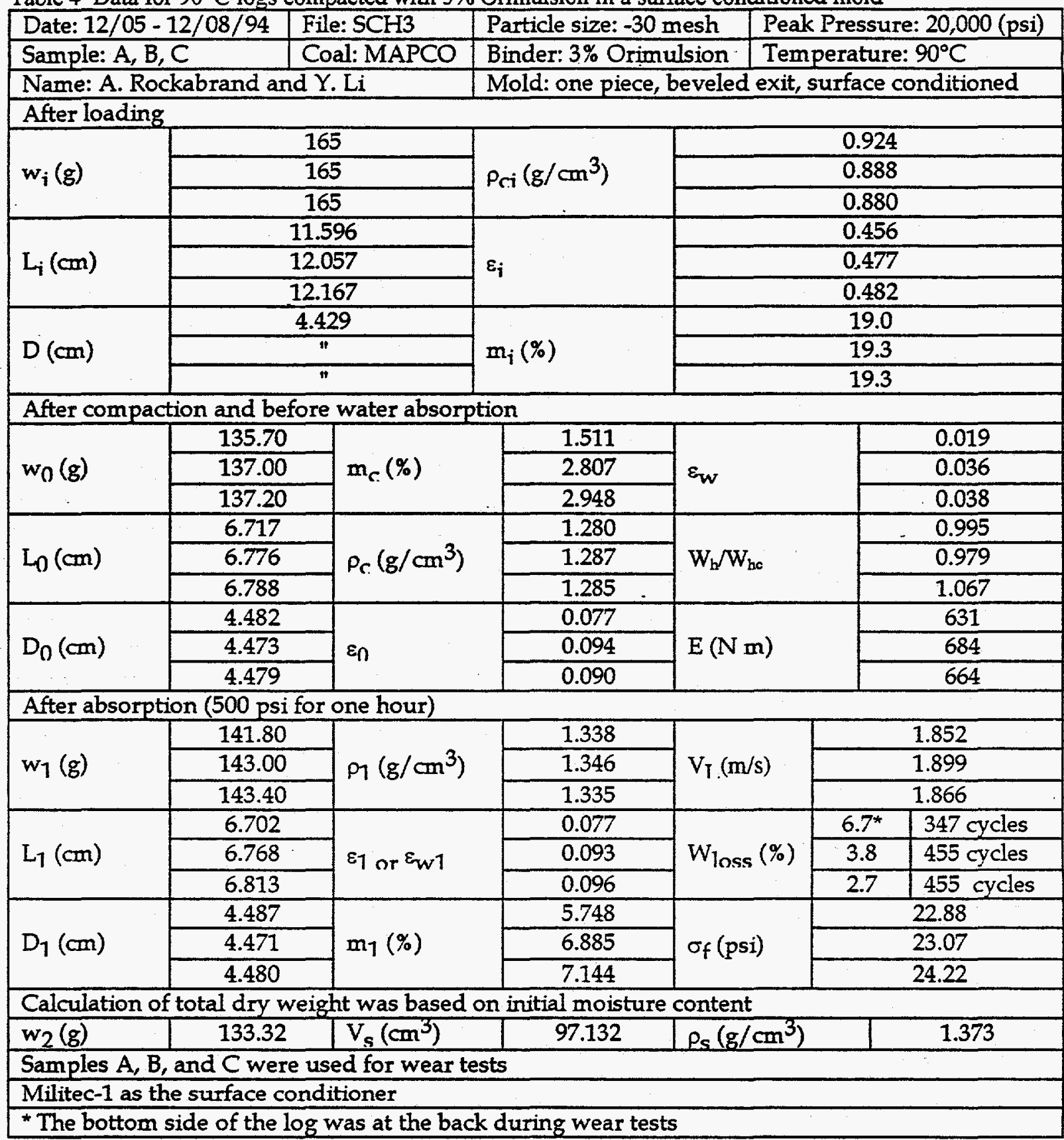


CONCEPTUAL DESIGN AND COST ESTIMATE

OF

A COAL LOG COMPACTION PLANT

\author{
Guoping Ji \\ Research Assistant \\ Yuyi Lin, Ph.D, PE \\ Assistant Professor of Mechanical \& Aerospace Engineering
}

Capsule Pipeline Research Center

University of Missouri-Columbia

4 January 1995 


\section{DESIGN SUMMARY}

\section{Main Features of Design}

There are three flow sheets and three tables, which summarize the main features of this revised design. Fig. 1 is a flow sheet for the process of grinding the coal material, mixing them with proper amount of binder and water, and heating up to room temperature (heating may not be necessary in some cases). Costs of the equipment and energy consumption for grinding and mixing can be seen in Table 1. The data shown in these figures are preliminary, and may be changed when manufacturing process is changed or the design concept is changed.

Fig. 2 shows the material flow for a 10 -second compaction process. This process has not yet been proved in the laboratory to produce good quality logs, due to limitations of available laboratory equipment. The equipment costs and energy consumption are shown in Table 2 . Similar flow sheet for a 30-second process is shown in Fig. 3 and Table 3. The 30-second process is based on a recent report by Dr. Luecke. He used about 20 seconds to move the compaction piston to obtain 20000 psi maximum pressure, and 10 second to withdraw. This is the fastest time allowed by our current laboratory equipment. Comparison of costs between the 10 and 30 -second processes are shown in Table 1. The CPRC has been advised by the IAB Subcommittee to carry out this round of design based on laboratory proven processes. The purpose of showing a 10-second process is to demonstrate, in terms of cost saving, why a faster process is more desirable than a slower process. This provides an important feedback from machine design to further research on shortening the time for coal log fabrication.

Based on the 8-logs-per-second requirement for the plant output, it takes 90 high-pressure 
compaction stations to make the necessary number of logs. The exact number of machines is not material, it is the total cost that is important. Because in an assembly-line-style plant, there can be 90 machines. If desired, two or three high-pressure compaction stations can be arranged in a single machine, so that the total number of machines can be reduced to half or one third. However, such arrangement will not change the cost figure significantly, since the same amount of compaction cylinders and power of hydraulic pumps will be needed. The most costly items are these higher pressure hydraulic pump station and cylinders, as seen from Tables 1 and 3.

\section{Major Differences between Current Design and Design of Last Year(1994) 1. Compaction pressure increased from 10.000 psi to $20.000 \mathrm{psi}$}

Depending on the type of coal, with or without binder, heating and vacuuming, this maximum compaction pressure may be further changed. In the 1994 design, we used two-stage, high-pressure compaction of 10,000 psi. Due to the advances in coal log fabrication process research, one-stage high pressure compaction appears just as good if not better than two-stage compaction.

\section{Annual throughput is more than $40 \%$ higher (increased from 2 to $2.8 \mathrm{MTPV}$ )}

In the 1994 design, the pipeline throughput was set at 2 Million Tons_Per Year. The current design is based on nominal 8", Schedule 60 pipeline. The throughput is based on $90 \%$ log-diameterto-pipe-diameter ratio, $90 \%$ of linefill, and logs being transported at lift-off velocity.

\section{Compaction time adjust to currently proven process}

Dr. Luecke and his student showed recently that the quality of logs made with single-stroke compaction at higher pressure can be as good as multiple-stroke compactions. He also used a pressure profile that is about 20 -second compaction plus 10 -second release. 


\section{Heating costs included in last design revision, but nat in this design}

Heating has a positive effect on log quality but it is costly. However, it is possible to reduce compaction pressure or time or binder if heating is used. Mr. W. Burkett has a separate analysis for the heating cost.

\section{Mold caps and two-piece mold idea were eliminated}

One major criticism about the last design was the use of end caps to keep pressure inside a mold for a specific time. These end caps is costly to manufacture, and may cause operation and maintenance problems. The two-piece mold concept in the last design is changed to one-piece mold. This change reduces the weight of the mold and simplifies the design and manufacture. We are able to make these changes, thanks to the advanices in coal log fabrication research.

\section{Last design was based on HWF process, the design is based on lower-binder process}

Hot-Water-Formed process is still a viable process, as seen from the results of the Conway test. However, based on input received from IAB Subcommittee members, the current design allows the use of binder but avoids high temperature during comparison. The fact that this design was based on the low-temperature binder process rather than the HWF process is not an endorsement of the former over the lattter. At present, insufficient data exist to prove which of the two processes is more economical. Both processes are considered promising at this point. The decision to switch to the low-temperature process is somewhat arbitrary and hence must be considered tentative. The design is also tentative pending new information from future development.

\section{What Costs Have Not Been Included}

In Tables 1-3, costs for the following items have not been included: 
1. Installation, operating and maintenance costs (what was considered was the equipment costs only).

2. Control items such as computer and other process monitoring device.

3. Parts to be manufactured, such as support frames for the machines, fixtures, and the molds.

4. Vacuum and heating equipment and costs, which may or may not be necessary depending on the manufacturing process chosen. 
Table 1 Energy consumption and cost of the purchased equipment

1. Energy Consumption (KW)

\begin{tabular}{|l|c|c|}
\hline & $10 \mathrm{sec}$. & $30 \mathrm{sec}$. \\
\hline grinding, screening, mixing & 1030 & 1030 \\
\hline compaction & 20792 & 32961 \\
\hline total & 21822 & 33991 \\
\hline
\end{tabular}

2. Cost of Purchased Equipment (\$)

\begin{tabular}{|l|c|c|}
\hline & $10 \mathrm{sec}$. & $30 \mathrm{sec}$. \\
\hline grinding, screening, mixing & 483,000 & 483,000 \\
\hline compaction & $3,028,580$ & $5,652,396$ \\
\hline total & $3,511,580$ & $6,135,396$ \\
\hline
\end{tabular}

Notes:

1. Compaction cost only includes the cost of purchased equipment items. The cost of installation, made parts, and other offside facilities are not included.

2 . This is not the final estimated cost. The complete cost estimation will be given upon more information has been obtained. 
Table 2 Cost estimate for purchased equipment (machine speed: 10 seconds per log per machine)

\begin{tabular}{|c|c|c|c|c|c|}
\hline Equipment Name & $\begin{array}{l}\text { Item } \\
\text { No. }\end{array}$ & $\begin{array}{l}\text { Specification } \\
\quad \text { (size) }\end{array}$ & $\begin{array}{l}\text { Number } \\
\text { Required }\end{array}$ & $\begin{array}{l}\text { Unit Price } \\
\qquad(\$)\end{array}$ & $\begin{array}{l}\text { Total Price } \\
\text { (\$) }\end{array}$ \\
\hline Hydraulic cylinder I & 5 & $14 " * 5 "$ & 90 & 6,700 & 603,000 \\
\hline Hydraulic cylinder II & 7 & $10^{\prime *} 17^{\prime \prime}$ & 180 & 4,211 & 757,980 \\
\hline $\begin{array}{l}\text { Injection System: } \\
\text { Injection conveyor, } \\
\text { with support, drive, } \\
\text { injection rail }\end{array}$ & $\begin{array}{c}11 \\
23,26 \\
22\end{array}$ & $\begin{array}{l}12 " \text { wide } \\
50^{\prime} \text { long } \\
150 \mathrm{fpm}\end{array}$ & 10 & 10,000 & 100,000 \\
\hline $\begin{array}{l}\text { Lift-clamping } \\
\text { cylinder }\end{array}$ & 12 & $3 * 3^{*}$ & 540 & 560 & 302,400 \\
\hline $\begin{array}{l}\text { Screw feeder and } \\
\text { support }\end{array}$ & 13,15 & $331,88 \mathrm{TPH}$ & 9 & 15,000 & 135,000 \\
\hline Ejection cylinder & 19 & $3 " * 25 "$ & 90 & 850 & 76,500 \\
\hline Mounting bolt & 20 & all sizes & 5000 & 0.50 & 2,500 \\
\hline $\begin{array}{l}\text { Ejection System: } \\
\text { Automatic gate, } \\
\text { proximity sensor, } \\
\text { ejection rail }\end{array}$ & $\begin{array}{c}24 \\
25 \\
27-29\end{array}$ & & 90 & 2,000 & 180,000 \\
\hline $\begin{array}{l}\text { Mold transportation } \\
\text { conveyor }\end{array}$ & 8 & $\begin{array}{l}\text { 12"wide } \\
\text { 6'long,30fpm }\end{array}$ & 90 & 3,500 & 315,000 \\
\hline Hydraulic pump I & unlabeled & $\mathrm{M} 14 * 2500$ & 360 & 420 & 151,200 \\
\hline Hydraulic pump II & unlabeled & PV092*5000 & 90 & 4,500 & 405,000 \\
\hline Total & & & & & $3,028,580$ \\
\hline
\end{tabular}

\section{References:}

1. Parker Hydraulic Products and Total System Engineering, House of Tools \& Engineering, Inc.

2. General Catalog, Hytrol Conveyor Company, Inc.

3. Means Building Construction Cost Data, R.S.Means Company, Inc. 
Table 3 Cost estimate for purchased equipment

(machine speed: 30 seconds per log per machine)

\begin{tabular}{|c|c|c|c|c|c|}
\hline Equipment Name & $\begin{array}{l}\text { Item } \\
\text { No. }\end{array}$ & $\begin{array}{l}\text { Specification } \\
\quad \text { (size) }\end{array}$ & $\begin{array}{l}\text { Number } \\
\text { Required }\end{array}$ & $\begin{array}{l}\text { Unit Price } \\
\qquad(\$)\end{array}$ & $\begin{array}{l}\text { Total Price } \\
\qquad(\$)\end{array}$ \\
\hline Hydraulic cylinder I & 5 & $14 " * 5 "$ & 264 & 6,700 & $1,768,000$ \\
\hline Hydraulic cylinder II & 7 & $10^{\prime \prime *} 15^{\prime \prime}$ & 176 & 4,211 & 741,136 \\
\hline $\begin{array}{l}\text { Injection System: } \\
\text { Injection conveyor } \\
\text { with support, drive } \\
\text { injection rail }\end{array}$ & $\begin{array}{c}11 \\
23,26 \\
22\end{array}$ & $\begin{array}{l}12 \text { "wide } \\
50^{\prime \prime l o n g} \\
150 \mathrm{fpm}\end{array}$ & 10 & 10,000 & 100,000 \\
\hline $\begin{array}{l}\text { Lift-clamping } \\
\text { cylinder }\end{array}$ & 12 & $3 " * 5 "$ & 880 & 560 & 492,800 \\
\hline $\begin{array}{l}\text { Screw feeder and } \\
\text { support }\end{array}$ & 13,15 & $331.88 \mathrm{TPH}$ & 9 & 15,000 & 135,000 \\
\hline Ejection cylinder & 19 & $3 " * 25 "$ & 88 & 850 & 74,800 \\
\hline Mounting bolt & 20 & all sizes & 5000 & 0.50 & 2,500 \\
\hline $\begin{array}{l}\text { Ejection System: } \\
\text { Automatic gate, } \\
\text { proximity sensor; } \\
\text { ejection rial }\end{array}$ & $\begin{array}{c}24 \\
25 \\
27-29\end{array}$ & & 88 & 2,000 & 176,000 \\
\hline $\begin{array}{l}\text { Mold transportation } \\
\text { conveyor }\end{array}$ & 8 & $\begin{array}{c}\text { 12"wide } \\
\text { 6"long,30fpm }\end{array}$ & 264 & 3,500 & 924,000 \\
\hline Hydraulic pump I & unlabeled & $\mathrm{M} 14 * 2500$ & 264 & 420 & 110,880 \\
\hline Hydraulic pump II & unlabeled & PV080*5000 & 264 & 4270 & $1,127,280$ \\
\hline Total & & & & & $5,652,396$ \\
\hline
\end{tabular}

\section{References:}

1. Parker Hydraulic Products and Total System Engineering, House of Tools \& Engineering, Inc.

2. General Catalog, Hytrol Conveyor Company, Inc.

3. Means Building Construction Cost Data, R.S.Means Company, Inc. 


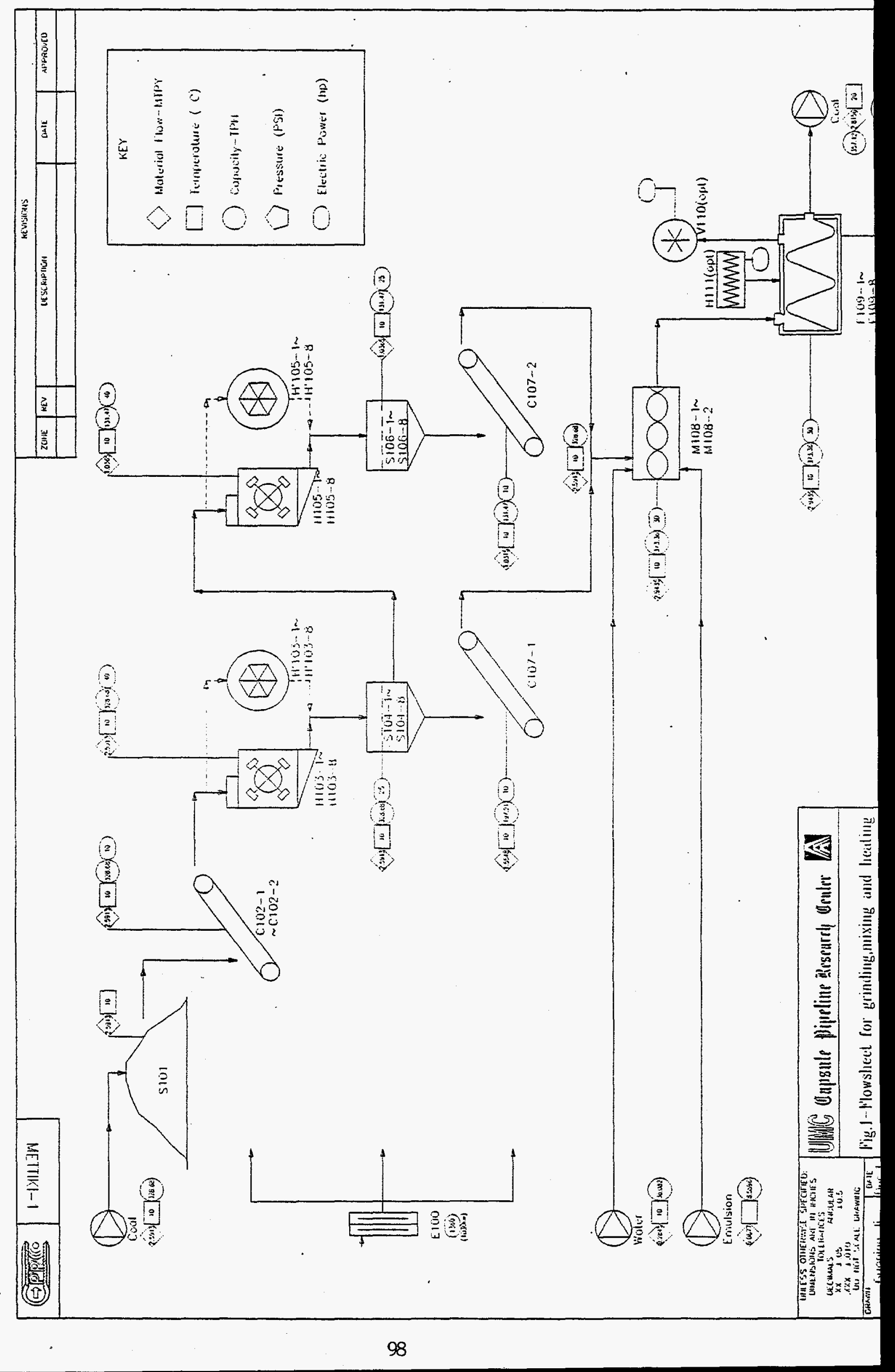


66

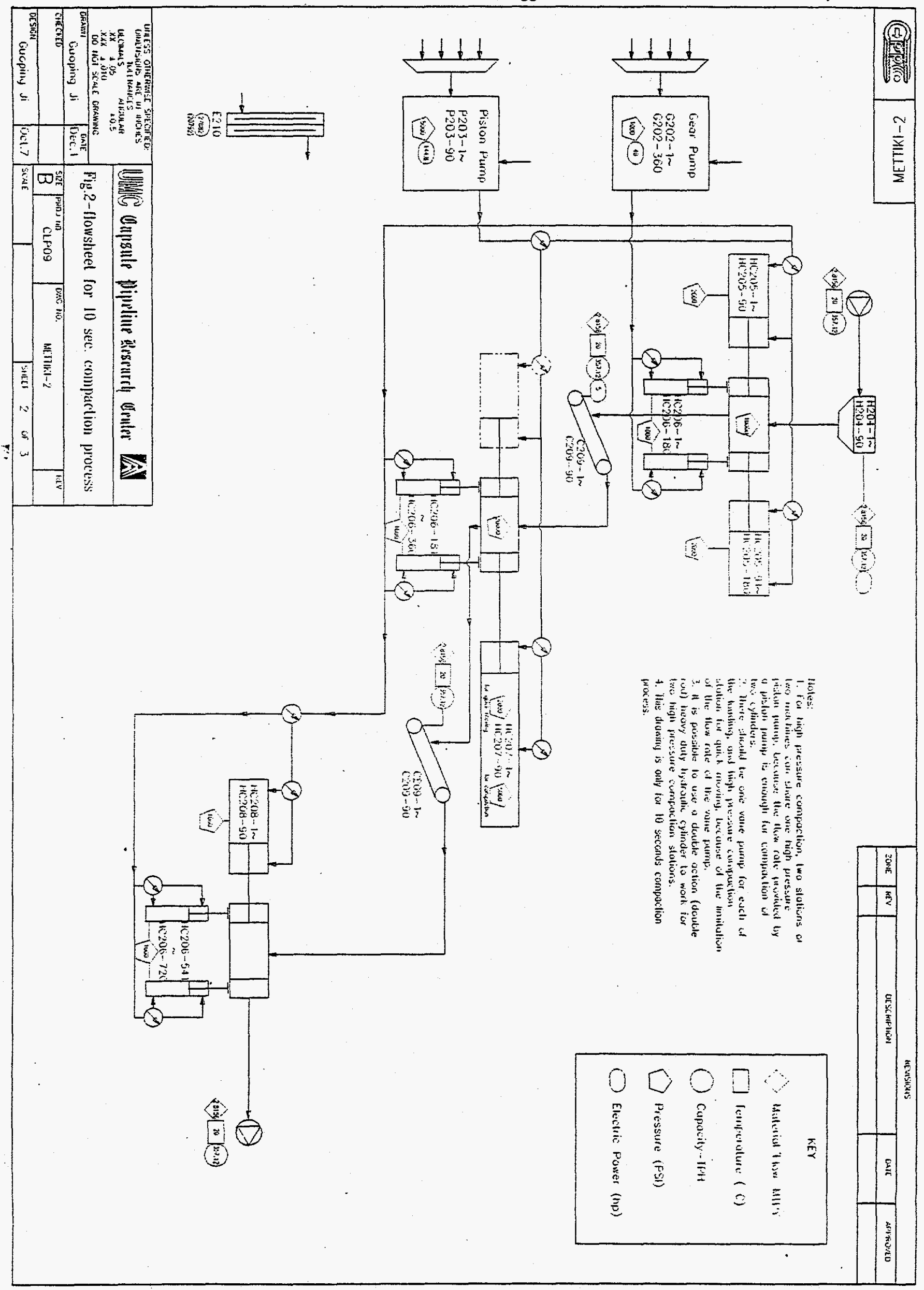




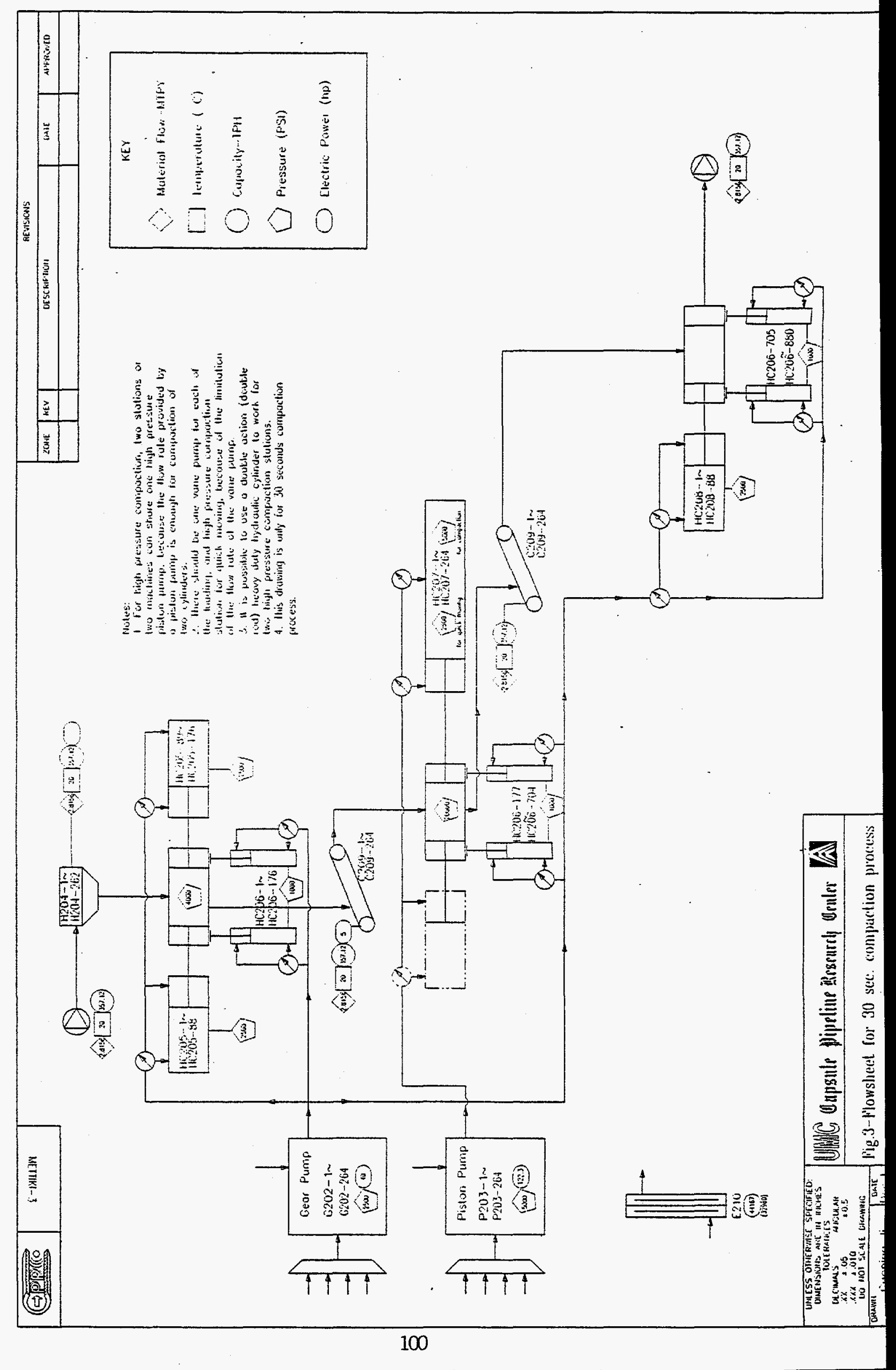




\title{
CAPSULE PIPELINE RESEARCH CENTER
}

\author{
Quarterly Report
}

(Period Covered: 10/1/94 - 12/31/94)

Project Title: Vacuum Systems to Enhance Coal Log Production and Quality

Principle Investigator: Dr. Alley C. Butler, Asst. Professor, Mechanical \& Aero. Engineering

Graduate Research Assistants: Jun-Jun Tang

David Woerner

\section{Purpose of the Research:}

To investigate the effects of vacuum (and steam preheating) on the fabrication of coal logs, as a means of improving the speed of manufacture as well as increasing coal log quality. The focus is on improving compressive processes as a method for coal log fabrication.

\section{Work Accomplished During the Period:}

This research task is developed around a two phase experimental program. In Phase I vacuum and steam preheat are applied to coal in the 1.75 inch floating, split mold. In Phase II the vacuum and steam preheat are applied to the coal prior to loading into the mold. Work undertaken in this period involves Phase I experimentation, only. Work accomplished includes: 1) completion of checkout for Phase I apparatus, 2) completion of an initial set of experiments, 3) refinement of the Phase I apparatus, and 4) development of financial information to support decision making regarding alternative manufacturing processes.

Phase I experiments with steam preheating involved admitting saturated steam at approximately $50 \mathrm{psi}$ to the bottom of the mold. A vent system is provided at the top of the mold to allow steam to travel into a condenser. The compaction process includes a relatively small amount of compression initially to generate friction, thereby allowing the mold to float. This provides resistance to steam movement, and the steam escaped from the mold through small gaps adjacent to the bolts and through the split in the mold, rather than through the vent. Water was collected in the condenser, only when the compression pressure was increased to $20,000 \mathrm{psi}$. Logs produced with steam used a beveled piston, and the ends of the coal logs adhered to the piston in the beveled area. Additionally, the logs were heated to $90^{\circ} \mathrm{C}$ in 2 to 8 minutes which is much shorter than the normal 45 minutes. The steam preheated logs absorbed less water under 500 psi water pressure, and wear test of steam preheated logs proved that they were superior to those fabricated under room temperature conditions.

As an additional part of the Phase I experiments, logs were fabricated and tested under vacuum conditions. Initial experiments were conducted under low vacuum until leaks in the mold were sealed using vacuum grease applied to the split in the mold. Automatic control of vacuum level has also proved to be a challenge, and stable automatic control is not yet available. As a result of experimentation, the application of vacuum was extended to include application of vacuum 5 minutes before and 5 minutes after the compression process. Experiments were conducted with 2 percent Orimulsion as binder at both room temperature and $90^{\circ} \mathrm{C}$. Logs produced at room temperature gained less weight in water absorption tests and demonstrated less 


\section{Work Accomplished During the Period (Continued):}

weight loss in pipeline wear tests. Logs fabricated under vacuum conditions at $90^{\circ} \mathrm{C}$ gained slightly more weight under water absorption tests and demonstrated almost identical wear in pipeline wear tests. Refinement of the experimental apparatus and experimentation is continuing.

\section{Future Plans:}

Research with the Phase I apparatus will continue, with the addition of equipment to attain stable automatic control of the mold cavity Optimization of process variables will be undertaken with the goal of finding upper limits to coal log quality under vacuum and steam preheat conditions. The experiments in steam preheating of the coal will be continued with a focus on eliminating the adherence of coal to the pistons and further characterization of the benefits from steam preheating.

In the related Phase II effort, the effects of vacuum (and preheating) of coal will be test prior to loading in the 1.75 inch mold. This involves the use of a screw conveyor for moving a preparing the coal, as shown in figure 1. This process uses vacuum (and/or preheating) of the coal and asphalt mixture prior to feeding the mixture into the compaction mold with a prototyp system. Measurements regarding increases in the speed of compression will be taken, and automation through process instrumentation and control will be employed. This will result in experience with automatic feeding of compaction molds, and increases in the speed with which coal logs can be manufactured will be determined. By demonstrating automated coal preparati and feeding with a manufacturing prototype system, confidence in the commercialization of the coal $\log$ fabrication process can be gained. It is anticipated that fabrication and check out of th manufacturing prototype system will commence during Winter semester 1995.

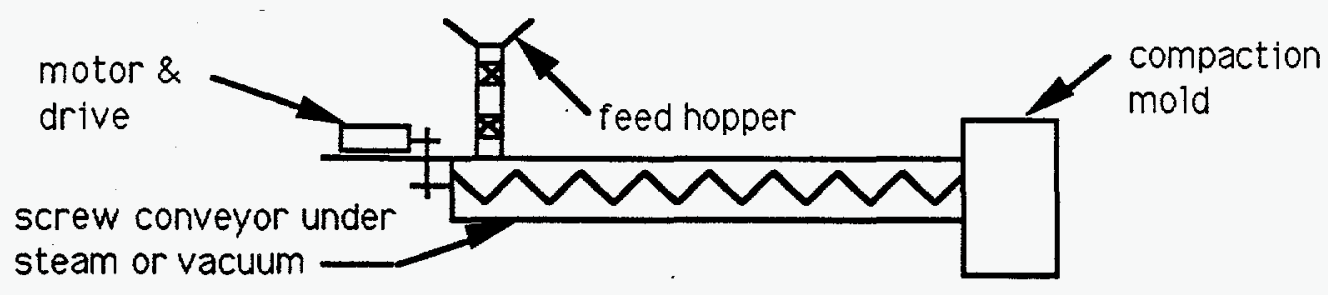

Figure 1 - Manufacturing Prototype System 
To: Veronica Boneparte, Capsule Pipeline Research Center

From: James Seaba, MAE

Subject: Quarterly report, Oct. 1, 1994 to Dec. 31, 1994

Title: Capsule train behavior in pipeline

\section{Purpose:}

The behavior of a capsule train ( $>200$ capsules) is studied; pressure drop, capsule velocities (regimes I through IV, corresponding to stationary to lifted capsules), clearance between pipe and capsule, capsule-capsule interaction during transport, and capsule jamming and trapping are correlated to water velocity, capsule aspect ratio and diameter ratio. Past experiments have focused on a few capsules (32 maximum) in the pipeline. Large capsule trains may exhibit different pressure and transport properties compared to the short trains due to capsule-capsule interaction. Capsule interaction and pipeline curvature may also contribute to jamming problems in the pipeline.

\section{Present Work:}

The two inch Plexiglas line has been instrumented with pressure taps, flow meter, and electromikes. The instruments have all been recalibrated. A new data acquisition system using Labview software is being developed. New pressure transducers to measure the capsule pressure drop are being implemented into the existing closed loop Plexiglas system.

\section{Future Work:}

Take total and capsule pressure drop as a function of bulk flow velocities to compare with the small capsule train data previously taken. Assess the capsule transport around the bends, taking into account the acceleration and capsule-pipe interactions. The new data will be compared to the current capsule transport computational model. Discrepancies that may exist between the long capsule train and the current model will provide insight into the hydrodynamics of capsule transport. The existing model may be impoved from the new data, generating a better model for commerical pipeline design. 


\section{Capsule Pipeline Research Center Quarterly Report}

\section{(Period Covered : 10/1/94 - 12/31/94)}

\section{Project Title : $\quad$ Automatic Control of Coal Log Pipeline System}

\section{Principal Investigator : Satish S. Nair, Asst. Professor of Mechanical and Aerospace Engrg}

\section{Graduate Research Assistants : Hongliu Du and Sanjay Mistry}

\section{Purpose of the Research :}

To study, design, test, and improve an automatic control system needed for reliable operation of coal log pipeline systems. To model the system dynamics as well as the interactions between the pumps, valves and the capsules for effective control design and system sizing.

\section{Work Accomplished During the Period :}

Separator Design : The design using laser beams to detect the presence of coal logs before the stopper was engaged is the preferred one and the details for the design have been worked out. It uses two lasers one on each side of the stopper and a simple control strategy. The stopper is engaged only if neither of the lasers, which are positioned carefully, detect coal logs. A reliable design for the stopper has been developed using solenoid type actuation. The selection of electromagnetic actuation as opposed to hydraulic or pneumatic was on the basis of input provided by the industrial advisory board.

Extensive tests were performed to determine the intensity of the laser beam required to penetrate water with different concentrations of slurry present. The objective was to simulate the conditions existing in commercial pipelines with degradation and wear of the coal logs. Plots of receiver effectiveness were obtained as a function of the diameter of the pipe as well as a function of the concentration of the slurry medium. It was decided that a concentration level of $1 \%$ of M-20 fine slurry would be the maximum to be expected in a commercial system. The appropriate laser beam just required a 100 milli-watt laser beam in the 2-inch clear PVC system used in the laboratory. The larger diameter pipe of a commercial system would require a higher wattage laser but our calculations, based on the results with the small-scale system show that the laser beam strategy would not be a problem at all for the commercial system. The final design using the laser beam sensing system is shown in Figure 1. 
All these designs are being tested on the small-scale system. Only the fixtures for the stopper system are remaining to be fabricated before the train separator design is tested. The remaining components including the diffusers, valves, laser beams, etc. are already in place.

Simulation Modeling : A paper has been completed for submission reporting the first order modeling approach and the very good experimental results obtained thus far. The simulation modeling approach using the method of characteristics is being continued to precisely determine the time for stopper actuation, to predict the forces on the stopper, and to predict the intra-capsule impact forces. This should help finalize the train separator design.

\section{Computer Hardware/Software Strategy. Coordination Requirements}

Details of the SCADA system for the commercial pipeline system were investigated and the relevant component of the chapter for the manual of practice for coal log pipeline systems was written. This is a draft of the methodology for systematic design and selection of the various SCADA subsystems. The selection of components for the prototype small-scale system is almost complete while the software component using visual- $\mathrm{C}$ is being initiated. The student involved with this part was on unpaid leave for the good part of a month during the quarter.

\section{Work Proposed for the Next Quarter :}

(i) Complete the fabrication associated with the stopper design. Install the stopper and test the separator design. Since it is very difficult to predict intra and inter-train spacing dynamics using simulations, observation experiments on the small-scale system will be conducted including investigating train spacing changes during long duration travel, effectiveness of flow bypass in reducing capsule speeds, energy loss analysis, etc.

(ii) Initiate the design of a recirculating loop to be added to the small-scale system.

(iii) The addition of the train separator in the small scale system will involve modifications in the existing control program for which the strategy will have to be designed and implemented. .

(iv) Acquire all the components needed for the SCADA system and interface them with the computer.

(v) Develop a control strategy for the distributed control architecture, taking into account reliability and safety.

(vi) Initiate development of a SCADA type display package for the small scale system using Visual-C. 


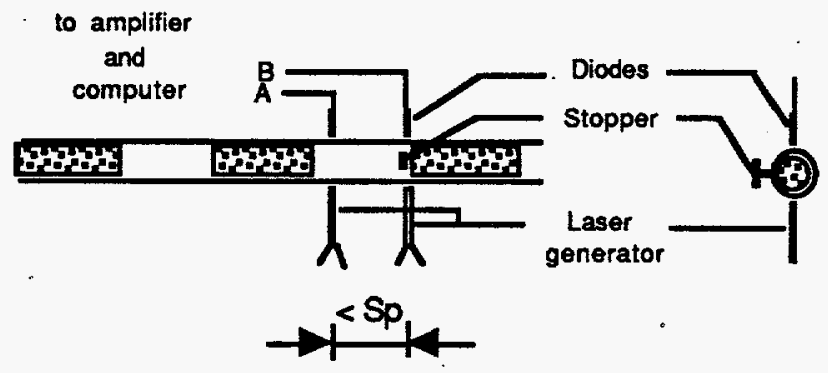

(a)

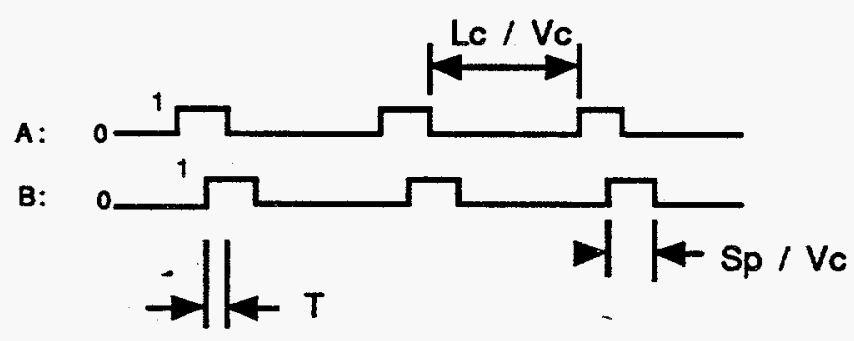

(b)

Figure 1. Laser-based sensing system for the separator design. 